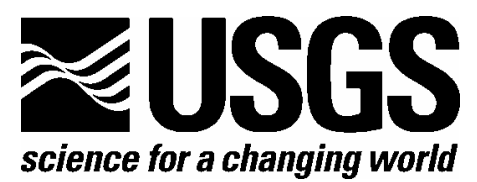

\title{
Status of Forest Birds in the Central Windward Region of Hawai i Island: Population Trends and Power Analyses
}

By P. Marcos Gorresen, Richard J. Camp, Thane K. Pratt, and Bethany L. Woodworth

Open-File Report 2005-1441 


\section{U.S. Department of the Interior \\ Gale A. Norton, Secretary}

\section{U.S. Geological Survey \\ P. Patrick Leahy, Acting Director}

U.S. Geological Survey, Reston, Virginia 2005

For product and ordering information:

World Wide Web: http://www.usgs.gov/pubprod

Telephone: 1-888-ASK-USGS

For more information on the USGS - the Federal source for science about the Earth,

its natural and living resources, natural hazards, and the environment:

World Wide Web: http://www.usgs.gov

Telephone: 1-888-ASK-USGS

Suggested citation:

Gorresen, P.M., Camp, R.J., Pratt, T.K., and Woodworth, B.L., 2005, Status of forest birds in the central windward region of Hawai $i$ Island: population trends and power analyses:

U.S. Geological Survey, Biological Resources Discipline, Open-File Report 2005-1441, 81 p.

Any use of trade, product, or firm names is for descriptive purposes only and does not imply endorsement by the U.S. Government.

Although this report is in the public domain, permission must be secured from the individual copyright owners to reproduce any copyrighted material contained within this report. 


\section{Contents}

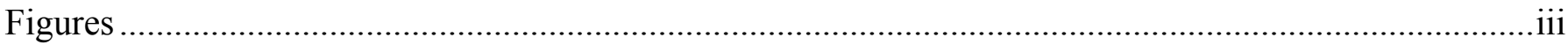

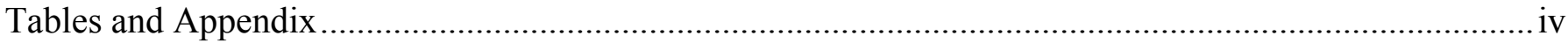

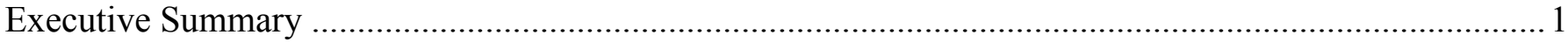

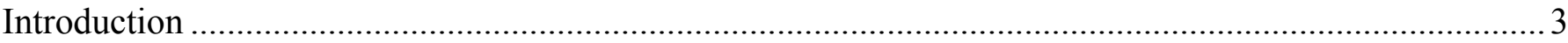

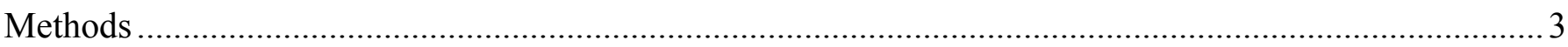

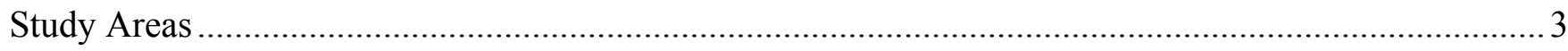

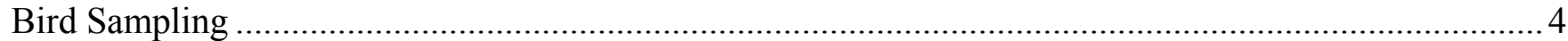

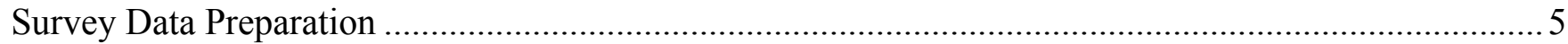

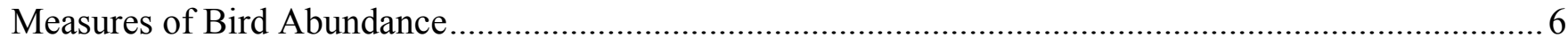

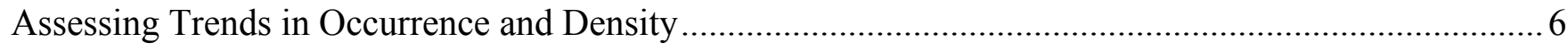

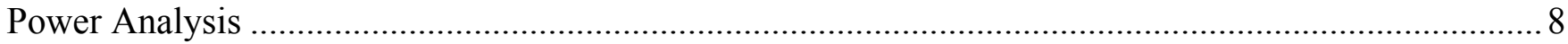

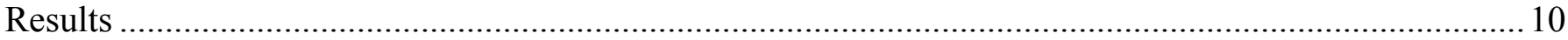

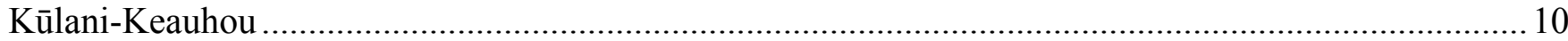

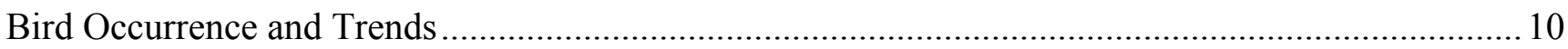

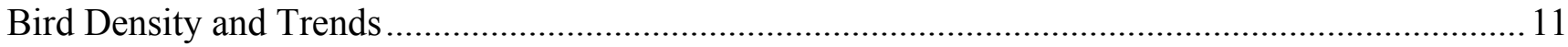

'Ölà

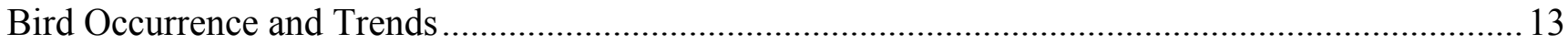

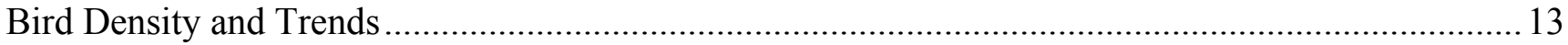

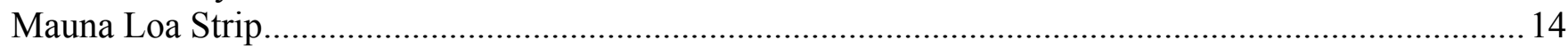

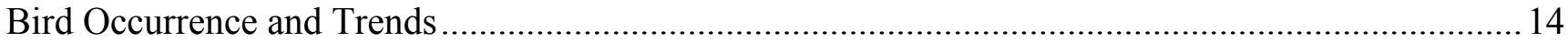

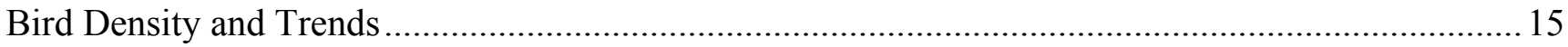

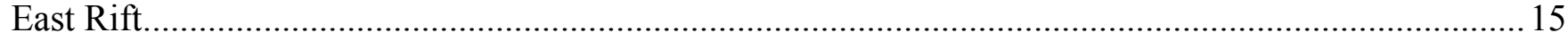

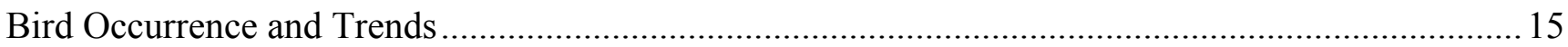

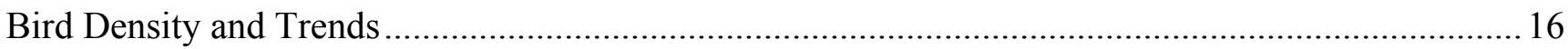

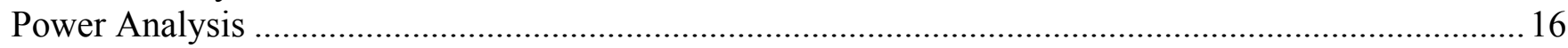

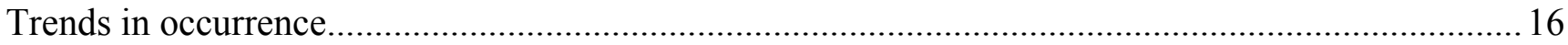

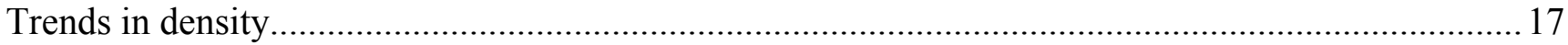

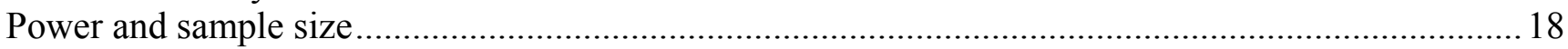

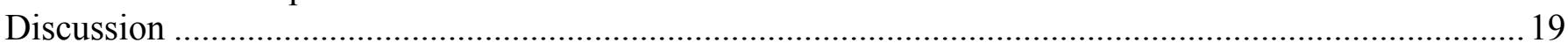

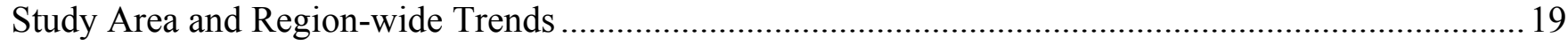

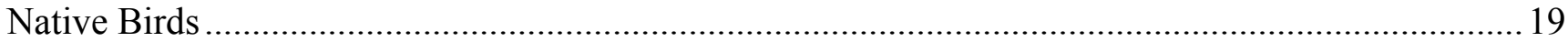

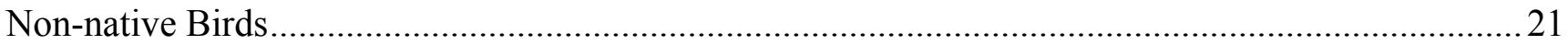

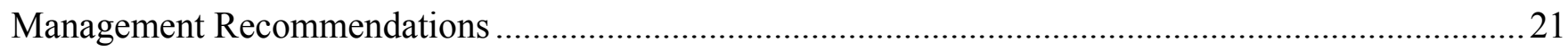

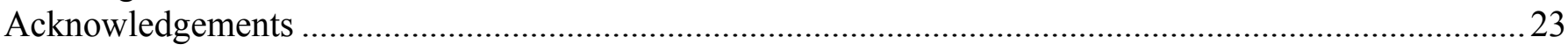

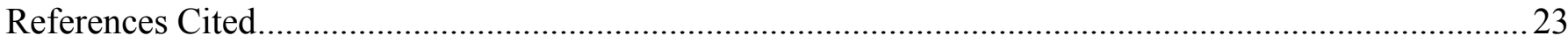

\section{Figures}

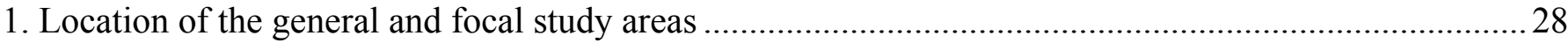

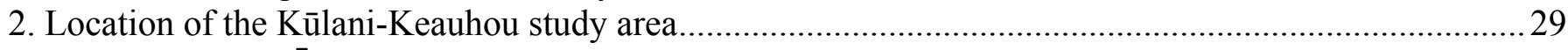

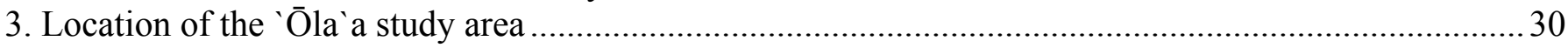

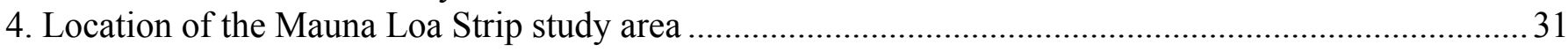

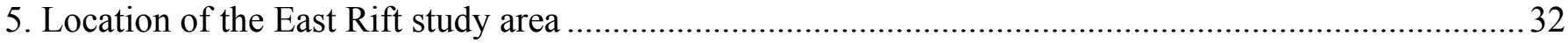

6. Hawai ` $i$ 'Elepaio occurrence and density in the Kūlani-Keauhou study area...........................................33

7. 'Ōma`o occurrence and density in the Kūlani-Keauhou study area.......................................................... 34

8. 'T'iwi occurrence and density in the Külani-Keauhou study area ............................................................ 35 
9. `Akiapōlā'au occurrence and density in the Kūlani-Keauhou study area .................................................36

10. Hawai' i Creeper occurrence and density in the Kūlani-Keauhou study area...........................................37

11. Hawai' $\mathrm{i}$ `Amakihi occurrence and density in the Kūlani-Keauhou study area ........................................38

12. Hawai' $\mathrm{i}$ 'Ākepa occurrence and density in the Kūlani-Keauhou study area............................................. 39

13. `Apapane occurrence and density in the Kūlani-Keauhou study area.................................................. 40

14. Red-billed Leiothrix occurrence and density in the Kūlani-Keauhou study area ................................... 41

15. Japanese White-eye occurrence and density in the Kūlani-Keauhou study area .....................................42 42

16. Northern Cardinal occurrence and density in the Kūlani-Keauhou study area .......................................43

17. House Finch occurrence and density in the Kūlani-Keauhou study area................................................ 44

18. Hawai' $\mathrm{i}$ 'Elepaio occurrence and density in the Mauna Loa Strip study area ........................................ 45

19. 'Ōma`o occurrence and density in the Mauna Loa Strip study area ...................................................... 46

20. Hawai $\mathrm{i}$ `Amakihi occurrence and density in the Mauna Loa Strip study area........................................47

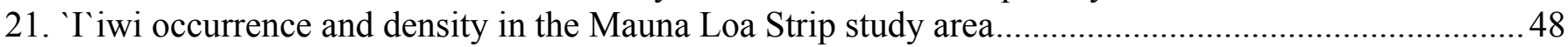

22. 'Apapane occurrence and density in the Mauna Loa Strip study area ................................................... 49

23. Red-billed Leiothrix occurrence and density in the Mauna Loa Strip study area ..................................50

24. Japanese White-eye occurrence and density in the Mauna Loa Strip study area ....................................51

25. Northern Cardinal occurrence and density in the Mauna Loa Strip study area......................................52

26. House Finch occurrence and density in the Mauna Loa Strip study area .............................................53

27. Power to detect a trend in density as a function of the annual rate of decline and the risk of incorrectly

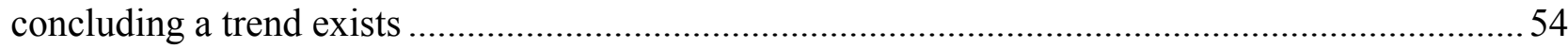

28. Power to detect a trend in density as a function of sample size ...........................................................5 55

29. Summary of population trends for native forest birds in the Central Windward region ..........................56

30. Summary of population trends for non-native forest birds in the Central Windward region...................57

31. Recommended changes to survey design in the Central Windward region ..........................................58

\section{Tables and Appendix}

1. Annual surveys conducted in the Central Windward study area...........................................................59

2. Effective detection radius by species in the Kūlani-Keauhou and 'Ōla`a study areas................................. 62

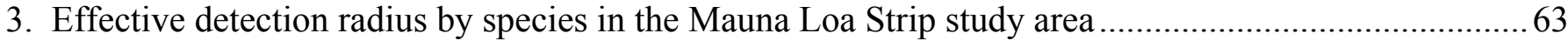

4. Effective detection radius by species in the East Rift study area ...........................................................64

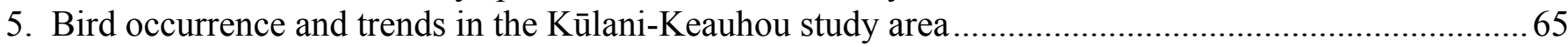

6. Power to detect a negative trend in occurrence for native bird species..................................................66

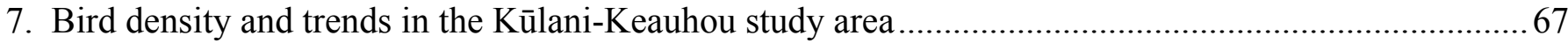

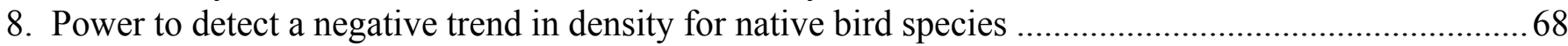

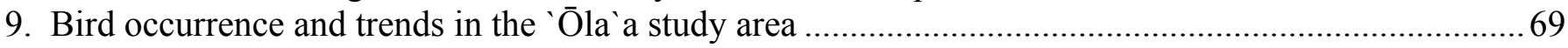

10. Bird density and trends in the 'Ōla`a study area ................................................................................ 70

11. Bird occurrence and density trends in the Mauna Loa Strip study area.............................................. 71

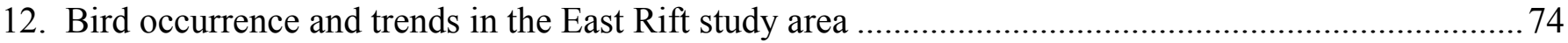

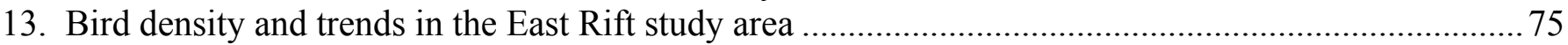

14. Power to detect a negative trend in density as a function of sample size..............................................76

Appendix 1. Annual forest bird survey results for the Kūlani-Keauhou study area ................................... 77 


\section{Status of Forest Birds in the Central Windward Region of Hawai i Island: Population Trends and Power Analyses}

By P. Marcos Gorresen, Richard J. Camp, Thane K. Pratt, and Bethany L. Woodworth

\section{Executive Summary}

This report presents analyses by the Hawai i Forest Bird Interagency Database Project of bird survey data collected in the Central Windward region of Hawai i Island. This region includes about $670 \mathrm{~km}^{2}$ of native forest in Hawai i Volcanoes National Park, Kamehameha School lands at Keauhou Ranch and Kīlauea Forest, and Kūlani Correctional Facility, State of Hawai i (Figure 1). Together these lands harbor one of the three most important concentrations of native forest birds on the Island of Hawai i, including populations of three endangered species.

The 12 forest bird surveys analyzed herein were conducted between 1977 and 2003 by Kamehameha Schools, the State of Hawai i Division of Forestry and Wildlife, the National Park Service, U.S. Geological Survey, and U.S. Fish and Wildlife Service, and include a total of 66 transects and 1,004 stations. To account for survey effort and the range of land-use histories and habitats, the region was divided into four study areas: Kūlani-Keauhou, 'Ōla`a, Mauna Loa Strip, and East Rift. The objectives of this study were to (1) examine the distribution of native and exotic forest birds; (2) estimate trends in occurrence and density over time; and (3) evaluate the effectiveness of current monitoring to detect trends in forest bird populations.

At least five of the eight native forest bird species in the Kūlani-Keauhou study area may be undergoing declines in occurrence and/or density. These include two endangered species, 'Akiapōlā'au and Hawai i Creeper. A third endangered species, Hawai i `Ākepa, exhibits sufficient variability that downward trends might remain undetected. The observed declines in Hawai' $\mathrm{i}$ 'Elepaio, 'Ōma'o and 'I'iwi numbers were modest, but they may be a cause for concern because the distribution and density of these species have declined elsewhere in their range. Hawai $i$ 'Amakihi and 'Apapane were ubiquitous and showed increasing or stable trends in the Kūlani-Keauhou study area.

Native forest birds trends in the Mauna Loa Strip study area appear to be stable, with the exception of 'Ōma 'o, whose numbers have declined since the 1977/1979 HFBS. However, all native bird populations in the 'Ōla`a and East Rift study areas appear to be in decline. Downward trends have been pronounced for Hawai $i$ 'Elepaio and 'I 'iwi, and declines in the mid-elevation habitat may indicate that these species' ranges are contracting westward and upslope in the Central Windward region. Tragically, the 'O'u, down to just a few individuals in the 1970s, disappeared altogether from `Ōla`a, one of its last haunts, and is now feared to be extinct. 
The trends of the non-native species generally were decreasing in Kūlani-Keauhou, mixed in 'Ōla'a and East Rift, and increasing in Mauna Loa Strip. Japanese White-eye appeared to be undergoing a decline in occurrence and density in the Kūlani-Keauhou study area. This was the only area where this species demonstrated downward trends. Elsewhere, Japanese White-eye has shown markedly increasing occurrence and density. Red-billed Leiothrix numbers appeared to be declining in the Kūlani-Keauhou and 'Ōla'a study areas, and highly variable with non-significant trends in Mauna Loa Strip. Northern Cardinal appears to be in decline in Kūlani-Keauhou and East Rift, but possibly increasing in the 'Ōla`a and Mauna Loa Strip study areas. House Finch was uncommon to rare and highly variable in all study areas, and analyses of its trends were inconclusive. The Japanese Bush-warbler, which became established on the Big Island in recent years and is present at Waiākea not far to the north, has not yet been detected in the study area.

Bird surveys in the four study areas have not been of sufficient duration or conducted on an adequately consistent basis to enable an intensive analysis of trends. The assessment of bird trend, in most cases, has been limited to the comparison of survey results for two periods. Conclusions drawn from limited data run the risk of incorrectly inferring trends from short-term population cycles. In addition, the high variability intrinsic to bird densities and occurrence (especially for endangered species), has resulted in the inability of analyses to confirm potentially positive or negative trends for several species. Therefore, efforts should be made to ensure that surveys are sustained for the long-tem, and that sites are regularly revisited to maintain spatial and temporal consistency. These measures will improve the ability to detect trends from bird surveys.

Given observed variability and densities, downward trends for most species in the Kūlani-Keauhou study area can only be reliably detected if they are severe (i.e., greater than or equal to $10 \%$ per year). However, additional sampling effort may not necessarily result in a sufficient increase in statistical power. In fact, analyses demonstrated that current sampling could be reduced by about $1 / 3$ without much loss of statistical power. Reduced sampling in this area can be reallocated to provide a more extensive sampling of adjacent areas or low-elevation habitats that are currently inadequately surveyed.

The results suggest establishment of a comprehensive monitoring framework that intensively samples select areas and extensively samples a larger region to provide both the "close-ups" and the "big picture" needed to anticipate and follow changes in bird numbers, occurrence and distribution. To a large extent, such a program can build on recent and current surveys in the region. Annual surveys should be reinitiated in the Mauna Loa Strip, 'Ōla'a and East Rift study areas. In addition, annual surveys should be established in the high elevation forest habitat directly north of the Kūlani-Keauhou study area (i.e., within Upper Waiākea Forest Reserve and eastern Kīpuka 'Āinahou Nēnē Sanctuary). This area still harbors the endangered ‘Akiapōlā’au, Hawai `i Creeper, and Hawai `i ‘̄kepa, and provides a critical link between populations in Kūlani-Keauhou and those in the North Windward (i.e., Hāmākua) region. In addition, a less intensive, but larger-scale survey program should be established to monitor range contraction or expansion of forest birds, particularly at mid-elevations.

Variable-circular plot methods and other count data are relatively ineffective at tracking trends of rare species such as `Akiapōlā’au, Hawai i Creeper and Hawai i `Ākepa. Demographic studies for these species should be considered in the Kūlani-Keauhou study area. 


\section{Introduction}

An accurate and current measure of population status and trend is necessary for conservation and management efforts. Scott and Kepler (1985) provided a comprehensive review of the status of native Hawaiian birds based on the extensive Hawaii Forest Bird Survey (HFBS) of the main islands (Scott et al. 1986). At that time, they documented declining populations and decreasing ranges for most species, and the extinction of several species over the previous 50 years. Many native bird species continue to decline throughout Hawai i (Jacobi and Atkinson 1995, Gorresen et al. In review).

The area addressed by this study focuses on the mid-to-high elevation rainforest on the windward slopes of Mauna Loa Volcano, Hawai $i$, and is referred herein as the Central Windward region (Figure 1). This region encompasses forest lands protected by Hawai i Volcanoes National Park, Keauhou Ranch and Kīlauea Forest belonging to Kamehameha Schools, and the Kūlani Correctional Facility (Hawai'i Dept. of Public Safety). Together these lands are habitat for one of three main concentrations of native forest birds on the Island of Hawai' $i$ (the other two being centered on Hakalau Forest National Wildlife Refuge to the north and the Ka' $\mathrm{u}$ Forest Reserve to the southwest.)

Because the region harbors such important populations of native and endangered forest birds in some of the best remaining forest habitat on the island, it has been a focus of forest bird surveys since the 1970s. Portions of the Central Windward region were first quantitatively surveyed from 1972 to 1975 by the International Biological Program (IBP; Conant 1975) and in 1977 and 1979 by the Hawaii Forest Bird Survey (HFBS; Scott et al. 1986). Since 1986, a total of 16 forest bird surveys on a total of 66 transects and 1,004 stations were conducted by Kamehameha Schools, the State of Hawai i Division of Forestry and Wildlife, the National Park Service, U.S. Geological Survey, and U.S. Fish and Wildlife Service.

In this report, we present analyses of trends and an assessment of the effectiveness of surveys at monitoring trends in native forest bird occurrence and density within the Central Windward region of Hawai' $i$ Island. We report on three endangered native Hawaiian honeycreepers: 'Akiapōlā'au (Hemignathus munroi), Hawai i Creeper (Oreomystis mana), and Hawai i 'Ákepa (Loxops coccineus); one endangered honeycreeper that probably became extinct during the study period, the 'O'u (Psittarostra psittacea); five additional native species, the Hawai i ‘Elepaio (Chasiempis sandwichensis), 'Ōma`o (Myadestes obscurus), Hawai ' `Amakihi (Hemignathus virens), 'I'iwi (Vestiaria coccinea) and 'Apapane (Himatione sanguinea); and four non-native passerines: Red-billed Leiothrix (Leiothrix lutea), Japanese White-eye (Zosterops japonicus), Northern Cardinal (Cardinalis cardinalis), and House Finch (Carpodacus mexicanus).

\section{Methods}

\section{Study Areas}

The Central Windward region of Hawai'i includes approximately $673 \mathrm{~km}^{2}$ of mid-to-high elevation rainforest on the windward slopes of Mauna Loa Volcano, between 700 and 2,100 m elevation (Figure 1). Because the area is a mosaic of habitat types, management history, and survey history, we divided it into four study areas for purposes of data analysis: Kūlani-Keauhou (Figure 2); 'Ōla`a (Figure 3); Mauna Loa Strip (Figure 4); and East Rift (Figure 5).

The Kūlani-Keauhou study area and surrounding region is comprised of wet 'ôhi a (Metrosideros polymorpha) and koa (Acacia koa) dominated forests. The area is under 
management by the Kūlani Correctional Facility, Kamehameha Schools, Hawai i Volcanoes National Park, and Hawai i Department of Land and Natural Resources. These landowners have formed a partnership, the 'Ōla 'a-Kîlauea Partnership, to protect the biological and cultural values of the area. The clearing of forest and ranching largely ceased in the 1990s, and the region is now managed mainly as native forest. Recent management has included removal of livestock, tree-planting, and in some areas removal of feral ungulates and weed control. More detailed habitat descriptions of the Külani and Keauhou areas are available in Jacobi and Warshauer (1996) and Sakai (1988).

The `Ōla`a study area is comprised of wet `ohi`a and hāpu`u (Cibotium glaucum) forests, and is described in Loh and Tunison (1999). The study area is under management by the Hawai i Volcanoes National Park, and management actions include the eradication of pigs and control of alien plants.

Management of the Mauna Loa Strip study area by the Hawai i Volcanoes National Park includes the exclusion of ungulates (cows, goats, pigs and sheep) and the control of alien plants. The study area is rapidly regenerating with koa, particularly in the koa-'ohi ' a vegetated kipukas. A detailed, although somewhat dated, description of the Mauna Loa Strip study area is available in Mueller-Dombois et al. (1981).

The East Rift study area is comprised of wet 'ōhi'a dominated forests, and is described in Pratt et al. (1999). The portion of the study area that lies within the Hawaii Volcanoes National Park (HVNP) has received ungulate control. The adjacent area (i.e., Kahauale`a Natural Area Reserve) has received no alien plant or ungulate control. The forest surrounding and including parts of study area have been extensively disturbed by lava flows, fire and `ôhi`a die-back.

\section{Bird Sampling}

The HFBS established the basis for long-term population monitoring in Hawai i, using variable circular plot (VCP) counts arranged along transects spaced throughout the study area (Scott et al. 1986; see below). The Central Windward area is comparable to the southern part of the Hāmākua region, most of the Kīpuka region, and the upper Puna region delineated by Scott et al. (1986). In these regions, HFBS sampling stations were established approximately every 134 $\mathrm{m}$ along transects spaced 3-5 km apart. The four study areas addressed here were all surveyed by HFBS between 1977 and 1979. In all, the HFBS surveyed 13 transects and 327 stations throughout the four study areas ( 3 transects and 95 stations in Kūlani-Keauhou; 3 transects and 54 stations in 'Ōla`a; 5 transects and 79 stations in Mauna Loa Strip; and 2 transects and 99 stations in East Rift). Transect and station tallies here and below exclude surveys that lie outside of the study areas, were not conducted during the breeding season (December-July), or for which survey data are not yet available (e.g., 1977-1982 U. S. Forest Service surveys in the Keauhou Ranch and Kīlauea Forest Reserve).

Surveys subsequent to the HFBS commenced in 1990 in the Kūlani-Keauhou study area, adding many more transects and stations (Table 1, Figure 2), and as of 2003, have sampled a total of 391 stations along 30 transects. Within the Kūlani-Keauhou study area, surveys in the Boy's School, Pu`u Kipu, Keauhou Ranch Kilauea Forest Reserve sections have provided a fairly thorough coverage of habitat above 1,500 $\mathrm{m}$ elevation, where the endangered bird populations are centered.

Following the HFBS, 15 new transects and 143 stations were established within the 'Ola`a study area in 1992 (Table 1, Figure 3). The study area was divided into three units: Pu'u Unit, Koa Unit and Small Track Unit, between the elevations of 900 and 1,300 m. Surveys were 
conducted annually between 1992 and 1994, with transects placed less than $500 \mathrm{~m}$ and stations 150 m apart.

Likewise, new transects and stations were established on Mauna Loa Strip following the HFBS (Table 1, Figure 4). The new transects parallel the contour, with 13 transects placed approximately $500 \mathrm{~m}$ apart and a total of 297 stations placed every 100 or $200 \mathrm{~m}$ apart.

Elevation ranged from 1,300 to 2,200 m. Quarterly or biannual surveys commenced in 1986 and continued until 1994. Survey information from 1988 has been lost, and surveys in 1989 were conducted only during the non-breeding season.

Surveys were conducted annually between 1992 and 1994 in the East Rift Unit of HVNP, and in December of 1993, within the Kahauale a Natural Area Reserve immediately adjacent to HVNP (Table 1, Figure 5). Portions of HFBS transect 37 and 38 were reestablished, although station locations were not coincident. Additionally, new transects were established between the HFBS transects, spaced 1-2 km apart with stations every $150 \mathrm{~m}$ between the elevations of 750 and $900 \mathrm{~m}$. In all, subsequent surveys sampled 173 stations along 8 transects.

All surveys were conducted using variable circular plot (VCP) count methodology (Reynolds et al. 1980). Trained and calibrated observers recorded the species, detection type (auditory, visual, or both), and distance from the station center point to birds detected during eight-minute counts. Time of sampling and weather conditions were also recorded, and surveying was halted when conditions hindered the ability to detect birds (wind and gust $>20$ $\mathrm{kph}$, and heavy rain).

\section{Survey Data Preparation}

For the purpose of assessing trends, analysis of the bird survey data first required addressing inconsistencies in temporal and spatial sampling. A rigorous selection of data was necessary to ensure that analyses were not biased by the inclusion of data for areas sampled in one period or place but not another. Survey stations sampled in each year were delineated to identify an area coincident to all surveys within the study area.

Sampling across the Kūlani-Keauhou study area was fairly irregular in spatial and temporal coverage (Table 1). Surveys subsequent to the HFBS were initiated in 1990 in the northern portion of the study area (Boy's School and Pu'u Kipu), and surveys in the southern portion (Keauhou Ranch) commenced in 1993. Both the north and south portions were sampled in 1995, 1997, 1998 and 2001-2003, and allowed for trend assessment across the study area. However, surveys from 1990-1994, 1996, and 1999-2000 were only conducted in a part of the study area, and precluded use of these data for trend analyses. This resulted in the dropping of all data from the U.S. Forest Service (i.e., "C.J. Ralph" plots), the Safe Harbor surveys, the Pu u Kipu survey transects 1, 1001 (1A), 2, and 2001 (2A), and the Keauhou Ranch survey transects 302, 303, 310 and 311 (Table 1). In addition, the 1977 HFBS did not sufficiently coincide with the area covered by subsequent surveys and was not used for trend analyses. Consequently, a subset totaling to 285 stations along 26 transects in the Kūlani-Keauhou study area were used for trend analyses.

The Kūlani-Keauhou survey data were further subset by identifying general specieshabitat associations, and delineating these habitats with vegetation maps developed by Jacobi (1989). This subset improved occurrence and density estimates by limiting trend analyses only to habitats in which species occurred. For Hawai $i$ 'Elepaio, Hawai $i$ Creeper and Hawai $i$ 'A kepa, only data from stations that occurred in or within $150 \mathrm{~m}$ of forest habitat was used to analyze trends. For 'Akiapōlā'au, only data from stations that occurred in or within $150 \mathrm{~m}$ of forest with koa was used to analyze trends. 
The Mauna Loa Strip survey data were subset to include only stations in proximity to both the HFBS and subsequent surveys (Figure 4). The coincident area used to subset the subsequent survey stations was delineated with a $500 \mathrm{~m}$ buffer around the HFBS stations. A total of 216 stations along 16 transects were used for trend analyses.

Subsequent to the HFBS, the 'Ōla'a management area of the HVNP was surveyed in three separate tracts - Koa Unit, Pu'u Unit and Small Tract. The `Ōla`a study area was delineated with a simple convex hull polygon around the subsequent survey stations, and this area was used to subset the HFBS stations included in trend assessments (Figure 3). A total of 197 stations along 18 transects in the 'Ōla'a study area were used for trend analyses. The East Rift study area and station subsets were also delineated in this manner, and 285 stations along 10 transects were used for trend analyses.

\section{Measures of Bird Abundance}

We present two measures of abundance for each species: frequency of occurrence and density. Frequency of occurrence was calculated as the proportion of the total number of stations sampled in a year for which there was at least one detection (e.g., Mossman et al. 1998). Occurrence (i.e., presence-absence) was calculated using only observations that lay within "truncation" distances derived from density analysis (described below). This procedure ensured that the data analyzed did not include very distant and unreliable observations.

We used the program DISTANCE 4.1 (Thomas et al. 2003) to produce density estimates for each species. Within each study area, observations from all surveys conducted between December and July (i.e., the typical breeding season for most species) were used to fit a detection function following the model selection methods described by Buckland et al. (2001, 2004) and Thomas et al. (2003). Model selection is the process of assessing simplified models to identify the "best-fit" model. A priori model selection was restricted to half normal and hazardrate detection functions with expansions series of two orders. These models are most appropriate for VCP surveys and allow for covariate analysis. We accounted for the covariate variables observer, time of day, cloud cover, rain, wind, gust, year, and month following methods described by Buckland et al. (2001), Burnham and Anderson (2002), Camp et al. (2003), and Thomas et al. (2003). Density was derived only for observations that lay within the species- and region-specific truncation distances used to exclude very distant and unreliable data. Data were truncated at a distance where the detection probability was approximately 0.10 , typically equal to $10 \%$ truncation. Histograms of the data and the detection function were plotted and the fit of the function examined. Data were further truncated to increase the fit of the detection function (Tables 2 to 4 ).

To adjust for sampling effort for each species, the number of birds detected at a station over the entire survey period (e.g., 1995-1998) was divided by the number of times that station was sampled within the survey period, to obtain an average number of detections at each station. Densities were then calculated by dividing detections by the effective area surveyed for each sample year or period. Annual and survey-period density is presented throughout this report as the mean of density per station values, and the observed variability in density values are described by standard errors.

\section{Assessing Trends in Occurrence and Density}

The method chosen to evaluate trends in occurrence and density depended on the number of years of survey data available for analysis. For study areas where surveys were of sufficient duration, we used logistic and linear regression methods to test for trends in species occurrence 
and density, respectively. Only the Mauna Loa Strip study area surveys were of sufficient duration to use these methods. For study areas with sparser data sets, e.g., Kūlani-Keauhou, 'Ōla `a, and East Rift study areas, we pooled data across surveys (see below) and used contingency analyses and z-tests to examine trends.

Logistic regression. - Trends in occurrence data in Mauna Loa Strip study area were assessed with logistic regression, an analytical method appropriate to binary response variables (e.g., detected, not detected; Legendre and Legendre 1998). Logistic regression was performed with a generalized linear model and a quasi-likelihood approach to parameter estimation (S-Plus 2001a). The approach allows the estimation of parameters to be carried out without specifying the (unknown) underlying error distribution of the response variable, and also corrects for circumstances in which the variance and mean of the occurrence data are not equal (i.e., over- or under-dispersed). The odds ratio provided an interpretation of the logistic "slope" coefficient (e.g., an odds ratio equal to 1.23 indicates that occurrence increased at a rate of $23 \%$ per year; Neter et al. 1996). The significance of the trend was assessed with a partial deviance test.

Linear regression. - For density data in Mauna Loa Strip study area, a linear regression of the means of log-transformed densities on year assessed the significance of a trend, and the slope coefficient was used to characterize the rate of change and direction of the trend. Although other more complex modeling methods are available to determine the significance and direction of trends, linear regression is a method commonly used to assess trends (e.g., Mossman et al. 1998; Nur et al. 1999; Lind et al. 2001) because it captures overall change in mean annual densities, and it avoids the difficulty of quantifying and interpreting the significance of short-term trajectories in a non-linear trend (i.e., the issue of interest is the overall change, not the individual among-year ups and downs).

Pooling data. - The duration of survey data for the Kūlani-Keauhou, 'Ōla`a, and East Rift study areas were not adequate for using regression to assess trends. The years with consistent sampling and full spatial coverage numbered only 6, 4 and 2-3 for these study areas, respectively. Trends for these study areas were instead assessed by comparing data for two survey periods. For the Kūlani-Keauhou study area the data were pooled into the periods 19951998 and 2001-2003. For the 'Ōla`a study area trends were evaluated by comparing the 1977 HFBS to the most recent year of survey data (1994). Trends in the East Rift study area were evaluated by comparing the 1979 HFBS to pooled data for the years 1993 (December) and 1994 (January). The pooling of the 1993 and 1994 data was necessary to generate an area of coverage comparable to the 1979 HFBS.

Contingency analysis. - Trends in the frequency of occurrence for the Kūlani-Keauhou, 'Ōla 'a and East Rift study areas were examined with contingency analysis. For this analysis, occurrence was derived by summing the presence and absence of a species within each survey period. $2 \times 2$ contingency tables were developed for the two occurrence categories (i.e., presence/absence) and two surveys periods (e.g., HFBS and most recent year of survey). Analysis was performed with Fisher's exact test and a two-tailed test of significance to simultaneously test for increasing or decreasing frequencies between periods. 'Apapane data were not amenable to contingency analysis because one or more individuals were observed at all stations during both periods in the Külani-Keauhou study area.

Two-sample z-tests. - Trends in bird densities for the Kūlani-Keauhou, 'Ōla’a and East Rift study areas were assessed for each species by comparing mean density estimates between periods with a two-sample z-test (Sokal and Rohlf 1995). Although less powerful than a onetailed test, a two-tailed test was used because we were interested in simultaneously assessing the 
presence of both positive and negative trends (a one-tailed test would only examine either a positive or negative trend).

One problem in trend detection is that count data are temporally autocorrelated (i.e., counts spaced closer in time are more similar than those spaced farther apart), and can thereby unduly reduce variance and result in tests that are too often declared significant (Legendre and Legendre 1998). Various methods are available that model autocorrelation (e.g., repeated measures) but these require that stations be sampled consistently and for an extended period of time [e.g., $>10$ yrs (Hatfield et al. 1996)]. Alternatively, one can mitigate for autocorrelation by adjusting post hoc the significance threshold used to declare significance (e.g., use of the more "conservative" alpha of 0.01; Hatfield et al. 1996). However, despite the problems associated with autocorrelation, in this analysis we have adopted the use of more "liberal" thresholds for endangered species. Although the use of a more liberal threshold increases the likelihood that a non-significant trend is incorrectly declared significant, it also improves the chances that a trend, if present, can be detected. The rationale for this choice is more fully discussed in the following section and in Hatfield et al. (1996). Therefore, increasing and decreasing trends were designated as such if the significance of tests were $\leq 0.10$ for the endangered species (i.e., 'Akiapōlā au, Hawai $i$ Creeper and Hawai' $i$ 'A kepa) or $\leq 0.05$ for all other species. Stable trends were inferred in cases where a test was not significant, but for which variability in a species' occurrence or density was relatively small, and consequently, the likelihood of being able to detect a trend if one existed was expected to be high. Finally, trends were designated as "not detected" if tests were not significant and variability was sufficiently large such that that trend detection was not likely.

The threshold distinguishing "relatively small" from "sufficiently large" was established at coefficient of variation (CV) values of $\leq 0.10$ and $>0.10$, respectively. A CV is a standardized measure of variability that permits its comparison among species. Species with a $C V \leq 0.10$ ensured that biologically significant declines in occurrence and density (e.g., $>3 \%$ per year) were not likely to be missed. The species-specific CV values were derived from results of the power analyses that assess the ability of a monitoring program to detect trends if they are present (see the following section for a description of CV calculation, and the Results section Power Analysis for an explanation of how trends are interpreted in light of variability in occurrence and density).

\section{Power Analysis}

Power analysis was conducted to determine the effectiveness of the current and proposed surveys at monitoring trends in bird density and occurrence. The analysis seeks to determine whether an existing or planned survey program could detect trends if they are actually present, and to identify management options for improving monitoring effectiveness. As an exploratory assessment of monitoring effectiveness, we conducted power analysis using survey data and the current monitoring design employed in the Külani-Keauhou study area. However, the results are generally applicable to areas other than that for which the analysis was performed.

Trend detection depends on four parameters - effect size, variance, sample size, and alpha (Steidl et al. 1997) - and these are described in this section in terms of bird density, but are equally relevant to frequency of occurrence. Effect size (i.e., magnitude) may refer either to the proportional rate of change in mean densities over time (e.g., 1\% decline per year) or an absolute change over a time period (e.g., 30\% decline in 10 years). Variance is a measure of the variability in density over time, and is comprised of both within-year and between-year variance. Variance may be derived from existing survey observations or anticipated values derived from the literature (e.g., Gibbs 2000). Sample size is the number of stations surveyed. Alpha 
represents the probability of incorrectly concluding that density has changed when it has not (i.e., "false positive"; Type I error typically indicated in statistical output with the symbol $P$ ). A second type of error is beta, and corresponds to the risk of concluding that density has not changed when in fact it has (i.e., "false negative"; Type II error). Power is generally defined as the ability to detect a change over time when one actually exists (i.e., "true positive").

We analyzed power using a 10-year monitoring period because it was sufficiently brief to satisfy management objectives without unduly reducing power. The 1994-2003 survey period in the Kūlani-Keauhou study area included several years (1994, 1996, 1999 and 2000) for which sampling did not fully cover the study area. This may bias mean annual densities and occurrence, and yield inaccurate variance for those years; however, this inclusion was necessary to provide an approximation of the power expected from a 10-year survey program.

Variance for each species was estimated by first obtaining residuals of the regression of mean annual density by year (Hatch 2003). This step removed the component of variance attributable to trend but retained within- and between-year variability. The standard deviation of the residuals was subsequently divided by the average of the mean annual densities for the 19942003 survey period, and converted to CV for input in the power analysis program TRENDS (Gerrodette 1987, 1993). Variance was calculated for frequency of occurrence in the same manner.

Population declines corresponding to low, moderate, high, and very high rates of change were produced by selection of a 1\%,3\%,5\%, and 10\% decrease in mean annual density and occurrence in the program TRENDS. These annual rates of decline correspond to absolute declines of $9 \%, 24 \%, 37 \%$ and $61 \%$ for a 10 -year period, respectively. The range of rates includes that used for bird density monitoring by the North American Breeding Bird Survey (i.e., $-2.7 \%$ per year, or $50 \%$ decline over a 25 -year period; Peterjohn et al. 1995).

Power was calculated for alpha levels of $0.05,0.10$ or 0.20 . These significance levels provided a sufficient range of Type I error risk for which to evaluate the resulting power of a 10year monitoring period given observed variability in bird density and frequency of occurrence.

Although a model of exponential change in density was available as a program option, a preliminary examination of changes in density and occurrence over time for native bird species did not reveal such trends. Moreover, trends are fit about equally well with either linear or exponential models for short time periods and result in similar power estimates (Hatch 2003). Therefore, we selected linear trend as a TRENDS program option.

Power analysis was performed as a one-sided test of the null hypothesis $H_{\mathrm{o}}$ "mean annual density (or occurrence) is not decreasing" versus the alternative hypothesis $H_{\mathrm{A}}$ "mean annual density (or occurrence) is decreasing". This test is specific to an assessment of the power of detecting declining trends, and has no power to detect changes in the opposite direction. A onetailed test was used because it is appropriate to the monitoring objective of detecting declines and has greater statistical power than a two-tailed test (Sokal and Rohlf 1995).

To assess the effect of sample size (i.e., number of survey stations) on the power to detect declining trends in mean annual densities, a custom program was written in the software package S-Plus (version 6; S-Plus 2001b) to randomly resample observations of densities made during a 10 -year period (1994 to 2003). This was simulated for 1,000 iterations over a range of sample sizes $(10,25,50,100,150,200,250,300,350,400,500$ and 600 stations) for Hawai i `Elepaio, 'Akiapōlā'au and Hawai 'i Creeper (i.e., species with low, moderately high and very high variability in mean annual densities). At each iteration, an average of the annual mean densities and a standard deviation of the residuals of the regression of mean annual density by year were 
calculated. A CV was obtained by dividing the latter by the former value, and the mean $\mathrm{CV}$ for all iterations was input into the program TRENDS. The exercise used three combinations of effect size (i.e., rate of decline) and alpha levels to capture the range of power under various scenarios (listed here from low to high power): (1) small declines with use of a fairly conservative alpha (i.e., decline rate $=3 \%$ and alpha $=0.05)$; (2) moderate declines with a moderately liberal alpha (i.e., decline rate $=5 \%$ and alpha $=0.10)$; and (3) severe declines with a very liberal alpha (i.e., decline rate $=10 \%$ and alpha $=0.20$ ).

The random selection of observations as applied in the sample size simulation does not fully reproduce the consistency of bird densities that exists at each site over time. This is because, at each iteration, the process may draw observations from entirely different sets of survey sites and partially disassociates the existing temporal autocorrelation. The result is that the simulated data has somewhat higher variance and CVs than that observed in actual sample sizes. For example, the average sampling effort in the Kūlani-Keauhou study area between 1994 and 2003 was 179 stations. The observed CV for the Hawai $i$ 'Elepaio during this period was 0.118 , whereas for simulated data for a comparable sample size it was 0.142 . For this reason, the exercise should be considered a conservative assessment of power as a function of sample size, and power may actually be up to about $10 \%$ greater than indicated.

Power was defined in this study as adequate at levels $\geq 80 \%$ (i.e., beta $=0.20$ ). However, this threshold is somewhat arbitrary and should be evaluated in light of management objectives that balance the two types of interrelated error (alpha and beta) and the risks they represent (Di Stefano 2003). For example, an alpha of 0.05 is a level widely used to assess significance in many statistical tests, and is a fairly conservative standard that ensures against incorrectly rejecting the null hypothesis. However, it may also be advantageous to assess trends given a "liberal" alpha of 0.10 or 0.20 . Although this approach increases the risk of concluding that a trend exists when in fact it is not present, it also may be consistent with a management objective that ensures that power is maximized and existing declines in species of concern are not missed. Moreover, an alpha level of 0.20 matches the risk associated with a beta level of 0.20 . Although these equivalent error levels may reasonably balance risks, an assessment of the power of a monitoring program should establish and apply error thresholds based on species-specific considerations. For example, monitoring the trends of threatened and endangered species may require use of an alpha of 0.20 and a beta of 0.20 (i.e., power $=80 \%$ ). Species whose status and trends are not of particular concern may be assessed with an alpha of 0.05 and an equivalent beta (i.e., power $=95 \%$ ). It is important to point out that significance levels and desired power should be established a priori during the experimental design of a monitoring program. This ensures that the sample size is appropriately anticipated given observed or expected variability in bird occurrence and density. It also requires that the magnitude of a trend one seeks to detect is established at a biologically meaningful level and is relevant to specific management objectives.

\section{Results}

\section{Kūlani-Keauhou}

\section{Bird Occurrence and Trends}

Native Birds

Five of the eight native forest birds in the Kūlani-Keauhou study area showed evidence of declining occurrence between the 1995-1998 ("1990s") and 2001-2003 ("2000s") survey periods 
(Table 5). Hawai ' 'Elepaio was abundant and fairly widespread; however, frequency of occurrence declined from $56 \%$ to $47 \%$ of the stations occupied $(P=0.002$; Figure 6$)$. Both 'Öma'o and 'I'iwi were ubiquitous in the study area, but showed modest declines in the proportion of stations occupied between the 1990 s and 2000 s $(97 \%$ to $91 \% ; P<0.001 ; 92 \%$ to $88 \% ; P=0.031$, respectively; Figures 7 and 8$)$. The endangered 'Akiapōlā'au was infrequently observed and showed a marginally significant decrease in occurrence $(12 \%$ to $8 \% ; P=0.042$; Figure 9). Likewise, occurrence of the endangered Hawai i Creeper significantly declined from $12 \%$ to $7 \%$ of stations surveyed $(P=0.003$; Figure 10$)$.

The remaining three native forest bird species showed no evidence of declining

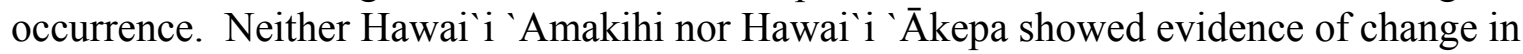
frequency of occurrence ( $P=0.340$ and $P=0.135$, respectively; Figures 11 and 12). This may be due to either the absence of an actual difference between the two periods, or the variability in one or both periods is sufficiently large that it obscures a trend. Hawai $i$ 'Amakihi exhibited low variability in occurrence over the 1994-2003 survey period $(\mathrm{CV}=0.076$; Table 6), and it is likely that the species' occurrence is stable in the study area. However, Hawai` $i$ 'A kepa show high variability in occurrence $(\mathrm{CV}=0.490)$, and this may mask potential change in occurrence.

Apapane were detected at all stations in both survey periods and consequently show no trend in occurrence (Figure 13).

Non-native Birds

Three of four non-native forest birds show evidence of a decrease in frequency of occurrence from the 1995-1998 to 2001-2003 survey periods (Table 5). Red-billed Leiothrix were found at about $50 \%$ of the stations during the $1990 \mathrm{~s}$, but at almost half that frequency in the 2000 s period $(P<0.01)$. Japanese White-eye were present at about $85 \%$ of stations in the 1990 s period, but occurrence declined to about $65 \%$ by the 2000 s $(P<0.01)$. Northern Cardinal occurrence also halved from about $32 \%$ to $16 \%$ during these two periods $(P<0.01)$. House Finch were uncommon $(<8 \%)$ but showed no apparent trend in occurrence $(P=0.13)$.

\section{Bird Density and Trends}

Native Birds

Hawai $i$ `Amakihi and `Apapane are common, widespread species with stable or increasing populations throughout much of Hawai'i Island (Camp et al. In prep., Gorresen et al. In review). Hawai ' 'Amakihi densities in the Kūlani-Keauhou study area significantly increased from the 1995-1998 ("1990s") to 2001-2003 ("2000s") survey period (3.2/ha to 4.0/ha; $P=$ 0.001; Table 7; Figure 11). Although not directly comparable because of methodological differences, an increasing trend is also supported by results of the 1972-1975 IBP survey of the Keauhou Ranch and the Kîlauea Forest Reserve and the 1977 HFBS in which 'Amakihi were recorded at a mean density of 2.4/ha (Conant 1975) and 3.6/ha, respectively (Appendix 1). Similarly, 'Apapane were observed at an average density of 16.5/ha in 1972-1975 (Conant 1975) and 19.2/ha in 1977 (Appendix 1). Densities also significantly increased from the 1990s to 2000s (i.e., 24.4/ha to 28.4/ha; Table 7; Figure 13).

'Ōma`o, Hawai $\mathrm{i}$ Creeper, and 'I'iwi showed negative trends in the Külani-Keauhou study area (Table 7), and these species have also shown range contraction and declining densities at the island-wide scale (Gorresen et al. In review). Although 'Ōma`o remain widespread and populations appear stable in Ka' $\mathrm{u}$ and the Hakalau Forest National Wildlife Refuge within the North Windward (i.e.,Hāmākua) region, densities in the Kūlani-Keauhou significantly declined 
from the 1990 s to 2000 s (2.8/ha to 2.0/ha; $P<0.001$; Table 7; Figure 7). Moreover, higher densities of 3.5/ha and 2.8/ha were previously observed during the 1972-1975 IBP survey (Conant 1975) and the 1977 HFBS, respectively (Appendix 1).

Densities of the endangered Hawai' i Creeper averaged 0.3/ha in the Keauhou Ranch and the Kîlauea Forest Reserve from 1972 to 1975 (Conant 1975) and 0.14/ha during the 1977 HFBS (Appendix 1). Although the trend was marginally significant, densities decreased from the 1990 s to 2000 s ( 0.34 to $0.23 ; P=0.10$; Table 7 ; Figure 10). High within- and between-year variability in Hawai i Creeper density likely contributes to the marginal significance of the trend. The species' range in the region currently excludes the HVNP from which creepers have been extirpated since the early 1970s (Conant 1975, Banko and Banko 1980).

'Tiwi numbers in the study area appear to have declined between the 1995-1998 and 2001-2003 survey periods ( 9.8 /ha to $8.5 /$ ha; $P=0.002$; Table 7 ; Figure 8 . However, inter-annual densities have been fairly variable (Appendix 1), and may reflect local movement in response to nectar availability (Ralph and Fancy 1995). Moreover, low densities were also observed during 1972-1975 and 1977 [averaging 3.2/ha and 8.6/ha (Conant 1975)], and may indicate that 'T'iwi have not declined in the study area.

Three of the eight native forest birds - Hawai' $i$ 'Elepaio, 'Akiapōlā'au, and Hawai'i 'Ákepa - showed change in density. This result could be due to either high variability or stable local densities. The latter is probably the case for Hawai' $\mathrm{i}$ 'Elepaio as its mean density was nearly identical in the 1990s and 2000s (Table 7), and the variability observed between 1994 and 2003 was low $(\mathrm{CV}=0.118$; Table 6$)$ and likely did not conceal a positive or negative trend (see the Results section Power Analysis - Trends in density). However, it should be noted that the 1972-1975 IBP and the 1977 HFBS recorded higher densities in Keauhou Ranch and the Kilauea Forest Reserve: 3.8/ha and 2.6/ha, respectively (Conant 1975; Appendix 1).

Hawai' $i$ 'Ākepa trends are difficult to analyze because of high variability $(\mathrm{CV}=0.574$; Table 8). Although the trend was not significant, densities appear to have declined between the $1995-1998$ and 2001-2003 survey periods ( 0.30 /ha to 0.23 /ha; $P=0.26$; Table 7 ; Figure 12 ). Moreover, although a comparison of the results of various surveys is complicated by differences in methodology, Hawai ${ }^{i}$ 'Ākepa densities averaged 0.46 birds/ha in the 1972-1975 IBP survey (Conant 1975) and 0.38/ha during the 1977 HFBS (Appendix 1). A regional population decline is also evident in the species' extirpation from adjacent areas within the HVNP (Banko and Banko 1980).

As with Hawai ' ' 'Ākepa, variability in `Akiapōlā'au density is high $(\mathrm{CV}=0.325$; Table 8), and may result in the failure to detect a trend if it is present. The 1972-1975 IBP survey of Keauhou Ranch and the Kīlauea Forest Reserve recorded an overall 'Akiapōlā'au density of 0.49/ha (Conant 1975), and subsequent surveys in 1977 (HFBS), the 1990s and 2000s detected densities of 0.10/ha, 0.10/ha, and 0.09/ha, respectively (Appendix 1; Table 7). Moreover, a 2002 survey of the Upper Waiākea Forest Reserve directly north of the Kūlani-Keauhou study area did not record 'Akiapōlā' au in areas in which they had been detected during the 1977 HFBS (Camp et al. In prep.), and may indicate the species' range has contracted upslope. Despite the apparent decline in 'Akiapōlā'au density, the assessment of trend remains inconclusive $(P=0.70$; Table 7; Figure 9). More encouragingly, regenerating koa in degraded or deforested areas on Kamehameha Schools' Keauhou Ranch and the Kapāpala Forest Reserve recently has been observed to support relatively high densities of `Akiapōlā'au (Pratt et al. 2001, Petchar 2004). 
Non-native Birds

Three of the four non-native forest birds in the Kūlani-Keauhou study area showed a significant decrease in density between the 1995-1998 and 2001-2003 survey periods (all $P<$ 0.01; Table 5; Figures 14 to 17). Red-billed Leiothrix numbers decreased from 1.5/ha to 0.8/ha, Japanese White-eye decreased from 8.8 /ha to 5.6/ha, and densities of the Northern Cardinal declined from 0.23 ha to $0.13 /$ ha. Although House Finch density declined $0.24 /$ ha to $0.17 /$ ha, the difference was not significant $(P=0.32)$.

\section{'ōla`a}

\section{Bird Occurrence and Trends}

Native Birds

The frequencies of occurrence of all five native forest birds in the 'Ōla`a study area were much lower in 1994 than during the 1977 HFBS (Table 9). Although fairly ubiquitous in 1977, Hawai $i$ 'Elepaio occurrence declined from $41 \%$ to $0 \%$ by $1994(P<0.001)$, and it was nearly absent in 1992 and 1993. 'Öma'o, 'I'iwi and 'Apapane also were widespread in 1977 $(67 \%, 54 \%$ and $96 \%$ occurrence, respectively), but were found at significantly fewer stations in all subsequent surveys (i.e., occurrence in 1994 was 42\%, 5\% and 58\%, respectively; all $P \leq$ 0.002). Hawai $i$ 'Amakihi were absent or nearly so throughout the entire survey period. This was expected because 'Amakihi typically now occur at low densities in wet forest habitats on Hawai'i Island (Camp et al. 2003). The most unfortunate decline of all was the 'O'u, which was recorded a few times at 'Öla'a in the 1970s and 1980s, only to drop out completely by the 1990s. The species is now likely extinct (Reynolds and Snetsinger 2001).

Non-native Birds

Only one of the four non-native forest birds in the 'Ōla'a study area showed a significant difference in its frequency of occurrence since the 1977 HFBS (Table 9). Red-billed Leiothrix were found at $>50 \%$ of the stations during in 1977 but declined in occurrence to $<8 \%$ between 1992 and $1994(P<0.001)$. Japanese White-eye occurred at $>90 \%$ of stations in three of the four years of survey, but showed no apparent trend $(P=0.32)$. Northern Cardinal occurrence varied between $11 \%$ and $26 \%$ but also did not exhibit a positive or negative trend $(P=1.00)$. Likewise, House Finch were uncommon (i.e., $<7 \%)$ and showed no apparent trend $(P=0.15)$.

\section{Bird Density and Trends}

Native Birds

Densities of three of the five native forest birds in the 'Ōla`a study area were significantly lower in 1994 than during the 1977 HFBS (Table 10). Perhaps most alarmingly, Hawai $i$ Elepaio densities dropped from 1.64/ha in 1977 to zero by $1994(P<0.001)$. The population decline in the study area is reflected elsewhere in the region within mid-elevation habitat (Camp et al. In prep.). The 1972-1975 IBP survey east of the Kîlauea Caldera revealed densities of only 0.43/ha in 'ōhi 'a forest at 1,100 m elevation (Conant 1975). Moreover, based on a 1973-1974 assessment of sites previously surveyed in the 1940s, Banko and Banko (1980) determined that Hawai ' $i$ 'Elepaio have disappeared from much of HVNP in mid- and low-elevation habitat.

'Tiwi densities declined more than ten-fold from 1977 to 1994 in the 'Ōla`a study area $(2.91 /$ ha to $0.23 /$ ha; $P<0.001)$. Although this change may reflect local movement in response to 
nectar availability (Ralph and Fancy 1995), other population declines have been noted in midelevation habitat and indicate that the species' range has contracted elsewhere in the region. For example, 'I'iwi density in forest east of Kîlauea Iki at 1,100 m was estimated at 0.40/ha in 19721975 (Conant 1975), but only a single breeding-season detection has been recorded in this area since the late 1970s (Camp et al. 2002). Furthermore, if the higher densities of 'I'iwi recorded during the summer counts of the HFBS were the result of post-breeding dispersal from higher elevations, then it would be expected that the subsequent counts conducted during the breeding season at higher elevations might show a corresponding increase in density from the birds moving upslope. This is not the case, for the 'I'iwi has declined at both low and high elevations simultaneously.

Most surprisingly, 'Apapane densities also appear to have declined (18.7/ha in 1977 to 6.9/ha in 1994; $P<0.001$ ). Although differences in observed densities may be due to population movement in response to nectar availability (Ralph and Fancy 1995) or to periodic declines in precipitation related to El Niño-Southern Oscillation events (Lindsey et al. 1997), densities in 1992 and 1993 were also markedly lower and may point to a sustained decline in this midelevation study site.

'Öma'o and Hawai 'i 'Amakihi densities during the 1977 and 1994 surveys were not significantly different. However, both species have shown highly variable densities over the four years of survey in the 'Ōla'a study area that may act to conceal trends. Most notably, Hawai' $i$ 'Amakihi were absent in two (1992 and 1993) of the four years of survey and do not appear to persist in the study area in great numbers. The species' apparent decline in mid-elevation habitat has been observed elsewhere in the region (Reynolds et al. 2003, Camp et al. In prep.).

The range of the 'Akiapōlā'au, Hawai $i$ Creeper and Hawai $i ~ ‘ \bar{A} k e p a$ no longer includes the 'Ōla`a Tract and 'Ōla`a Forest Reserve from which the former two species were recorded as late as the 1960s (Banko and Banko 1980).

Non-native Birds

Three of the four non-native forest birds showed a significant difference in the density between the 1977 HFBS and 1994 surveys. Red-billed Leiothrix numbers significantly decreased from $1.94 /$ ha to 0.24 /ha $(P<0.001$; Table 9$)$. Japanese White-eye increased from $13.5 /$ ha to 17.4 /ha during the same period $(P<0.001)$. Likewise, densities of the Northern Cardinal climbed from $0.13 /$ ha to $0.42 /$ ha $(P<0.001)$. House Finch density did not exhibit any apparent trend.

\section{Mauna Loa Strip}

\section{Bird Occurrence and Trends}

Native Birds

Trends in the frequencies of occurrence of the five native forest birds in the Mauna Loa Strip study area were all non-significant (Table 11; Figures 18 to 22). Although occurrence of Hawai 1 'Elepaio appears to be greater in all years since the 1977/1979 HFBS, the nonsignificant regression result $(P=0.14)$ and a fairly low incidence of variability indicates a generally stable trend for this common species. 'Öma'o showed the reverse situation in that occurrence dropped from $27 \%$ of the stations surveyed in the $1977 / 1979$ HFBS to $\leq 8 \%$ in subsequent surveys $(P=0.10)$, and its incidence since HFBS has been consistently low. The non-significant trend $(P=0.45)$ and moderately low variability of Hawai`i `Amakihi indicate 
that occurrence is also stable. 'I'iwi and 'Apapane were common to very common throughout the entire survey period, and did not exhibit increasing or decreasing trends $(P=0.17$ and 0.60 , respectively). The non-significant result may be due to the moderately high variability observed for these species, perhaps itself a consequence of local movement in response to nectar availability (Ralph and Fancy 1995).

Non-native Birds

The occurrences of three of the four non-native birds appear to be increasing in the study area (Table 11; Figures 23 to 26). Although trends over the eight years of survey were inconclusive for Red-billed Leiothrix because of highly variable numbers $(P=0.24)$, the species showed a marked increase in occurrence (i.e., from 5\% during the 1977/1979 HFBS to an average of about 40\% for the 1986-1994 survey period). Japanese White-eye showed a significant increase over the entire survey period $(P=0.02)$ primarily due to a prevalence of $\geq 80 \%$ since the HFBS (after which occurrence appeared stable). Although the overall trend was not significant $(P=0.07)$, the Northern Cardinal also exhibited a jump in occurrence since the late 1970 s, after which it was commonly detected ( $~ 60 \%$ of stations) and showed a stable trend. House Finch were common throughout the entire survey period (frequency of occurrence $=33$ $65 \%)$, but did not exhibit increasing or decreasing trends $(P=0.95)$.

\section{Bird Density and Trends}

Native Birds

With the exception of 'Ōma`o, none of the native forest birds showed a significant trend in density in the Mauna Loa Strip study area (Table 11; Figures 18 to 22). The nonsignificant results may be interpreted as evidence of stable densities given the relatively low among-year variability exhibited by these species in the nearby Kūlani-Keauhou study area (Table 8). The density of 'Ōma'o appears to have significantly decreased shortly after the $1977 / 1979$ HFBS, after which it maintained fairly stable, if low, densities.

Non-native Birds

Of the four non-native forest birds, only the Japanese White-eye demonstrated a marked and consistent increase in density between the 1977 and 1994 surveys (i.e., 3.1/ha to 10.8/ha; $P<$ 0.001; Table 11; Figures 23 to 26). Northern Cardinal densities showed a marginally significant increase $(P=0.05)$, primarily due to higher densities since the 1977 HFBS. Densities of both Red-billed Leiothrix and House Finch varied widely and showed no apparent trend $(P=0.96$ and $P=0.84$, respectively).

\section{East Rift}

\section{Bird Occurrence and Trends}

Native Birds

Of the four native forest birds in the East Rift study area, only the Hawai $i$ 'Elepaio showed a significant difference between the 1979 HFBS and 1993/1994 periods ( $P$ $<0.001$ ), and dropped in occurrence from $31 \%$ to $9 \%$ of stations surveyed (Table 12). Both 'Ōma'o and 'Apapane were very common and present at $>93 \%$ stations in both survey periods, and showed no change in frequency of occurrence $(P=0.65$ and 0.16 , respectively). Hawai $i$ 
'Amakihi were detected on $\leq 3 \%$ of stations in both periods, and showed no apparent trend $(P=$ $0.71)$.

Non-native Birds

As with other areas, the Japanese White-eye showed an increase in site occupancy (95\% to $99 \%$ of stations; $P=0.03$ ) in the East Rift study area. The Northern Cardinal decreased from $23 \%$ to $11 \%$ of the stations surveyed $(P=0.008)$. House Finch were not detected during the 1979 HFBS and were recorded at only 3 stations during the $1993 / 1994$ survey period $(P=$ 0.29). Red-billed Leiothrix were not detected during the 1979 HFBS, and only 2 birds were observed the 1993/1994 survey period; therefore, occurrence was not further analyzed.

\section{Bird Density and Trends}

Native Birds

Three of the four native forest birds present in the East Rift study area exhibited significant declines in density between the 1979 HFBS and 1993/1994 survey periods (Table 13). Hawai $\mathrm{i}$ `Elepaio densities dropped from 0.60/ha to 0.20/ha, 'Ōma`o densities decreased from 1.40/ha to $0.99 /$ ha, and 'Apapane numbers declined from 10.2/ha to 6.3/ha (all $P<0.001$ ). Hawai' $\mathrm{i}$ 'Amakihi were nearly absent from the study area, and occurred at a density of $0.02 /$ ha in both survey periods.

Non-native Birds

Two of the three non-native forest birds showed a significant difference in the density between the 1979 HFBS and 1993/1994 surveys (Table 13). Japanese White-eye density increased from 8.0/ha to 12.6/ha, whereas Northern Cardinal numbers decreased from 0.14 /ha to $0.04 /$ ha (both $P<0.001$ ). No House Finch were recorded during the 1979 HFBS, and only three birds were detected in the 1993/1994 surveys; the species' trend was not analyzed because of the very low densities. Red-billed Leiothrix were not detected in sufficient number to estimate density (i.e., only 7 observations in the entire Puna district).

\section{Power Analysis}

\section{Trends in occurrence}

The power of a survey to detect declines in occurrence was examined for a range of downward trends and levels of risk (i.e., of incorrectly concluding that a trend exists). In general, the ability to track trends is greater when variability is low, a trend is severe, and when a more "liberal" threshold is used to assess the significance of a trend (see Methods section Power Analysis for a discussion on the selection of an appropriate alpha level). Surveys in the KūlaniKeauhou study area had more power to detect a trend in occurrence than to track a change in density for all species except 'Akiapōlā'au (Tables 6 and 8). Power was greater because occurrence was less variable than their respective densities. However, although this difference in power was most pronounced for the common species, CVs were only marginally smaller for densities of Hawai $i$ 'A kepa and Hawai ${ }^{\prime}$ Creeper. Thus, while monitoring trends in occurrence may provide a somewhat complementary measure of species status, it does not provide a surrogate to tracking trends in the density of endangered bird species.

The detection of a low (1\%) rate of annual decline in occurrence within a 10 -year period was only possible for 'Apapane, a species with the least variability in observed 
occurrence (i.e., $\mathrm{CV}=0.008$ ). However, moderately negative trends can also be detected for species with moderate variability, even at low alpha levels (e.g., Hawai' $\mathrm{'Elepaio} \mathrm{CV}=0.096$; power $=87 \%$ when decline rate $=3 \%$ and alpha $=0.05$; Table 6 ).

Trends of species with higher variability in site occupancy are only likely to be detected given high rates of decline and/or use of higher alpha levels. For example, the power to adequately monitor 'Akiapōlā'au occurrence trends would only be attained in cases in which it was undergoing very high rates of decline (e.g., $\mathrm{CV}=0.428$; power $=83 \%$ when decline rate $=$ $10 \%$ and alpha $=0.05$; Table 6). Trends for both Hawai' $\mathrm{i}$ 'A $\mathrm{kepa}(\mathrm{CV}=0.490)$ and Hawai $\mathrm{i}$ Creeper $(\mathrm{CV}=0.511)$ are also expected to remain undetectable unless trends are strongly negative and a fairly liberal threshold at which to declare significance is used.

\section{Trends in density}

As with the analysis of occurrence trends, the ability to detect a trend in density is greater in cases in which there is low variability, high rates of decline, and an acceptance of greater levels of risk of Type I error in assessing trends. Trends for species with the least variability in density (e.g., 'Apapane, Hawai ' $\mathrm{'Elepaio,} \mathrm{etc.)} \mathrm{had} \mathrm{considerably} \mathrm{greater} \mathrm{power} \mathrm{than} \mathrm{those} \mathrm{with}$ high variability (e.g., Hawai`i `Ākepa, Hawai`i Creeper, etc.; Table 8).

The detection of a low (1\%) rate of annual decline in density within a 10 -year period is not possible for even those species with the least variability in observed densities (e.g., 'Apapane, Hawai $i$ 'Elepaio, etc.). However, this is not surprising given that as effect size approaches zero, a statistical test becomes a test of the absence of trend. Since a null hypothesis can only either be rejected or not rejected, and is never formally "proved", the absence of a trend can only be indirectly inferred for those species that demonstrate high power. That is, if the observed variability in annual densities is low and a regression test were to reject the alternative hypothesis of trend, then one may tentatively conclude that densities are stable. For example, an exploratory assessment with regression of Hawai ' ' Elepaio densities between 1994 and 2003 in the Kūlani-Keauhou study area determined its trend was not significant $(P=0.960$; slope $=$ $+0.002)$. Because the species also exhibits low variability in density $(\mathrm{CV}=0.118$; Table 8$)$, there exists sufficient power to detect moderate rates of decline (e.g., power $=89 \%$ with a $3 \%$ rate and alpha $=0.10$ ), and one can confidently infer that local trends are stable. In contrast, species with high variability in density and low power do not permit one to conclude that there exists a stable trend because of the high likelihood of a Type II error (i.e., missing an actual trend). For example, Hawai i Creeper did not demonstrate a significant trend $(P=0.702$; slope $=$ -0.007), but because it also showed high variability in density $(\mathrm{CV}=0.656$; Table 8$)$ and low power given moderate rates of decline (e.g., power $=22 \%$ with a $3 \%$ rate and alpha $=0.10$ ), one can only conclude negative trends were not detected but may (or may not) be present.

Moderately (3\%) negative trends can be detected for species with low variability, particularly at greater alpha levels. For instance, power to detect trends is high for 'Apapane $(\mathrm{CV}=0.088)$ at moderate rates of decline and alpha (e.g., power $=98 \%$ with a $3 \%$ rate and alpha $=0.10$; Table 8).

Trends of species with somewhat higher variability in density are only likely to be detected given higher rates of decline and/or use of higher alpha levels. For example, only highly $(5 \%)$ negative trends in the density of 'I'iwi $(\mathrm{CV}=0.148)$ may be detected with a conservative alpha level of 0.05 (i.e., power $=97 \%$; Table 8). More moderate rates of decline in 'I iwi might be detected when more liberal alpha levels area used (e.g., power $=89 \%$ with a 3\% rate and alpha $=0.20$ ). 
Unfortunately, surveys of species with high variability in density are only likely to detect trends given very high rates of decline and the use of risky alpha levels. For 'Akiapōlā'au $(\mathrm{CV}=0.325)$, adequate power is achieved only for cases in which it is undergoing a rapid decline in density $(\geq 10 \%$; Table 8$)$. Similarly, sufficient power to detect negative trends in Hawai 'i 'Ākepa $(\mathrm{CV}=0.620)$ and Hawai $i$ Creeper $(\mathrm{CV}=0.698)$ may only be obtained given the $a$ priori decision to use a threshold alpha $\geq 0.20$, and will only do so when trends are strongly negative. The relationship of analytical power, the minimum rate of decline in density that a monitoring program seeks to detect, and the acceptable risk of incorrectly concluding that a trend exists (Type I error) is graphically summarized with surface plots (Figure 27) for Hawai' i 'Elepaio, 'Akiapōlā'au, and Hawai'i Creeper (i.e., species with low, moderate, and high variability in density, respectively).

\section{Power and sample size}

The power to detect downward trends in densities was also examined for a series of hypothetical sample sizes given a range of rates of decline and alpha thresholds. In general, power increases as a function of sample size (i.e., number of stations). However, the relationship is not linear, and at a certain point, a large increase in sampling gains only a small increase in power (Table 14; Figure 28).

In situations in which one seeks to detect small declines and uses a conservative alpha threshold (i.e., decline rate $=3 \%$ and alpha $=0.05$ ), power will not be adequate regardless of the sampling effort and degree of variability in density (Table 14). For example, Hawai' $\mathrm{i}$ 'Elepaio, 'Akiapōlā'au and Hawai'i Creeper (i.e., species with low, moderate, and high variability, respectively) attained power equal to $69 \%, 19 \%$ and $11 \%$ given a relatively high sampling effort of 600 stations. However, when moderate declines are sought using a moderately liberal alpha (i.e., decline rate $=5 \%$ and alpha $=0.10$ ), power is adequate for the less variable species. For example, power for Hawai 'i 'Elepaio was at least $98 \%$ given the average sampling effort of about 179 stations surveyed in the Kūlani-Keauhou study area between 1994 and 2003.

Surveys of species with low variability in density also have adequate power to detect trends given small sample sizes. For example, 50 stations is sufficient to track Hawai $i$ 'Elepaio densities if annual rates of decline were $\geq 5 \%$ and the moderately liberal alpha level of 0.10 was used to declare significance. Smaller rates of decline and/or alpha levels would require larger samples to achieve adequate power (Figure 27).

On the other hand, unless density is declining rapidly and/or a liberal alpha threshold of 0.20 is used, species with high variability do not attain adequate power regardless of the number of stations that can be reasonably sampled. For example, power for Hawai' i Creeper asymptotes at 0.29 with 300 stations; Table 14; Figure 28). At this point, the gain in power is often only marginally greater than that achieved for a much smaller sampling effort (e.g., power for Hawai $i$ Creeper is 0.27 with 100 stations).

Power also may be increased if the minimum detectable effect size is established at a higher level than that used for this exercise (e.g., 10\% annual rate of decline). In addition, using a higher threshold (e.g., alpha $=0.20$ ) at which to declare a significant trend will also increase power. For example, a sample effort of 150 stations attains sufficient power for Hawai'i Creeper given this rate and alpha level (Table 14; Figure 27). However, this represents an extreme and risky sampling regime that may not meet monitoring objectives. 


\section{Discussion}

\section{Study Area and Region-wide Trends}

It is important to point out that the trends derived from small or short-term datasets should be evaluated with caution. In order to monitor population changes, survey programs must be conducted over time scales of sufficient duration to capture population trajectories and cycles (Gunderson and Folke 2003, Redman and Kinzig 2003). Short-term programs may not be able to detect trends, especially for species for which abundances fluctuate widely (Hatfield et al. 1996). An additional word of caution is that surveys in the Mauna Loa Strip, 'Ola'a, and East Rift ceased in the mid-1990s, and because of this hiatus in monitoring, there has been no information on bird trends in these areas for more than a decade.

Native Birds

The native forest bird species exhibited different trend patterns across the four study areas (Figure 29). In general, native bird trends were mixed at high elevations in KūlaniKeauhou, declining at the mid-elevation sites in 'Ōla`a and East Rift, and mostly stable in Mauna Loa Strip.

Six of the eight native forest species in the Kūlani-Keauhou study area appear to be undergoing declines in occurrence and/or density. These results include two endangered species, 'Akiapōlā'au and Hawai 'i Creeper; and a third endangered species, Hawai' 1 'Ākepa, exhibits sufficient variability that downward trends might remain undetected. Declines in Hawaii Creeper and Hawaii Akepa may be related to loss of old growth habitat in Keauhou Ranch, particularly in the early 1980's. The other declining native species are 'Ōma`o, 'Iiwi, and Hawaii 'Elepaio. Although the decrease in 'Ōma'o is modest, it may be a cause for concern because the species has undergone range contraction and density declines elsewhere on Hawai' $i$ Island (e.g., forest east of Kîlauea Iki in Hawai ${ }^{i}$ Volcanoes National Park and adjacent Kahauale'a Natural Area Reserve; Camp et al. In prep., Gorresen et al. In review). 'T'iwi trends are suggestive of a downward trend, but fairly high inter-annual variability, possibly due to local foraging movements, currently precludes making a determination of a negative trend. Although Hawai' $i$ 'Elepaio density appears stable, its frequency of occurrence has decreased. The species warrants careful monitoring, particularly since densities have decreased on leeward and midelevation habitats of Hawai $i$ Island since the HFBS (Camp et al. In prep., Gorresen et al. In review). Two native species, Hawai' $\mathrm{Y}$ 'Amakihi and 'Apapane, were ubiquitous and showed increasing or stable trends in the Kūlani-Keauhou study area.

In the nearby 'Ōla'a study area, all four native birds (Hawai'i `Elepaio, 'I'iwi, 'Ōma`o, and 'Apapane) have shown declining numbers. These declines follow on the heels of the disappearance of 'O'u (Psittirostra psittacea) from `Ōla`a (Reynolds and Snetsinger 2001), and its probable extirpation from Hawai' $i$ Island. The declines have been most pronounced for the Hawai $i$ `Elepaio and 'I'iwi, species that became absent or nearly so by 1994.

Downward bird trends were also evident in either occurrence or density (or both) of three native species - Hawai ' 'Elepaio, 'Ōma`o and 'Apapane - in the East Rift study area. Hawai`i 'Amakihi, which were nearly absent during the HFBS, remain very rare. Both occurrence and density of the Hawai $i$ 'Elepaio have decreased considerably. Although 'Ōma`o and 'Apapane remain widespread, and the observed declines in density may fall within the range of long-term variability or be ascribed to local movements, it is noteworthy that both species have shown the same downward trend in the nearby 'Ōla`a study area. Collectively, these potential declines may 
signal a range contraction in portions of these species' mid-elevation distribution. Although Hawai'i 'Elepaio, 'Ōma`o, Hawai ' `Amakihi and `Apapane occur in the forest habitat $<1,100 \mathrm{~m}$ that extends along the East Rift into lower Puna, a contracting range that eventually excludes the 'Ōla'a study area may eventually divide the lower- and upper-elevation populations.

With the possible exception of 'Ōma' $\mathrm{o}$, the outlook for the extant native forest birds in the Mauna Loa Strip (MLS) study area is promising. Hawai' 'Amakihi, 'I'iwi and 'Apapane were ubiquitous and trends appeared to be stable. 'Öma'o numbers markedly decreased since the 1977/1979 HFBS, after which it persisted at very low densities. Pronounced habitat changes in the area (e.g., koa regeneration, reduced understory and shrub cover, etc.) may have contributed to the observed pattern for 'Ōma'o. However, surveys prior to the HFBS also indicate that 'Ōma'o now occur where they once had been absent or rare between 1940 and the early 1970s. A 1972-1975 survey (Conant 1975) detected only a single `Ōma`o in an area of upper MLS (i.e., Kīpuka Kulalio) described as "koa savanna" (i.e., relict koa stands with few understory fruiting plants as a result of fire and heavy grazing preceding ungulate exclusion of the MLS tract). A 1960-1961 survey of the "koa- 'ohi'a parkland" in MLS also recorded no 'Ōma o (Dunmire 1962). Moreover, sites in Kīpuka Kulalio surveyed from 1940 to 1949 did not detect 'Ōma`o (Banko 1980). Conversely, a 1973 survey (Banko 1980) of the same sites in Kīpuka Kulalio detected 'Ōma'o. In light of these reports, one could conclude that 'Ōma'o numbers were very low or non-existent between the 1940s and early 1970s, then modestly increased with irregular appearances and near disappearances in the 1970s, followed by low but continued presence through to the mid-1990s. 'Akiapōlā au were recorded in the 1940s in Kīpuka Kulalio and Kīpuka Puaulu (Banko 1980), but not subsequently recorded by any of the above mentioned researchers. Hawai' $i$ Creeper were also recorded in the 1940s in upper (Kipuka Kulalio) and lower MLS (Kipuka Puaulu), and although later surveys did not detect the species, Banko (1984) notes several anecdotal creeper observations recorded as late as 1971. Hawai' $i$ 'Ākepa were not recorded in MLS during any of the above-mentioned surveys, and Dunmire (1961) stated that "the last record in the Park was over 20 years ago" (i.e., 1940s).

In summary, the trends exhibited by native birds in the Central Windward region give both causes for concern and for hope. 'Akiapōlā'au, Hawai 'i Creeper; and Hawai 'i 'Ākepa have historically demonstrated contractions in distribution, and populations in the region are presently limited to a narrow band of high elevation forest habitat in Kūlani-Keauhou and may be isolated from those in the Ka $\bar{u}$ and North Windward regions. However, reforestation and habitat recovery in the MLS and Kūlani-Keauhou areas may permit the reestablishment of locally extirpated populations and connectivity between isolated demes. The `Ōma'o has been extirpated from much of its island range, and may be declining throughout the Central Windward region. On the other hand, 'Öma 'o appear to have recolonized habitat from which it had been extirpated (i.e., MLS), and the species' limited susceptibility to experimental infection with avian malaria and persistence at mid-elevations (Ralph and Fancy 1994, Atkinson et al. 2001) indicate that 'Ōma'o may be able to maintain its current range in the Central Windward region if habitat degradation does not increase. Hawa' $\mathrm{i}$ 'Elepaio trends appear stable at upper-elevations but downward in the mid-elevation study areas. 'T'iwi are extirpated from the mid-elevation study areas and are possibly in decline in Kūlani-Keauhou. Declines of Hawai'i 'Elepaio and 'T'iwi have been observed elsewhere within mid-elevation habitat (Reynolds et al. 2003, Camp et al. In prep., Gorresen et al. In review), and suggest that their ranges are contracting westward and upslope in the Central Windward region. Although Hawai $\mathrm{i}$ `Amakihi and 'Apapane trends are stable or increasing at the upper elevation study areas, they are downward at mid-elevation sites. 
Non-native Birds

The trends of the non-native forest bird species varied across the four study areas (Figure 30). In general, non-native bird trends were decreasing in Kūlani-Keauhou, mixed in 'Ōla'a and East Rift, and increasing in Mauna Loa Strip.

Japanese White-eye appeared to be undergoing a decline in occurrence and density in the Kūlani-Keauhou study area. This was the only area where this species demonstrated downward trends. Elsewhere, Japanese White-eye has shown markedly increasing occurrence and density. Red-billed Leiothrix numbers appeared to be declining in the Kūlani-Keauhou and 'Ōla' a study areas, and highly variable with non-significant trends in Mauna Loa Strip. Northern Cardinal appear to be in decline in Kūlani-Keauhou and East Rift, but possibly increasing in the 'Ōla'a and Mauna Loa Strip study areas. House Finch was uncommon to rare and highly variable in all study areas, and analyses of its trends were inconclusive.

\section{Recommendations}

The precarious status of much of the native forest bird fauna in the Central Windward region imparts particular urgency to the need for a comprehensive and effective monitoring of bird numbers, occurrence and distribution. This effort will benefit from coordination and planning among all major land managing agencies at the private, State and Federal levels. While the details of a monitoring program must be developed by the land managing agencies, we provide for the reader's consideration several general and specific recommendations on survey and analytical design.

\section{Conduct both extensive and intensive bird surveys.}

We propose the establishment of a monitoring framework that intensively samples select areas and extensively samples a larger region to provide both the "close-ups" and the "big picture" needed to anticipate and follow population changes. The type of information derived from intensive and extensive surveys differ in their applicability. Intensive surveys quantify the standard population indices (i.e., occurrence and density) necessary to assess trends, but are limited to focal areas (e.g., Kūlani-Keauhou) and typically do not afford a gauge of changes in a species' distribution. Extensive surveys, for logistical reasons, are limited in the frequency at which they are conducted and cannot effectively track populations trends. However, extensive, if infrequent, surveys can determine the extent of a species' range, changes in its coverage over time, population connectivity and size (from extrapolated or modeled densities). Information gathered a both scales are critical factors in assessing extinction risk and species status (see BirdLife International 2000).

\section{Reinitiate surveys in the Mauna Loa Strip, `Ōla`a and East Rift study areas.}

If intensive surveys, such as those presently conducted in the Kūlani-Keauhou study area, were re-established in the Mauna Loa Strip, 'Ōla'a and East Rift study areas, monitoring of forest birds across the region could again continue. A reinitiated monitoring program within these areas would benefit by using as much of the previously sampled transects as possible to capitalize on existing survey data in the region and strengthen analysis of trends.

\section{Survey habitat directly north of the Kūlani-Keauhou study area.}

Analyses conducted at the island-wide scale suggest that the endangered species in the Central Windward region may be partially or completely isolated from populations in the Ka' $\bar{u}$ and North Windward regions. Therefore, if surveys were to be expanded into intervening areas, the extent of the Central Windward populations and contiguity with adjacent populations could be established and monitored. The four study areas covered in this report are fairly well- 
distributed within a large part of the Central Windward region. However, there is room for additional intensive surveys in habitat that may still harbor the endangered 'Akiapōlā'au, Hawai i Creeper and Hawai 'i 'Ākepa. Specifically, high elevation forest habitat directly north of the Kūlani-Keauhou study area (i.e., within Upper Waiākea Forest Reserve and east Kīpuka 'Ainahou Nēnē Sanctuary) could be annually surveyed to monitor trends and establish the extent of connectivity between populations (Figure 31). If possible, expanded surveys should supplement and follow the HFBS transects (i.e., transects 25, 26, 92 and 93), and extend down to about $1,400 \mathrm{~m}$. Additional transects may need to be interspersed between the HFBS transects to fully sample the available habitat and attain a sufficiently large sample size to track occurrence and density.

\section{Survey mid-elevation habitat in the Central Windward region.}

Monitoring the margins of a species' distribution is essential for detecting range contraction or expansion (Rodriguez 2002). This type of information may be acquired through a more extensive and coarse-scale survey. For example, 'I 'iwi, Hawai $i$ `Elepaio, and `Ōma`o exhibit declining trends in mid-elevation habitat, and have ranges that currently may extend only 1 to $5 \mathrm{~km}$ below (i.e., east and southeast of) the Külani-Keauhou study area. We recommend expanding surveys to include some or all of the HFBS transects 25-31, and extending sampling down to at least 1,200 $\mathrm{m}$ (Figure 31). Determining species occurrence at the margins of a range does not require the degree of survey effort applied to tracking density trends. If necessary, these transects may be visited at moderately long time intervals (e.g., every 4-8 years), be widely spaced (e.g., HFBS transect 25, 27 and 29), and may sample stations at greater intervals (e.g., $300 \mathrm{~m}$ ) than do current surveys. The surveys presently organized by the Division of Forestry and Wildlife (i.e., the state forest bird surveys) may meet the objectives of a coarse-level survey if they are extended down into the edges of the native species' range. An extensive and coarselevel survey also would permit comparison of its results to that derived from the 1970s HFBS. Moreover, a broader range of sampled habitats would make possible an up-to-date specieshabitat modeling product that more fully describes distribution and population size than is presently possible from the intensive surveys analyzed in this report.

\section{Monitoring requires consistent sampling.}

Due to irregular survey coverage of the Kūlani-Keauhou, 'Ōla`a and East Rift study areas, trend analyses were limited to two-period comparisons of occurrence and density data. Repeated and spatially consistent monitoring would augment the number of annual surveys available for analysis and permit use of more robust statistical methods (e.g., repeated measures regression to account for temporal covariance) and increase the power of detecting trends.

\section{Monitoring requires a long-term commitment to surveying.}

Trends in occurrence and density become clearer as a function of the duration of a survey. In some cases, trends suggestive of a downward or upward direction may acquire significance as sample size (i.e., number of years sampled) increases. On the other hand, an apparently significant trend may be shown to be only a segment of long-term periodic cycling of an otherwise stable population. Temporally consistent monitoring would increase the power of detecting trends.

\section{Assess optimal sample size with power analyses.}

Power analyses demonstrated that, past a certain point, the ability to detect trends increased only minimally as a function of sample size within a limited area (i.e., comparable to the study areas analyzed herein). For example, there was little difference in power between samples of 200 and those of 300 stations for the three species examined in the Kūlani-Keauhou 
study area. This conclusion is also supported by analyses carried out for the Hakalau National Wildlife Refuge (Camp et al. 2003). Annual surveys in Kūlani-Keauhou since HFBS have been carried out with as many as 333 stations (and 140, 143, and 172 stations in the Mauna Loa Strip, 'Ōla'a and East Rift study areas, respectively.) However, an optimal sample size for an area receiving intensive annual surveys may be attained with about 200 stations if observed or expected variability in bird numbers is similar to that of the Külani-Keauhou study area. Given the constraints of time and resources, some sampling effort may be better allocated to monitoring bird trends in areas that are not currently surveyed.

\section{Conduct demographic studies to better assess status of rare and endangered species.}

Variable-circular plot (VCP) methods and other count data are relatively ineffective at tracking changes in species that occur at very low densities (Buckland et al. 2001).

Consequently, VCP has been of limited use in determining the status of rare species such as ‘Akiapōlā’au, Hawai `i Creeper and Hawai i ‘Ākepa. Monitoring the demographic parameters (e.g., survival, reproduction, health, movements, predation, etc.) that regulate population growth can provide substantially better information on species status than do surveys of occurrence and abundance (Steidl 2001). Demographic studies for these species should be considered in the Kūlani-Keauhou study area.

Forest habitat restoration is critical to recovery of endangered bird populations.

Ongoing habitat recovery and restoration in the upper elevations of the Central Windward region, at Hawai' i Volcanoes National Park and the Kūlani Correctional Facility, and presently accelerating on Kamehameha School lands at Keauhou, will result in improved prospects for native forest birds. The relatively high density of 'Akiapōlā'au observed in regenerating koa is encouraging. Reforestation of adjacent upper elevation habitat in the Kapāpala Forest Reserve may also promote reestablishment of endangered species populations and their connectivity to those in the Ka' $\bar{u}$ and Central Windward regions. Programs here and elsewhere to re-establish forest, reduce rat depredation, control weeds, and the fencing and removal of ungulates are essential for forest bird recovery in the high elevation habitat that now serves as a refuge for many species.

\section{Acknowledgements}

This report was produced under the auspices of the Hawaii Forest Bird Interagency Database Project, a project of the U.S. Geological Survey - Pacific Island Ecosystems Research Center, and the following cooperating agencies: National Park Service, USGS-Pacific Basin Information Node, University of Hawaii Pacific Cooperative Studies Unit, State of Hawaii Division of Forestry and Wildlife, Gap Analysis Program - Hawaii; Kamehameha Schools; Natural Heritage Program - Hawaii; The Nature Conservancy - Hawaii; U.S. Fish and Wildlife Service; and the U.S. Forest Service. We especially thank the managers and field biologists who collected the data and worked so hard to maintain a core group of trained counters, and the numerous interns that assisted with the preparation of data described here. Any use of trade, product, or firm names in this publication is for descriptive purposes only and does not imply endorsement by the U.S. Government.

\section{References Cited}

Atkinson, C.T., J.K. Lease, B.M. Drake, \& N.P. Shema. 2001. Pathogenicity, serological responses and diagnosis of experimental and natural malarial infections in native Hawaiian thrushes. Condor 103:209-218. 
Banko, P.C., and W.E. Banko. 1980. Historical trends of passerine populations in Hawaii Volcanoes National Park and vicinity. Pages 108-125 in Proceedings of the Second Conference on Scientific Research in the National Parks. Volume 8: Endangered and Threatened Species; Exotic Species. San Francisco, California. November 26-30, 1979. U.S. Department of the Interior, National Park Service.

Banko, W. E. 1986. History of endemic Hawaiian birds. Part 1. Population histories - species accounts, forest birds: 'Amakihi, Creeper, 'Akepa and Po`o Uli. Avian History Report 8B and 8C. Cooperative National Park Resources Studies Unit, University of Hawai i, Honolulu, HI, U.S.A.

BirdLife International. 2000. Threatened birds of the world. BirdLife International, Cambridge, U.K.

Buckland, S.T., D.R. Anderson, K.P. Burnham, J.L. Laake, D.L. Borchers, and L. Thomas. 2001. Introduction to Distance Sampling: Estimating abundance of biological populations. Oxford University Press, Oxford, U.K.

Buckland, S.T., D.R. Anderson, K.P. Burnham, J.L. Laake, D.L. Borchers, and L. Thomas, eds. 2004. Advanced Distance Sampling. Oxford University Press, Oxford, U.K.

Burnham, K.P., and D.R. Anderson. 2002. Model Selection and Multimodel Inference: A practical information-theoretic approach. Second Edition. Springer, New York, NY, U.S.A.

Camp, R.J., M. Gorresen, T.K. Pratt, and B.L. Woodworth. In preparation. Native Hawaiian forest bird density and trends. Pacific Island Ecosystems Research Center, Biological Resource Division, USGS.

Camp, R.J., M. Gorresen, B.L. Woodworth, and T.K. Pratt. 2002. Preliminary analysis of forest bird survey data for National Parks in Hawaii: Hawaii Volcanoes National Park 1977 - 2000.

Camp, R.J., M. Gorresen, B.L. Woodworth, and T.K. Pratt. 2003. Forest bird distribution, density and trends at Hakalau Forest National Wildlife Refuge, Hawaii. August 2003 report to Hakalau Forest National Wildlife Refuge, U.S. Fish and Wildlife Service. Pacific Island Ecosystems Research Center, Biological Resource Division, USGS.

Conant, S. 1975. Spatial distribution of bird species on the east flank of Mauna Loa. Technical Report 74, Island Ecosystems International Research Program, U.S. International Biology Program, University of Hawaii, Honolulu, HI, U.S.A.

Di Stefano, J. 2003. How much power is enough? Against the development of an arbitrary convention for statistical power calculations. Functional Ecology 17:707-719.

Dunmire, W. W. 1962. Bird populations in Hawai i Volcanoes National Park. Elepaio 22(9):65-70.

Gerrodette, T. 1987. A power analysis for detecting trends. Ecology 68:1364-1372.

Gerrodette, T. 1993. Program TRENDS: User's Guide. Southwest Fisheries Science Center, La Jolla, CA, U.S.A.

Gibbs, J.P. 2000. Monitoring populations. Pp. 213-252 in L. Boitani and T.K. Fuller, eds. Research techniques in animal ecology: controversies and consequences. Columbia University Press, NY, U.S.A.

Gorresen, P.M., R.J. Camp, M.H. Reynolds, B.L. Woodworth, and T.K. Pratt. In review. Status and trends of native Hawaiian passerines. Chapter 6 in T. K. Pratt, B. L. Woodworth, C. A. Atkinson, J. Jacobi, and P. Banko, eds. Hawaiian Forest Birds.

Gunderson, L., and C. Folke. 2003. Toward a "science of the long view". Conservation Ecology 7:15. online: www.consecol.org/vol7/iss1/art15. 
Hatch, S.A. 2003. Statistical power for detecting trends with applications to seabird monitoring. Biological Conservation 111:317-329.

Hatfield, J. S., W. R. Gould IV, B. A. Hoover, M. R. Fuller, and E. L. Lindquist. 1996.

Detecting trends in raptor counts: power and Type I error rates of various statistical tests.

Wildlife Society Bulletin 24:505-515.

Jacobi, J.D. 1989. Vegetation maps of the upland plant communities on the Islands of Hawaii,

Maui, Molokai, and Lanai. Technical Report 68. Cooperative National Park Resources

Studies Unit, University of Hawai $i$ at Manoa, Department of Botany, HI, U.S.A.

Jacobi, J. D., and C. T. Atkinson. 1995. Hawaii's endemic birds. Pages 376-381 in LaRoe, E.

T., G. S. Farris, C. E. Puckett, P. D. Doran, and M. J. Mac, eds. Our living resources: a report to the nation on the distribution, abundance, and health of U.S. plants, animals, and ecosystems. U.S. Department of the Interior, National Biological Service, Washington, DC, U.S.A.

Jacobi, J. D., and F. R. Warshauer. 1996. Survey of bird and plant populations in a section of the Kulani Correctional Facility. U.S. Department of the Interior, National Biological Service, Pacific Islands Science Center, Hawai i Field Station, Hawai i National Park, HI, U.S.A.

Legendre, P., and L. Legendre. 1998. Numerical ecology. Second English edition. Elsevier Science, Amsterdam, The Netherlands.

Lind, J., N. Danz, M.T. Jones, J.M. Hanowski, and G.J. Niemi. 2001. Breeding bird monitoring in Great Lakes National Forests: 1991-2001. NRRI Technical Report-2001/39 to

Chequamegon/Nicolet, Chippewa and Superior National Forests. Natural Resources Research Institute, Duluth, MN, U.S.A.

Lindsey, G.D., T.K. Pratt, M.H. Reynolds, and J.D. Jacobi. 1997. Response of six species of Hawaiian forest birds to a 1991-1992 El Nino drought. Wilson Bulliten 109:339-343.

Loh, R.K., and J.T. Tunison. 1999. Vegetation recovery following pig removal in 'Ōla 'a-Koa Rainforest Unit, Hawaii Volcanoes National Park. Pacific Cooperative Studies Unit, University of Hawaii at Manoa Technical Report 123.

Mossman, M.J., J.R. Sauer, G.A. Gough, L.M. Hartman, and R. Hay. 1998. The Wisconsin Frog and Toad Survey home page [http://www.mbr-pwrc.usgs.gov/wifrog/frog.htm].

Wisconsin Department of Natural Resources (Madison) and USGS Patuxent Wildlife Research Center, Laurel, MD, U.S.A.

Mueller-Dombois, D., G.Spatz, S. Conant, P.Q. Tomich, F.J. Badovsky, J.M. Tenorio, W. Gagne, B.M. Brennan, W.C. Mitchell, D. Springer, G.A. Samuelson, J.L. Gressitt, W.A. Steffan, Y.K. Paik, K.C. Sung, D.E. Hardy, M.D. Delfinado, D. Fujii, M.S. Doty, L.J. Watson, M.F. Stoner, and G.E. Baker. 1981. Altitudinal distribution of organisms along an island mountain transect. Pages 77-180 in D. Mueller-Dombois, K.W. Bridges, and H.L. Carson, eds. Island ecosystems: Biological organization in selected Hawaiian communities. US/IBP Synthesis Series \# 15. Hutchinson Ross Publishing Co., Stroudsburg, PA, U.S.A.

Neter, J., M.H. Hunter, C.J. Nachtsheim, and W. Wasserman. 1996. Applied linear regression models. Irwin, Inc., Chicago, IL, U.S.A.

Nur, N., S.L. Jones, and G.R. Geupel. 1999. A Statistical Guide to Data Analysis of Avian Monitoring Programs. Biological Technical Publication, U.S. Fish \& Wildlife Service, BTPR6001-1999.

Pejchar, L. 2004. Ecology of an endangered Hawaiian honeycreeper and implications for conservation on private land. Dissertation, University of California at Santa Cruz, Santa Cruz, CA, U.S.A. 
Peterjohn, B.G., J.R. Sauer, and C.S. Robbins. 1995. Population trends from the North American Breeding Bird Survey. Pages. 3-39 in T.E. Martin and D.M. Finch, eds. Ecology and management of neotropical migratory birds. Oxford University Press, NY, U.S.A.

Pratt, L.W., L.L. Abbott, and D.K. Palumbo. 1999. Vegetation above a feral pig barrier fence in rain forests of Kilauea's East Rift, Hawaii Volcanoes National Park. Pacific Cooperative Studies Unit, University of Hawaii at Manoa Technical Report 124.

Pratt, T.K., S.G. Fancy, and C.J. Ralph. 2001. Akiapolaau (Hemignathus munroi) and Nukupuu (Hemignathus lucidus). In A. Poole and F. Gill, eds. The Birds of North America, No. 600. The Birds of North America, Inc., Philadelphia, PA, U.S.A.

Ralph, C.J., and S. G. Fancy. 1994. Demography and movements of the Omao (Myadestes obscurus). Condor 96:503-511.

Ralph, C.J., and S.G. Fancy. 1995. Demography and movements of Apapane and Iiwi in Hawaii. Condor 97:729-742.

Redman, C. L., and A. P. Kinzig. 2003. Resilience of past landscapes: resilience theory, society, and the Longue Durée. Conservation Ecology 7(1):14 online: www.consecol.org/vol1/iss1/art14>.

Reynolds, M.H., R.J. Camp, B.M.B. Nielsen, and J.D. Jacobi. 2003. Evidence of change in a low-elevation forest bird community of Hawaii since 1979. Bird Conservation International 13:175-187.

Reynolds, M. H., and T. J. Snetsinger. 2001. The Hawaii rare bird search 1994-1996. Pages 133-143 in J. M. Scott, S. Conant, and C. Van Riper III, eds. Evolution, ecology, conservation, and management of Hawaiian birds: a vanishing avifauna. Studies in Avian Biology No. 22. Cooper Ornithological Society. Allen Press, Lawrence, KS, U.S.A.

Reynolds, R. T., J. M. Scott, and R. A. Nussbaum. 1980. A variable circular-plot method for estimating bird numbers. Condor 82:309-313.

Rodriguez, J.P. 2002. Range contraction in declining North American bird populations. Ecological Applications 12:238-248.

Sakai, H.F. 1988. Avian response to mechanical clearing of a native rainforest in Hawai i. Condor 90:339-348.

Scott, J.M., and C.B. Kepler. 1985. Distribution and abundance of Hawaiian native birds: a status report. Pages 43-70 in S.A. Temple, ed. Bird Conservation 2. The International Council for Bird Preservation. The University of Wisconsin Press, Madison, WI, U.S.A.

Scott, J.M., S. Mountainspring, F.L. Ramsey, and C.B. Kepler. 1986. Forest bird communities of the Hawaiian Islands: their dynamics, ecology, and conservation. Studies in Avian Biology No. 9. Cooper Ornithological Society. Allen Press, Lawrence, KS, U.S.A.

S-Plus. 2001a. S-Plus 6 for Windows Guide to Statistics, Volume 1. Insightful Corporation, Seattle, WA, U.S.A.

S-Plus. 2001b. S-Plus 6 for Windows Programmer's Guide. Insightful Corporation, Seattle, WA, U.S.A.

Sokal, R.R., and F.J. Rohlf. 1995. Biometry: the principles and practice of statistics in biological research. Third edition. W.H. Freeman and Co., NY, U.S.A.

Steidl, R. J. 2001. Practical and statistical considerations for designing population monitoring programs. Pages. 284-288 in R. Field, R. J. Warren, H. Okarma, and P. R. Sievert, eds. Wildlife, land and people: priorities for the 21st century. Proceedings of the Second International Wildlife Management Congress, The Wildlife Society, Bethesda, MD, U.S.A. 
Steidl, R.J., J.P. Hayes, and E. Schauber. 1997. Statistical power analysis in wildlife research. Journal of Wildlife Management 61:270-279.

Thomas, L., J.L. Laake, S. Strindberg, F.F.C. Marques, D.L. Borchers, S.T. Buckland, D.R. Anderson, K.P. Burnham, S.L. Hedley, and J.H. Pollard. 2003. Distance 4.1. Research Unit for Wildlife Population Assessment, University of St. Andrews, UK. <http://www.ruwpa.stand.ac.uk/distance/>. 


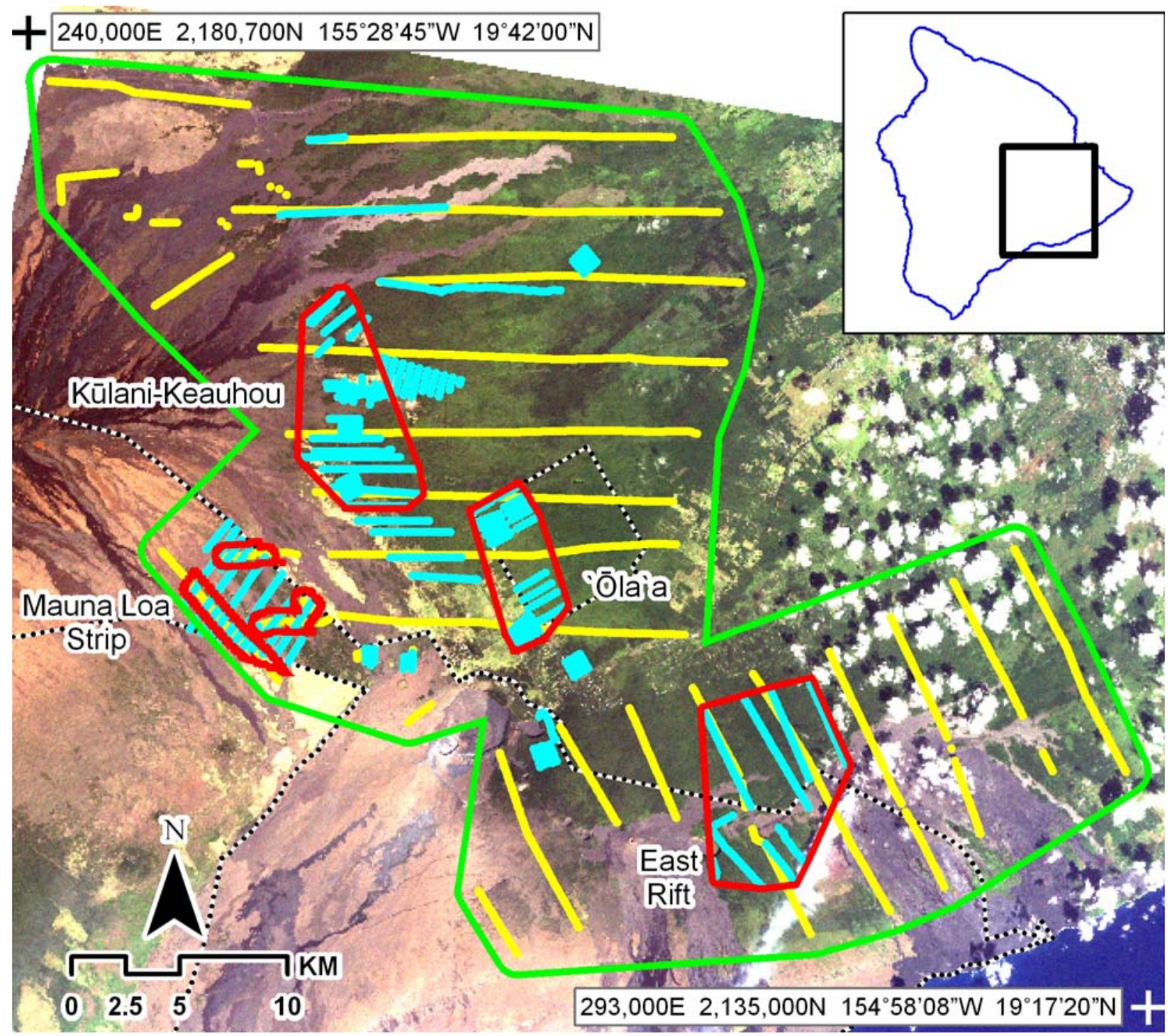

Figure 1. Location of the focal study areas (red polygons) for which bird trends were analyzed in the Central Windward region (green polygon) of Hawai i Island (inset). Hawai i Forest Bird Survey stations (yellow lines) and subsequent survey stations (blue lines) are overlaid on a Landsat ETM satellite image (path/row 62/47; dated January 31, 2001). The Hawaii Volcanoes National Park boundary is delineated with a dashed line. Map projection in UTM Zone 5 North, Datum NAD83. 


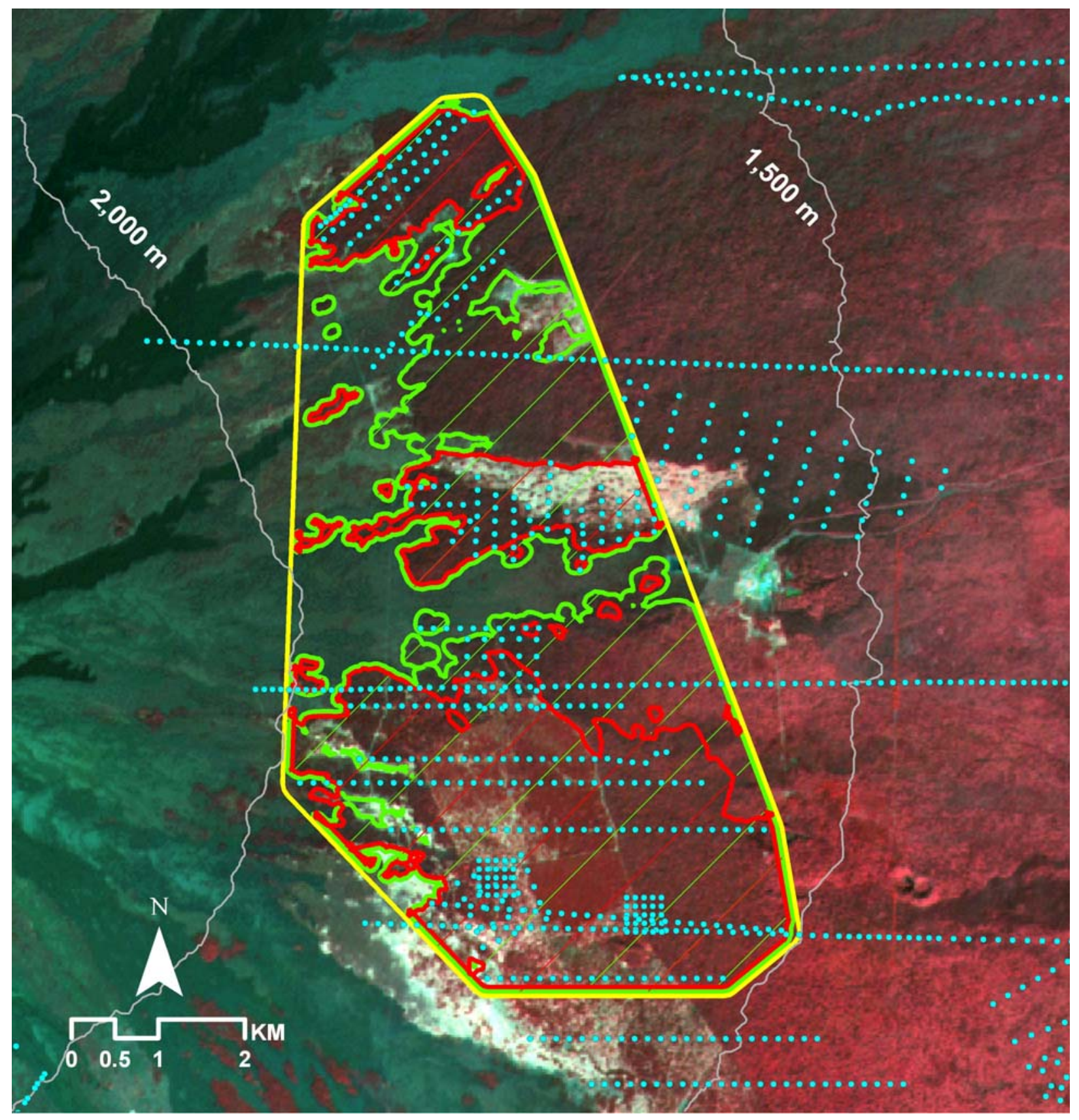

Figure 2. Location of the Kūlani-Keauhou study area (yellow polygon). Survey stations (blue dots) are overlaid on a false color SPOT satellite image (dated January 7, 1995). General landcover types include: forest (red), shrubland (blue-green), grassland and degraded forest (white and light red), and lava (black). Areas used to subset station data for analyses were delineated by forest habitat (green polygons) and forest with koa (red polygons). Elevation contours are shown in meters. 


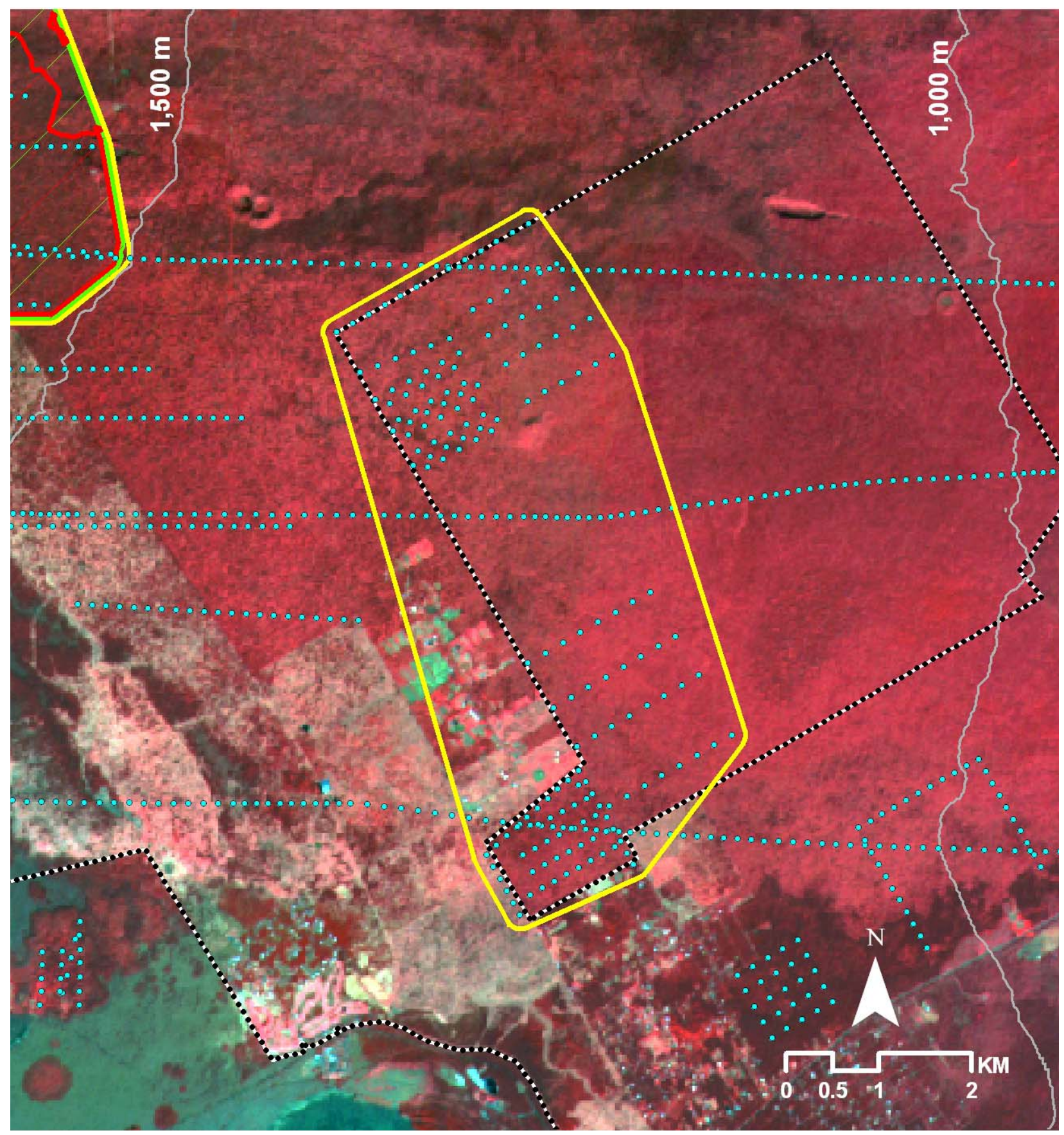

Figure 3. Location of the 'Ōla`a study area (yellow polygon). Survey stations (blue dots) are overlaid on a false color SPOT satellite image (dated January 7, 1995). General land-cover types include: forest (red), shrubland (blue-green), and grassland and degraded forest (white and light red). The Hawaii Volcanoes National Park boundary is delineated with a dashed line. Elevation contours are shown in meters. 


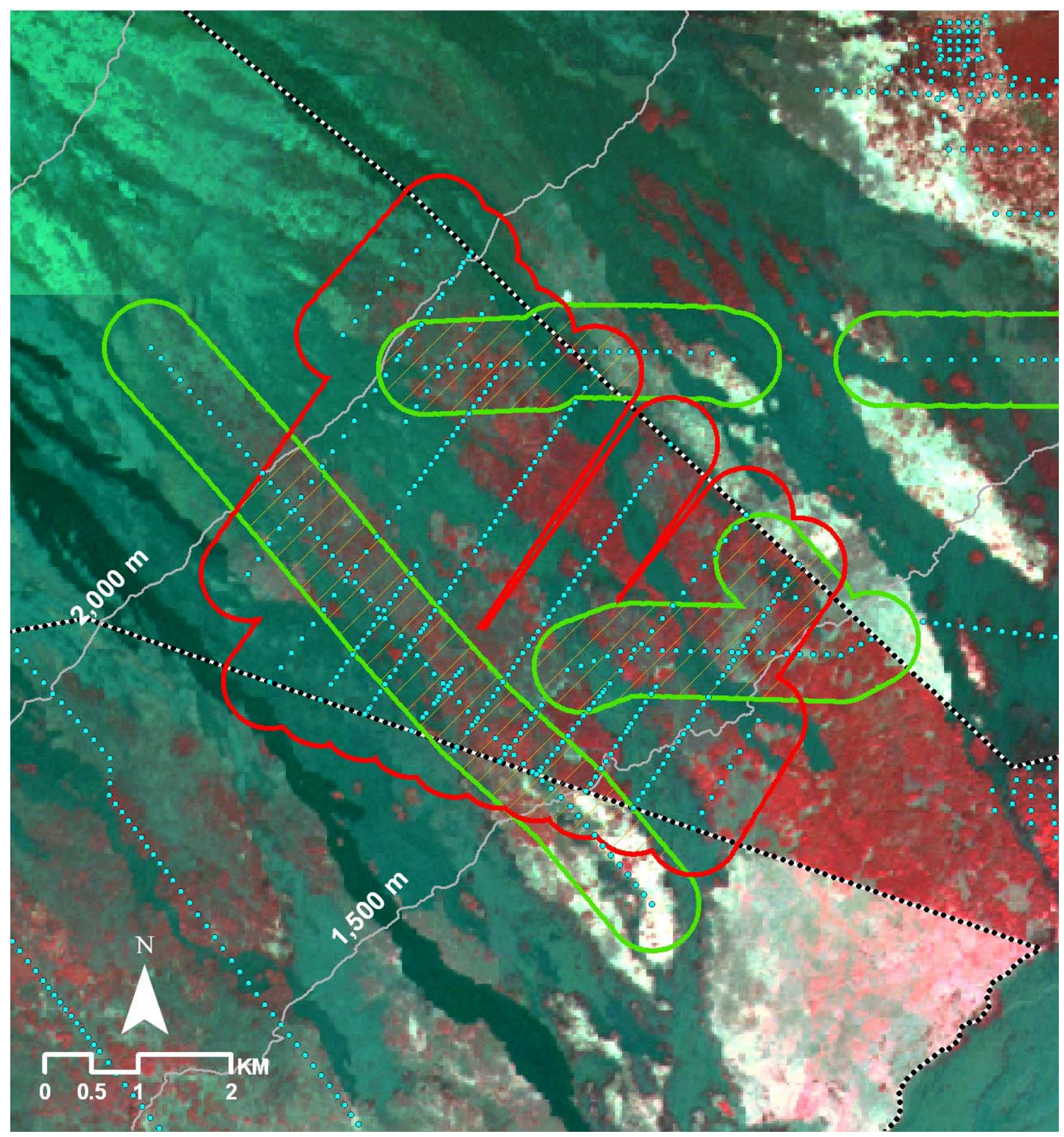

Figure 4. Location of the Mauna Loa Strip study area. Hawai i Forest Bird Survey transects are delineated in green and subsequent surveys are delineated in red. The subset of stations used for trend analysis are indicated with orange hatching. Survey stations (blue dots) are overlaid on a false color SPOT satellite image (dated January 7, 1995). General land-cover types include: forest (red), shrubland (blue-green), grassland and degraded forest (white and light red), and lava (black). The Hawaii Volcanoes National Park boundary is delineated with a dashed line. Elevation contours are shown in meters. 


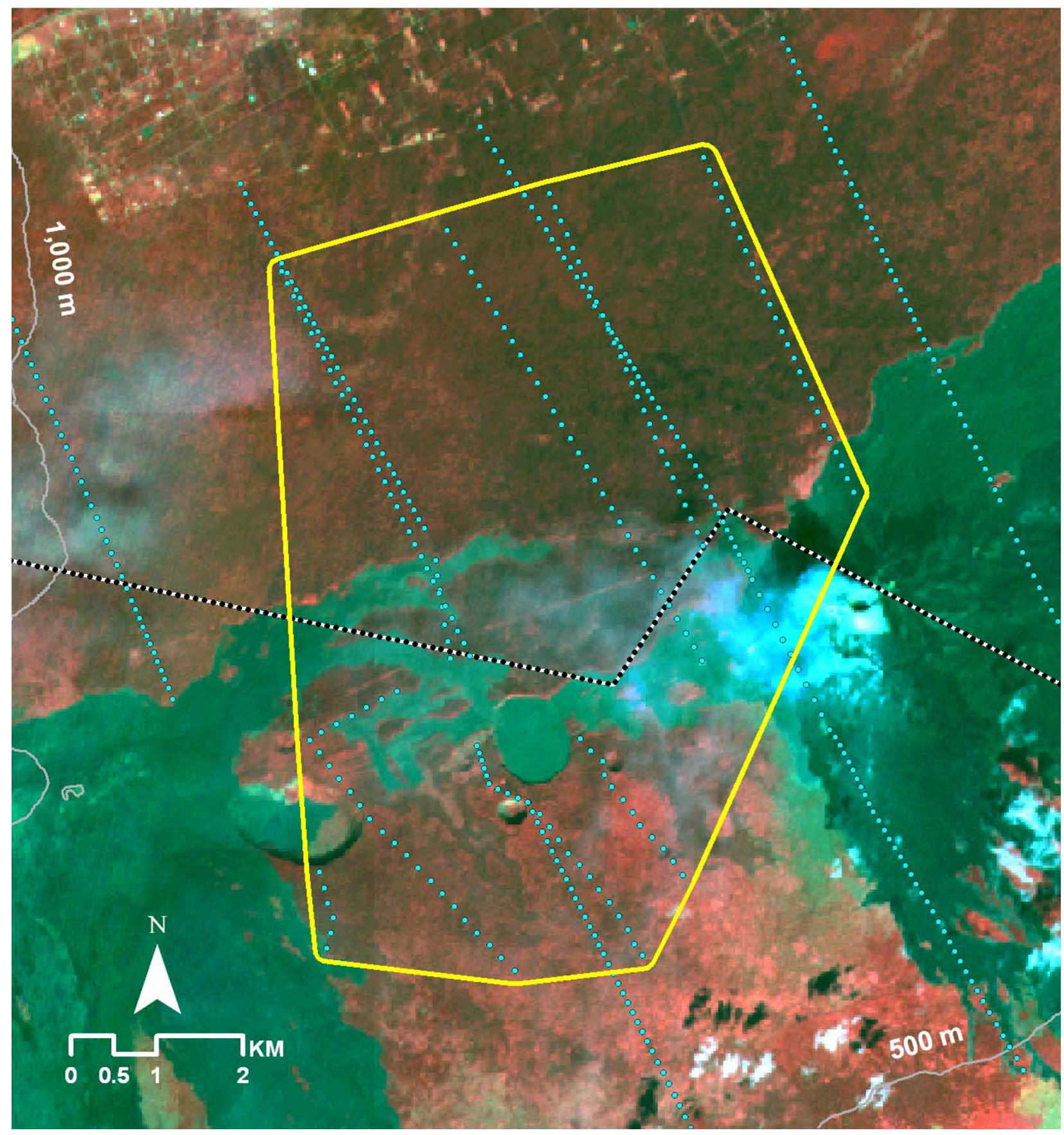

Figure 5. Location of the East Rift study area (yellow polygon). Survey stations (blue dots) are overlaid on a false color SPOT satellite image (dated January 7, 1995). General land-cover types include: forest (red), grassland and degraded forest (white and light red), and lava (blue-green). The Hawaii Volcanoes National Park boundary is delineated with a dashed line. Elevation contours are shown in meters. 
Hawai ' `Elepaio at Kūlani-Keauhou
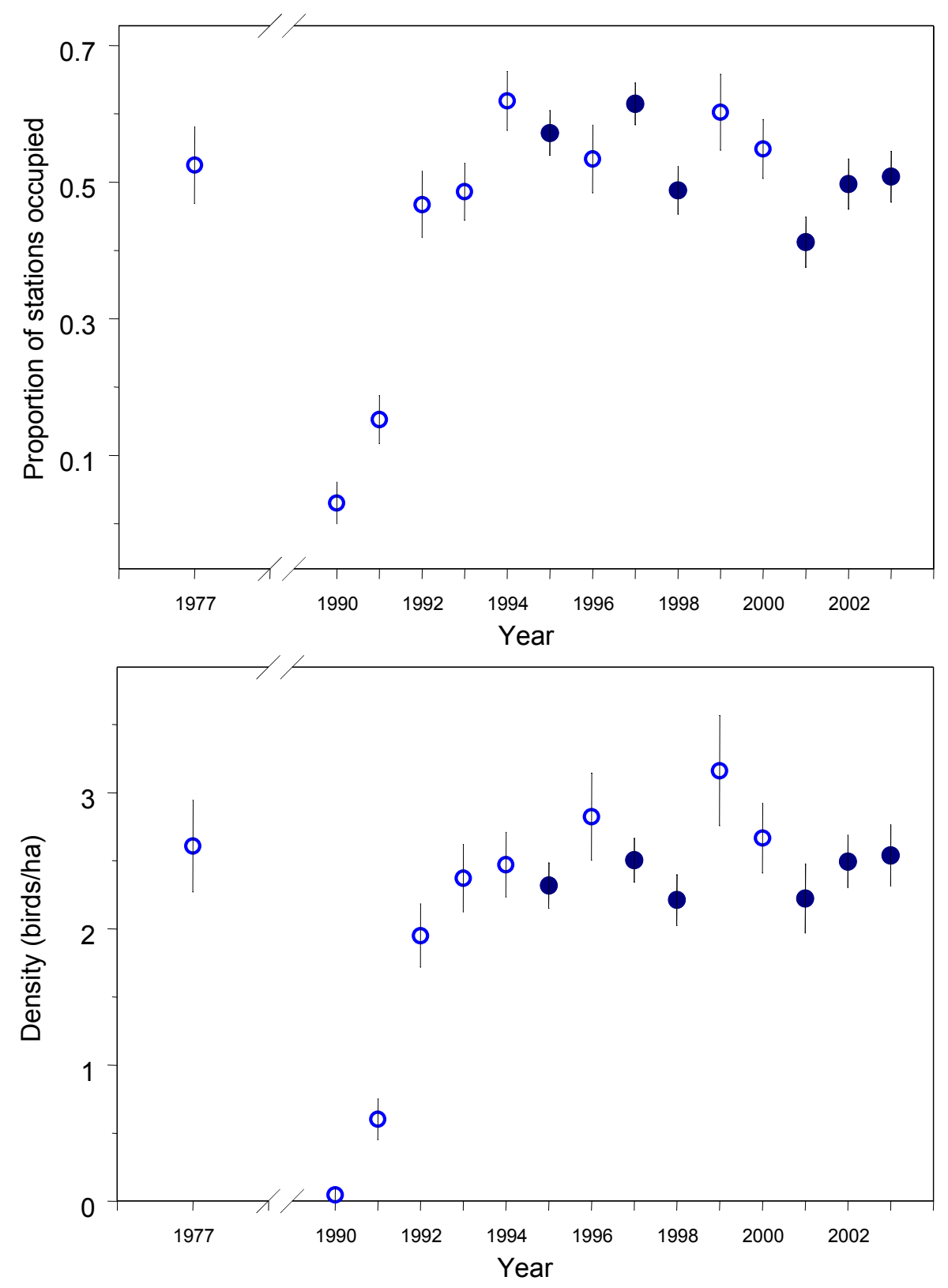

Figure 6. Hawai $i$ `Elepaio mean annual frequency of occurrence (proportion of stations occupied; scaled 0 to 1) and density (birds/hectare) between 1977 (HFBS) and 2003 in the Külani-Keauhou study area. Closed symbols indicate that surveys extended over the entire study area, whereas open circles indicate that coverage was incomplete. Contingency analysis determined the frequency of occurrence between the 1995-1998 and 2001-2003 survey periods to have significantly declined $(P<0.01)$. A z-test determined the difference in densities over the same two periods was not significant $(P=0.70)$. 
`Ōma`o at Kūlani-Keauhou
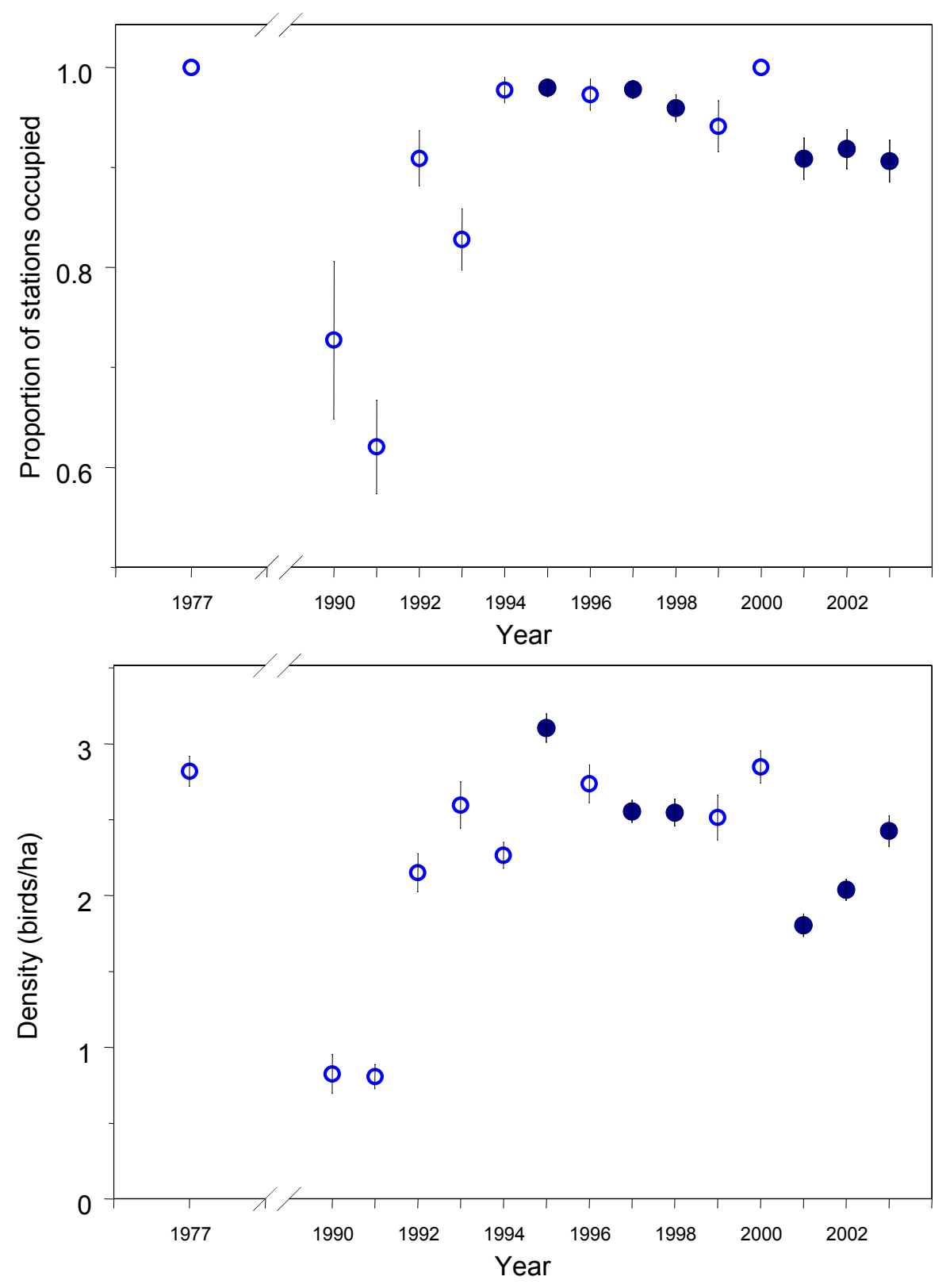

Figure 7. 'Ōma' o mean annual frequency of occurrence (proportion of stations occupied; scaled 0 to 1) and density (birds/hectare) between 1977 (HFBS) and 2003 in the Kūlani-Keauhou study area. Closed symbols indicate that surveys extended over the entire study area, whereas open circles indicate that coverage was incomplete. Contingency analysis determined the frequency of occurrence between the 1995-1998 and 2001-2003 survey periods to have significantly declined $(P<0.01)$. A z-test determined densities over the same two periods to have also significantly declined $(P<0.01)$. 
'I’iwi at Kūlani-Keauhou
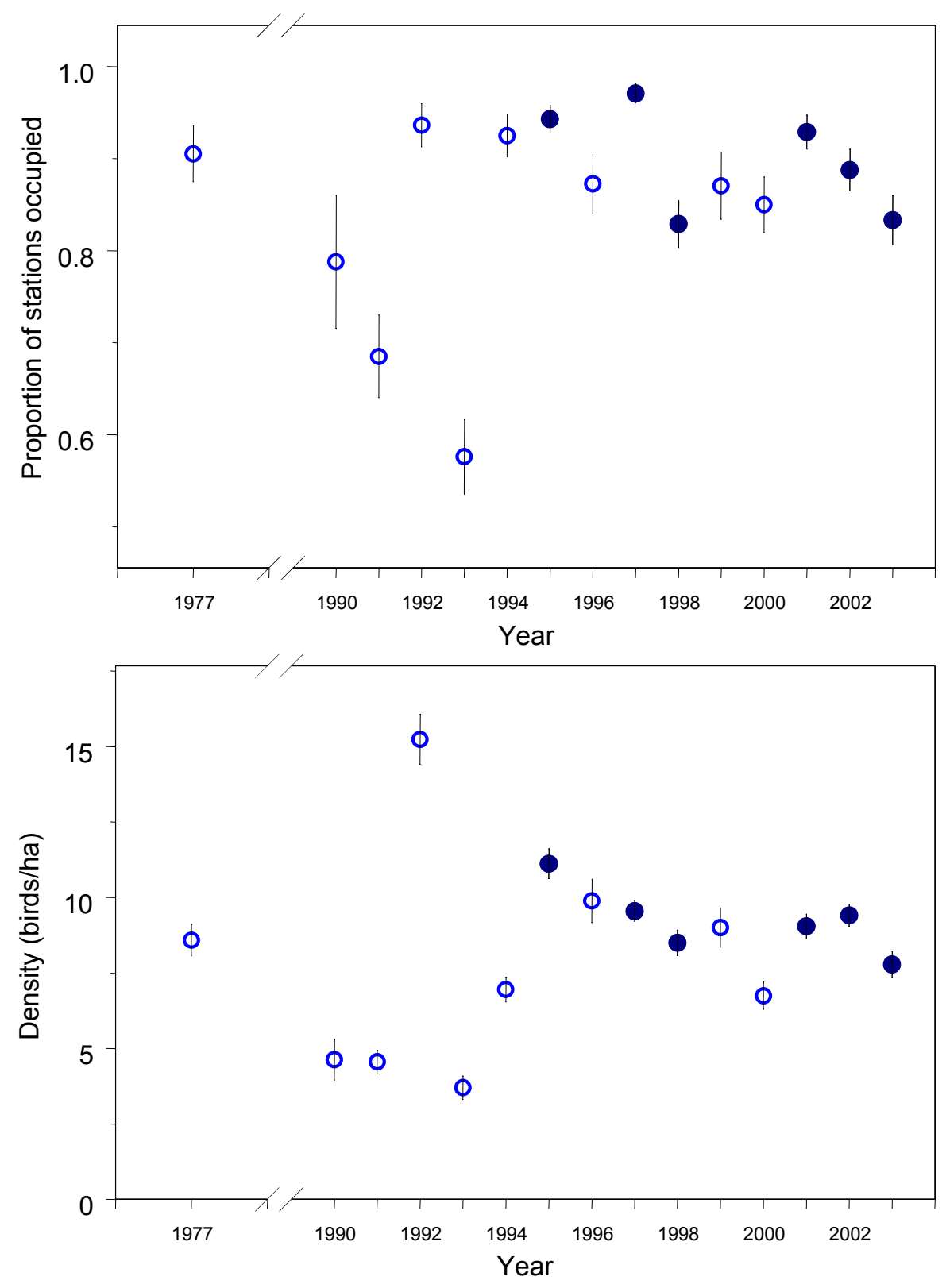

Figure 8. 'T'iwi mean annual frequency of occurrence (proportion of stations occupied; scaled 0 to 1) and density (birds/hectare) between 1977 (HFBS) and 2003 in the Kūlani-Keauhou study area. Closed symbols indicate that surveys extended over the entire study area, whereas open circles indicate that coverage was incomplete. Contingency analysis determined the frequency of occurrence between the 1995-1998 and 2001-2003 survey periods to have significantly declined $(P=0.03)$. A $z$-test determined densities over the same two periods to have also significantly declined $(P<0.01)$. 
‘Akiapōlā’au at Kūlani-Keauhou
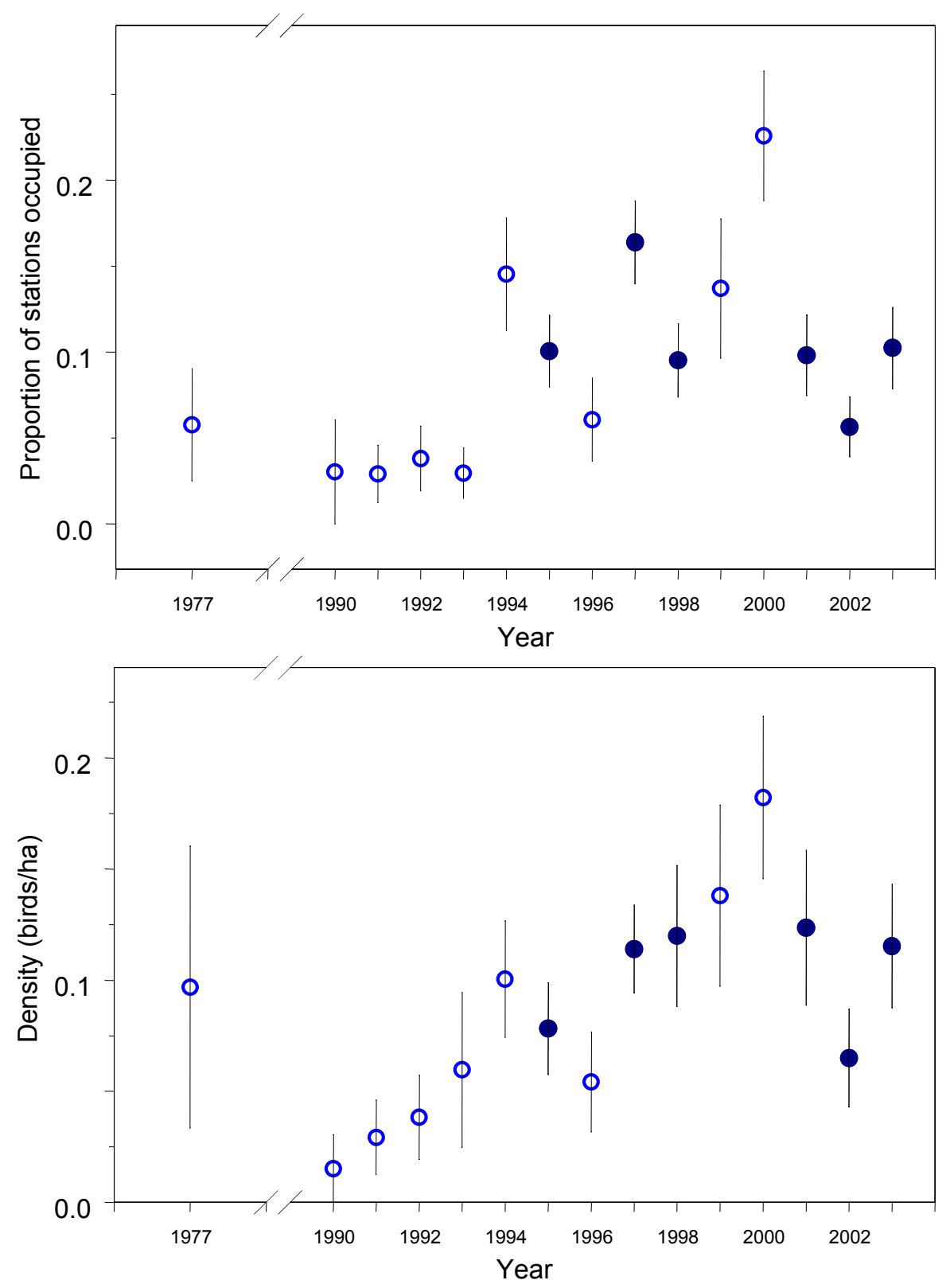

Figure 9. 'Akiapōlā'au mean annual frequency of occurrence (proportion of stations occupied; scaled 0 to 1) and density (birds/hectare) between 1977 (HFBS) and 2003 in the Kūlani-Keauhou study area. Closed symbols indicate that surveys extended over the entire study area, whereas open circles indicate that coverage was incomplete. Contingency analysis determined the frequency of occurrence between the 1995-1998 and 2001-2003 survey periods to have significantly declined $(P=0.04)$. A z-test determined the difference in densities over the same two periods was not significant $(P=0.70)$. 
Hawai' i Creeper at Kūlani-Keauhou
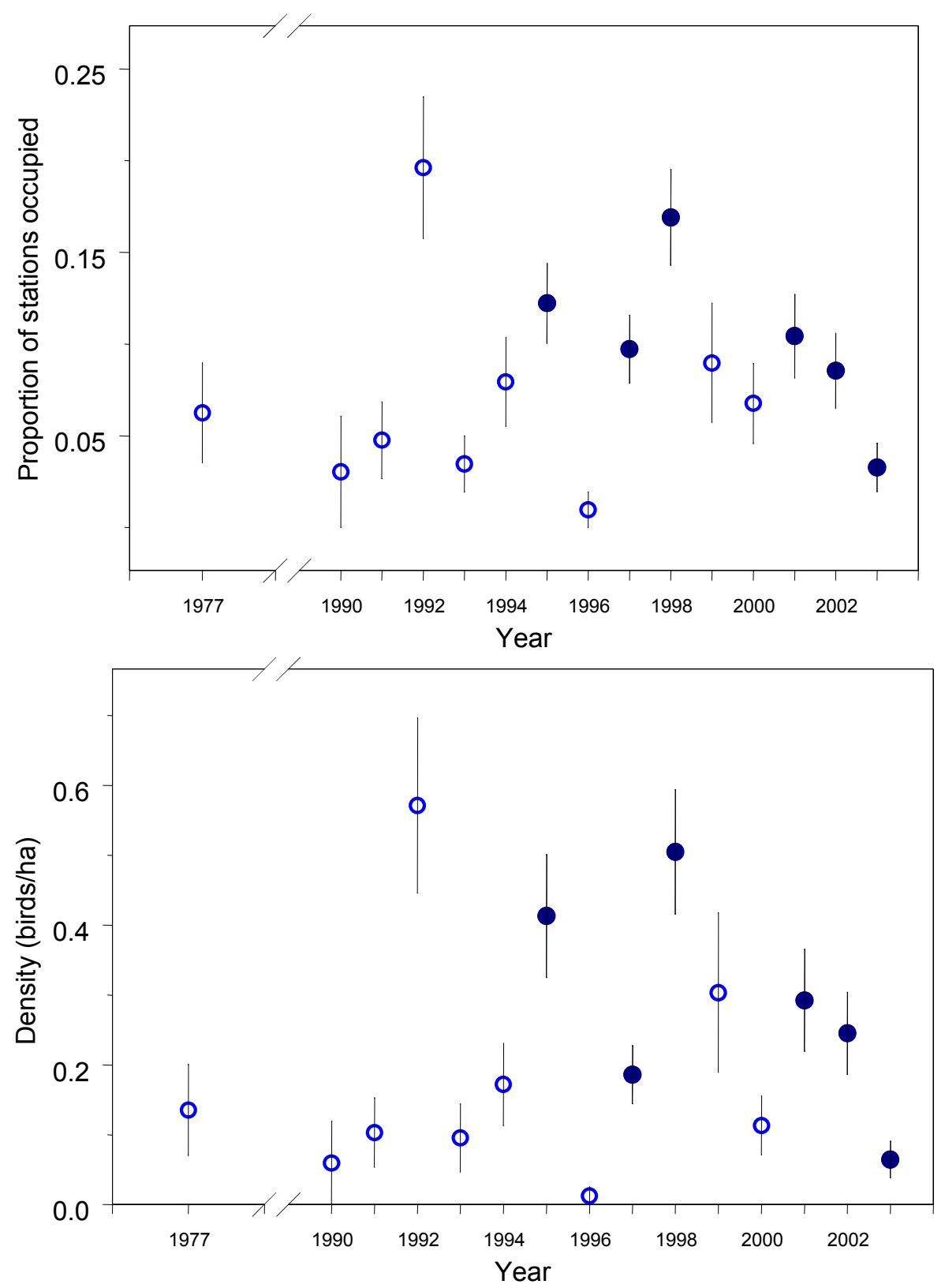

Figure 10. Hawai'i Creeper mean annual frequency of occurrence (proportion of stations occupied; scaled 0 to 1) and density (birds/hectare) between 1977 (HFBS) and 2003 in the Kūlani-Keauhou study area. Closed symbols indicate that surveys extended over the entire study area, whereas open circles indicate that coverage was incomplete. Contingency analysis determined the frequency of occurrence between the 1995-1998 and 2001-2003 survey periods to have significantly declined $(P<0.01)$. A z-test determined densities over the same two periods to have marginally declined $(P=0.10)$. 


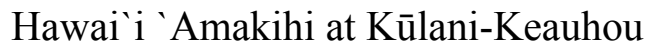
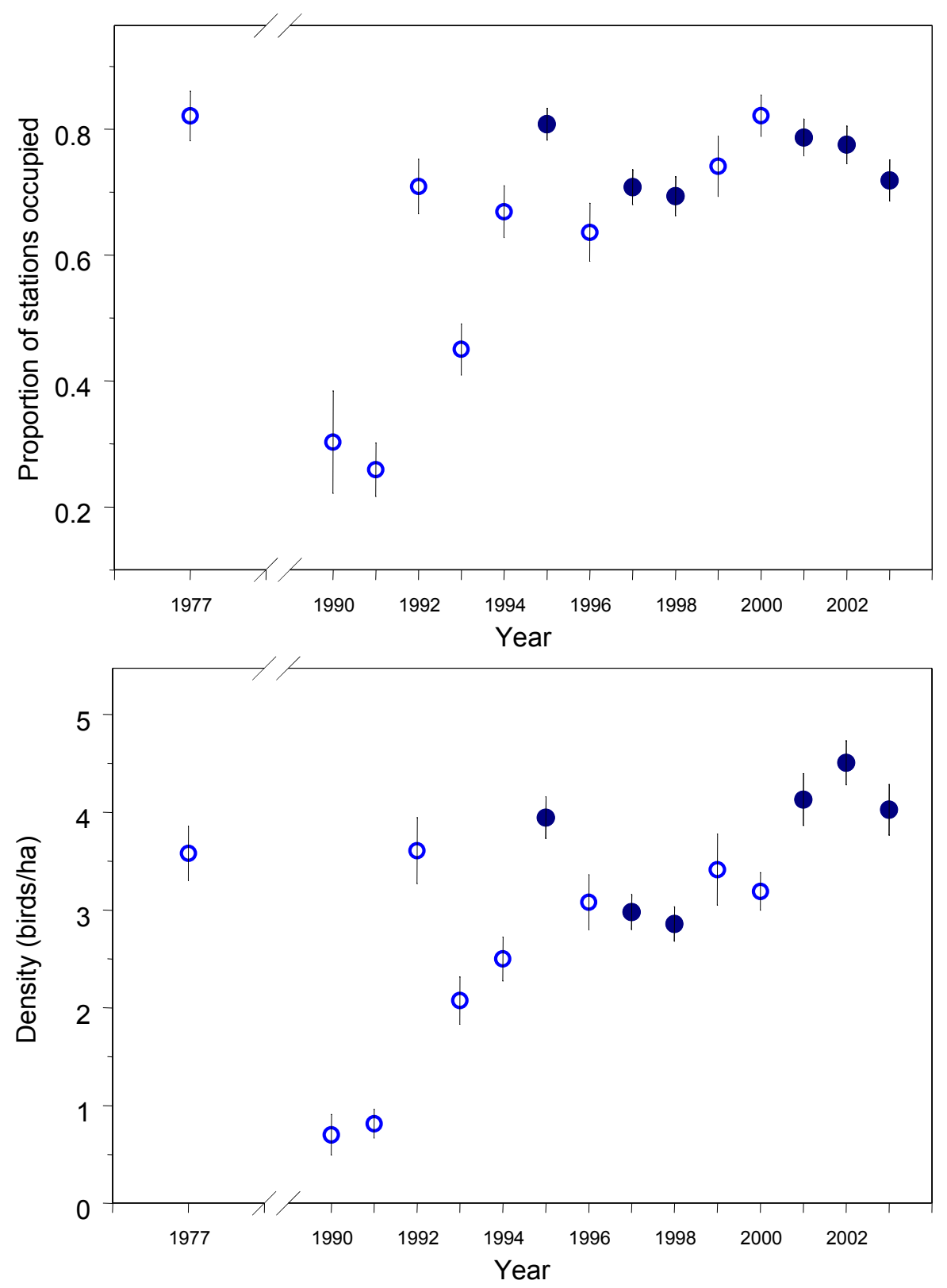

Figure 11. Hawai $i$ 'Amakihi mean annual frequency of occurrence (proportion of stations occupied; scaled 0 to 1) and density (birds/hectare) between 1977 (HFBS) and 2003 in the Külani-Keauhou study area. Closed symbols indicate that surveys extended over the entire study area, whereas open circles indicate that coverage was incomplete. Contingency analysis determined the difference in frequency of occurrence between the 1995-1998 and 2001-2003 survey periods to be non-significant $(P=0.34)$. A z-test determined densities over the same two periods to have significantly increased $(P<0.01)$. 
Hawai ${ }^{`}$ Ākepa at Kūlani-Keauhou
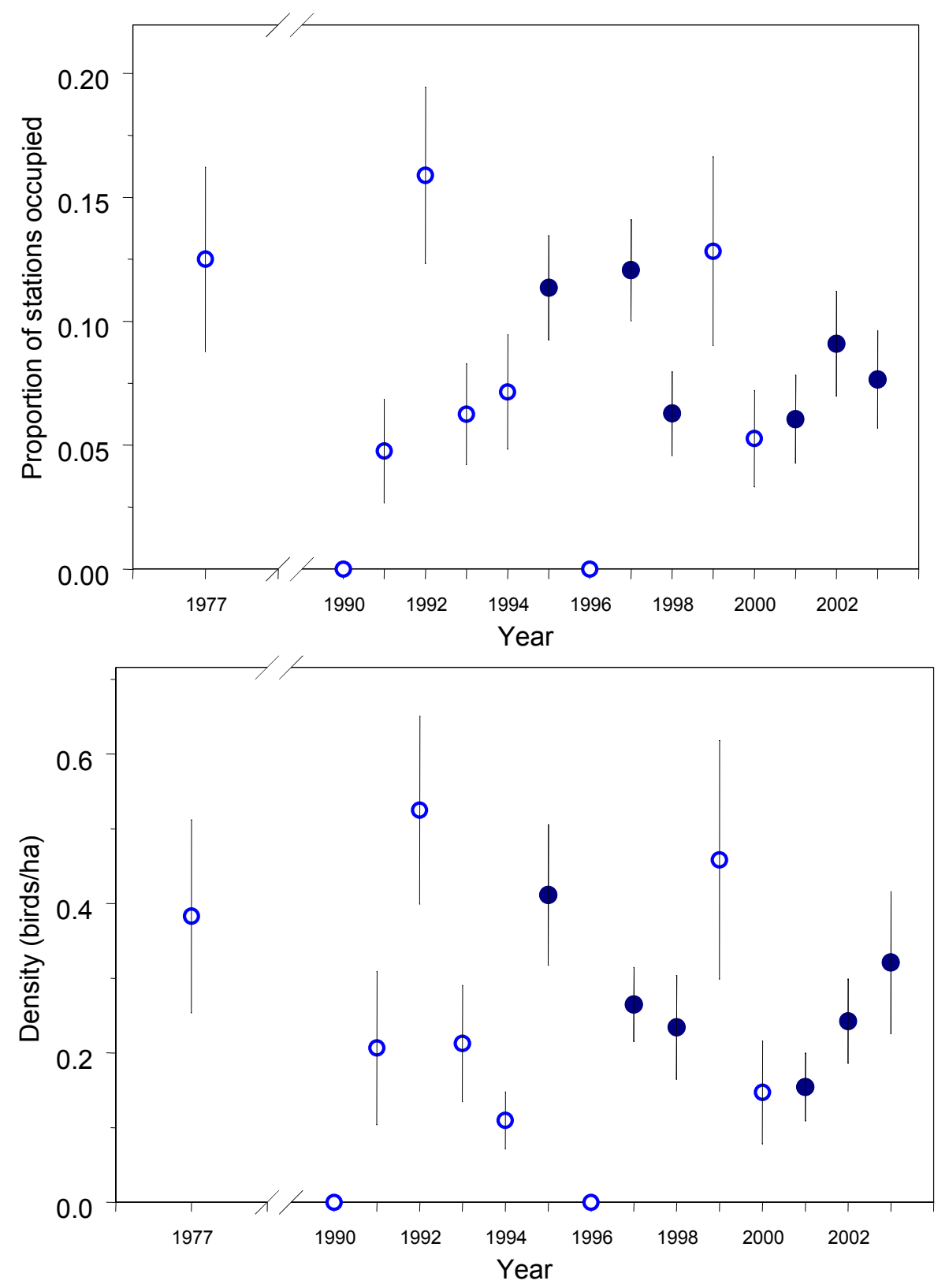

Figure 12. Hawai` ` 'A kepa mean annual frequency of occurrence (proportion of stations occupied; scaled 0 to 1) and density (birds/hectare) between 1977 (HFBS) and 2003 in the Kūlani-Keauhou study area. Closed symbols indicate that surveys extended over the entire study area, whereas open circles indicate that coverage was incomplete. Contingency analysis determined the difference in frequency of occurrence between the 1995-1998 and 2001-2003 survey periods to be non-significant $(P=0.14)$. A z-test determined the difference in densities over the same two periods was also not significant $(P=0.26)$. 
'Apapane at Kūlani-Keauhou
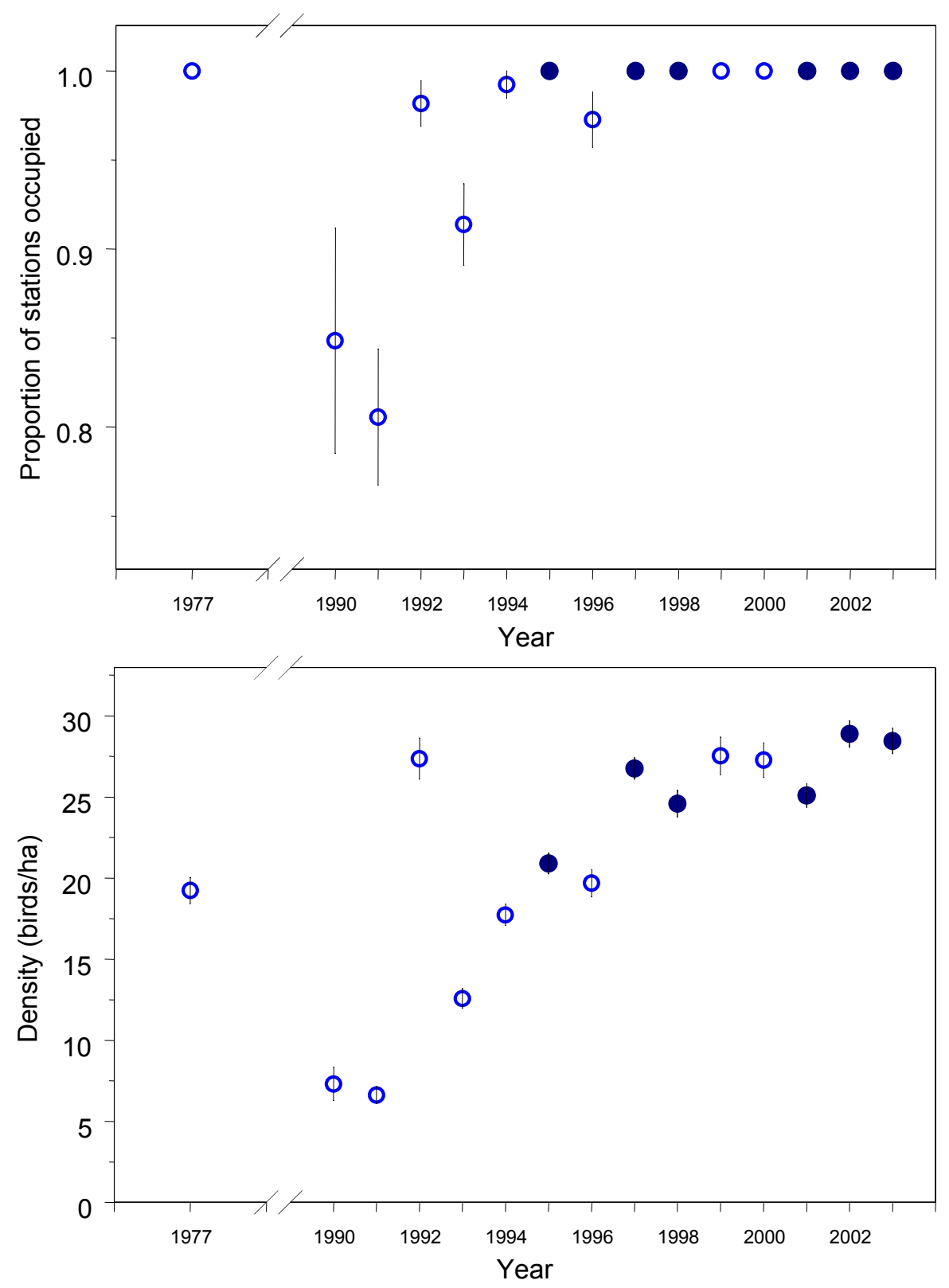

Figure 13. 'Apapane mean annual frequency of occurrence (proportion of stations occupied; scaled 0 to 1) and density (birds/hectare) between 1977 (HFBS) and 2003 in the Kūlani-Keauhou study area. Closed symbols indicate that surveys extended over the entire study area, whereas open circles indicate that coverage was incomplete. The frequency of occurrence was not analyzed because the species occurred at all sites during both the 1995-1998 and 2001-2003 survey periods. A z-test determined densities over the same two periods to have significantly increased $(P<0.01)$. 
Red-billed Leiothrix at Kūlani-Keauhou
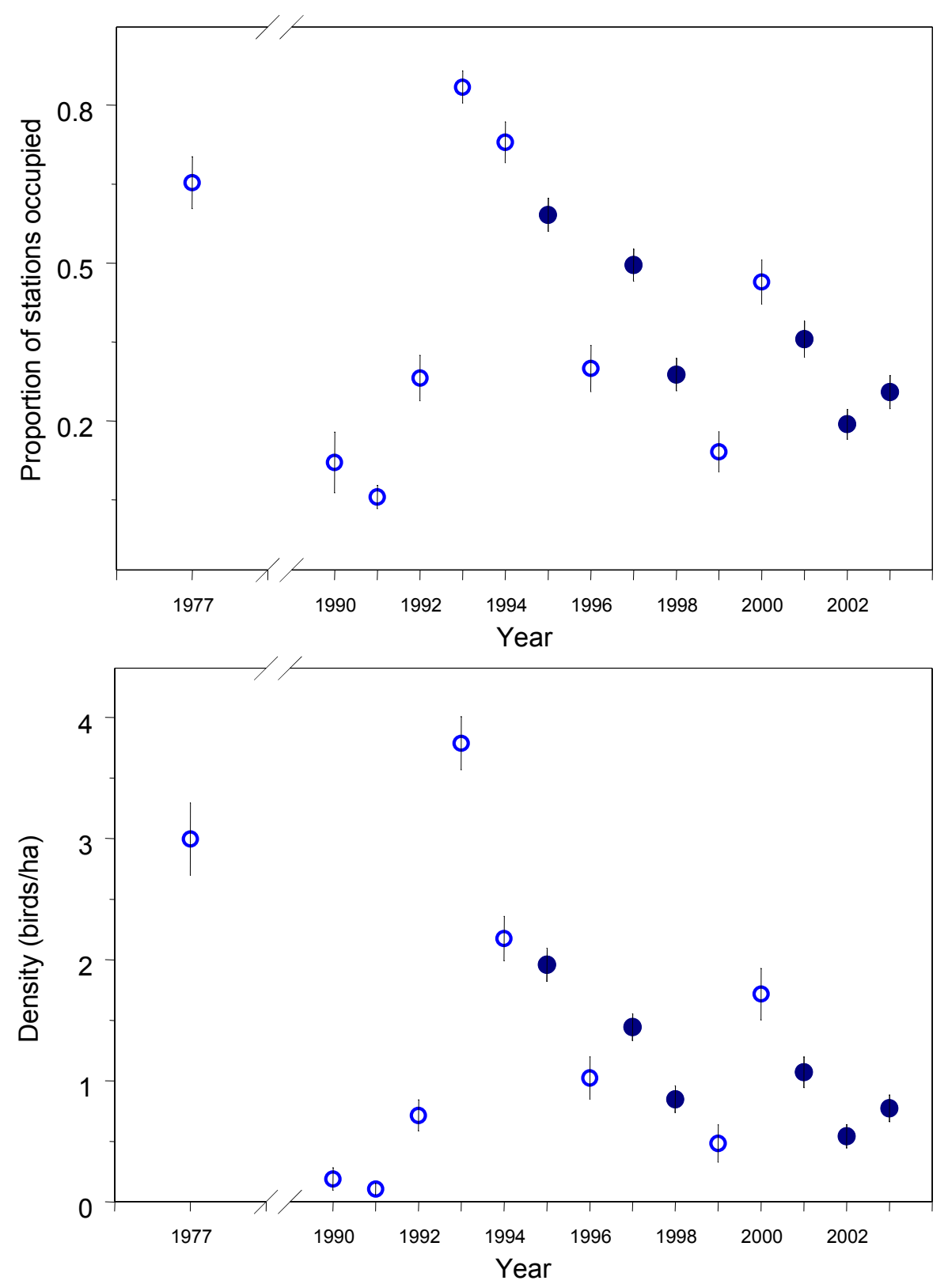

Figure 14. Red-billed Leiothrix mean annual frequency of occurrence (proportion of stations occupied; scaled 0 to 1) and density (birds/hectare) between 1977 (HFBS) and 2003 in the Kūlani-Keauhou study area. Closed symbols indicate that surveys extended over the entire study area, whereas open circles indicate that coverage was incomplete. Contingency analysis determined the frequency of occurrence between the 1995-1998 and 2001-2003 survey periods to have significantly declined $(P<0.01)$. A z-test determined densities over the same two periods to have also significantly declined $(P<0.01)$. 
Japanese White-eye at Kūlani-Keauhou
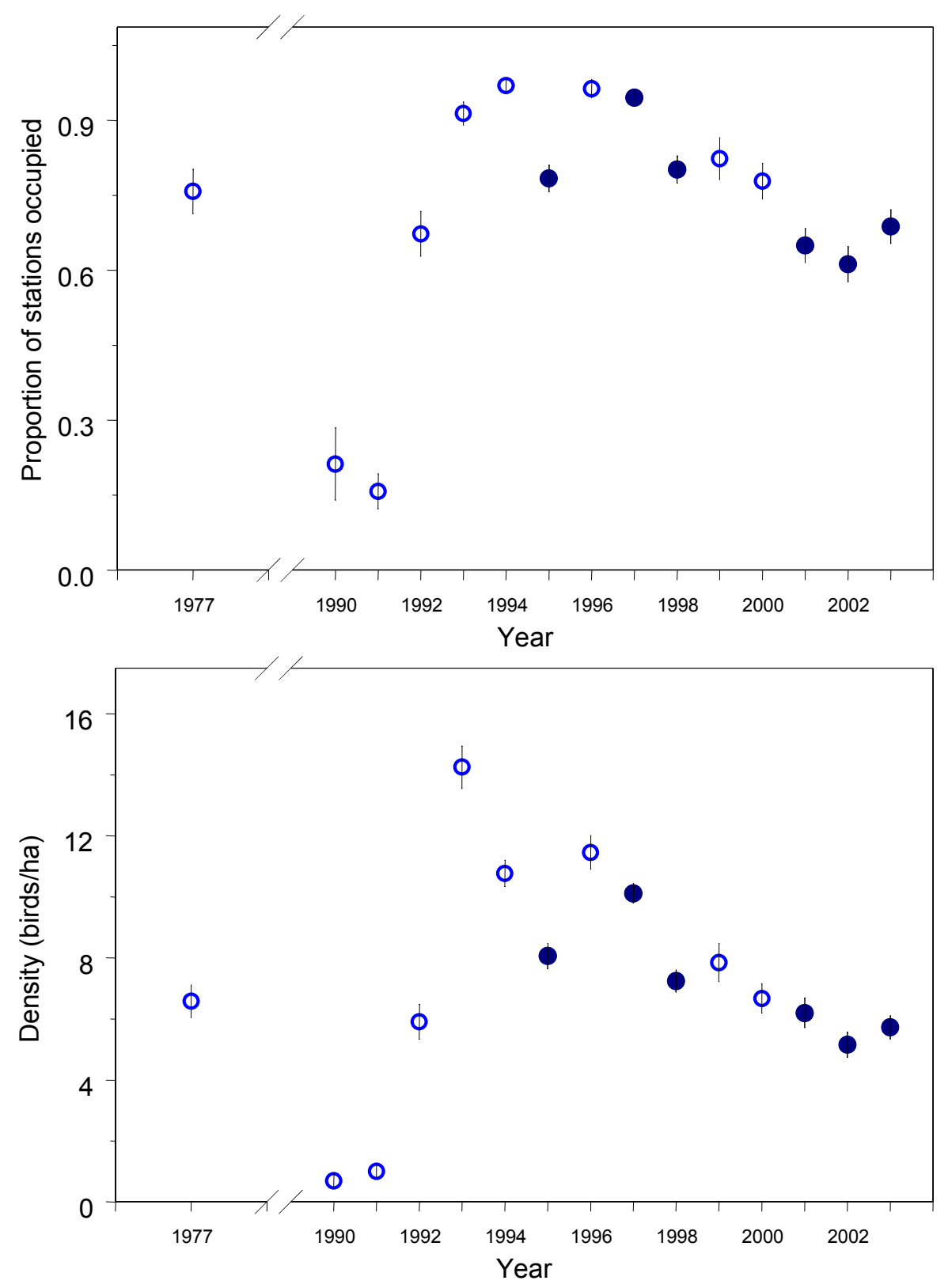

Figure 15. Japanese White-eye mean annual frequency of occurrence (proportion of stations occupied; scaled 0 to 1) and density (birds/hectare) between 1977 (HFBS) and 2003 in the Külani-Keauhou study area. Closed symbols indicate that surveys extended over the entire study area, whereas open circles indicate that coverage was incomplete. Contingency analysis determined the frequency of occurrence between the 1995-1998 and 2001-2003 survey periods to have significantly declined $(P<0.01)$. A z-test determined densities over the same two periods to have also significantly declined $(P<0.01)$. 
Northern Cardinal at Kūlani-Keauhou
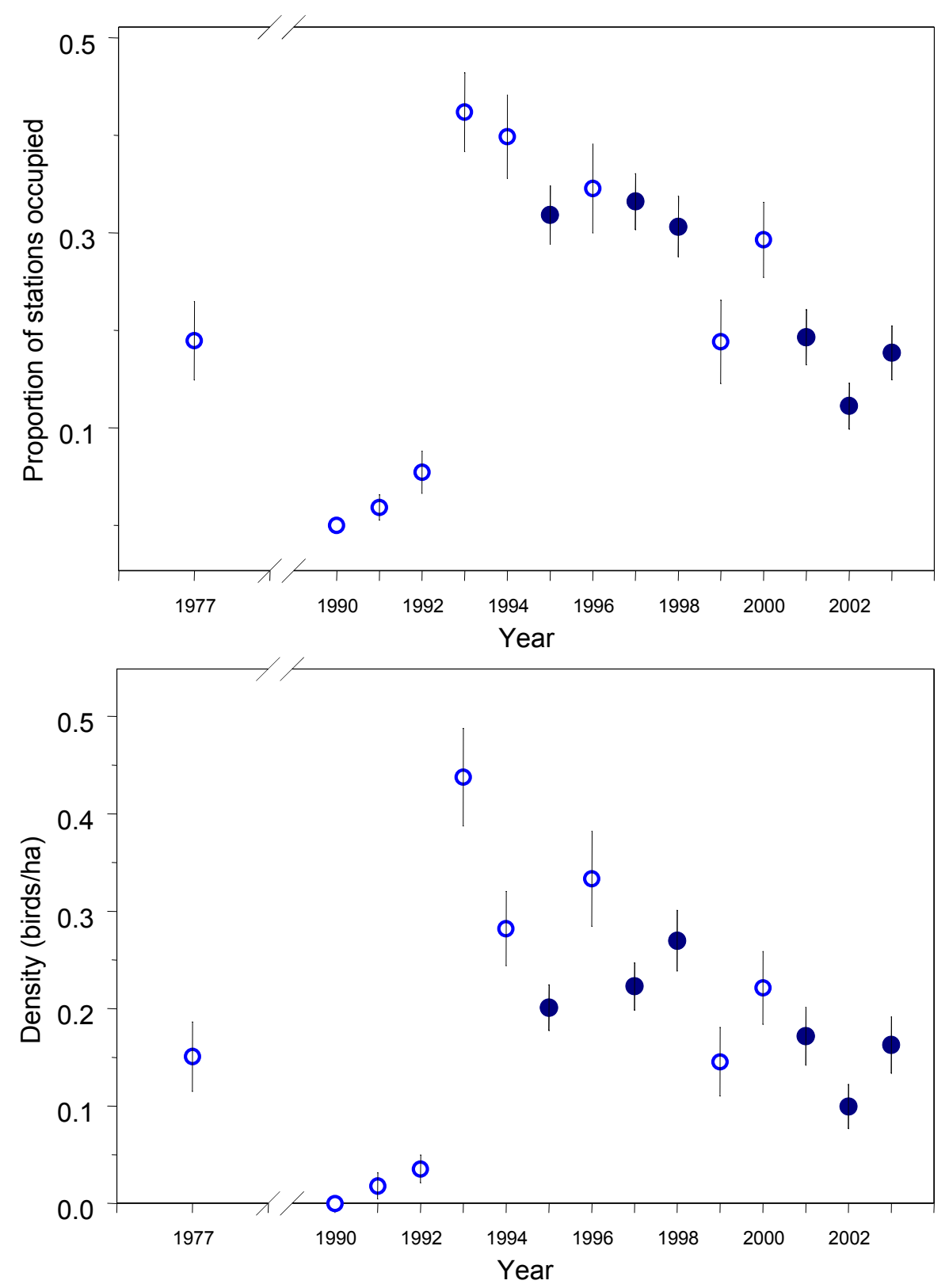

Figure 16. Northern Cardinal mean annual frequency of occurrence (proportion of stations occupied; scaled 0 to 1) and density (birds/hectare) between 1977 (HFBS) and 2003 in the Külani-Keauhou study area. Closed symbols indicate that surveys extended over the entire study area, whereas open circles indicate that coverage was incomplete. Contingency analysis determined the frequency of occurrence between the 1995-1998 and 2001-2003 survey periods to have significantly declined $(P<0.01)$. A z-test determined densities over the same two periods to have also significantly declined $(P<0.01)$. 
House Finch at Kūlani-Keauhou
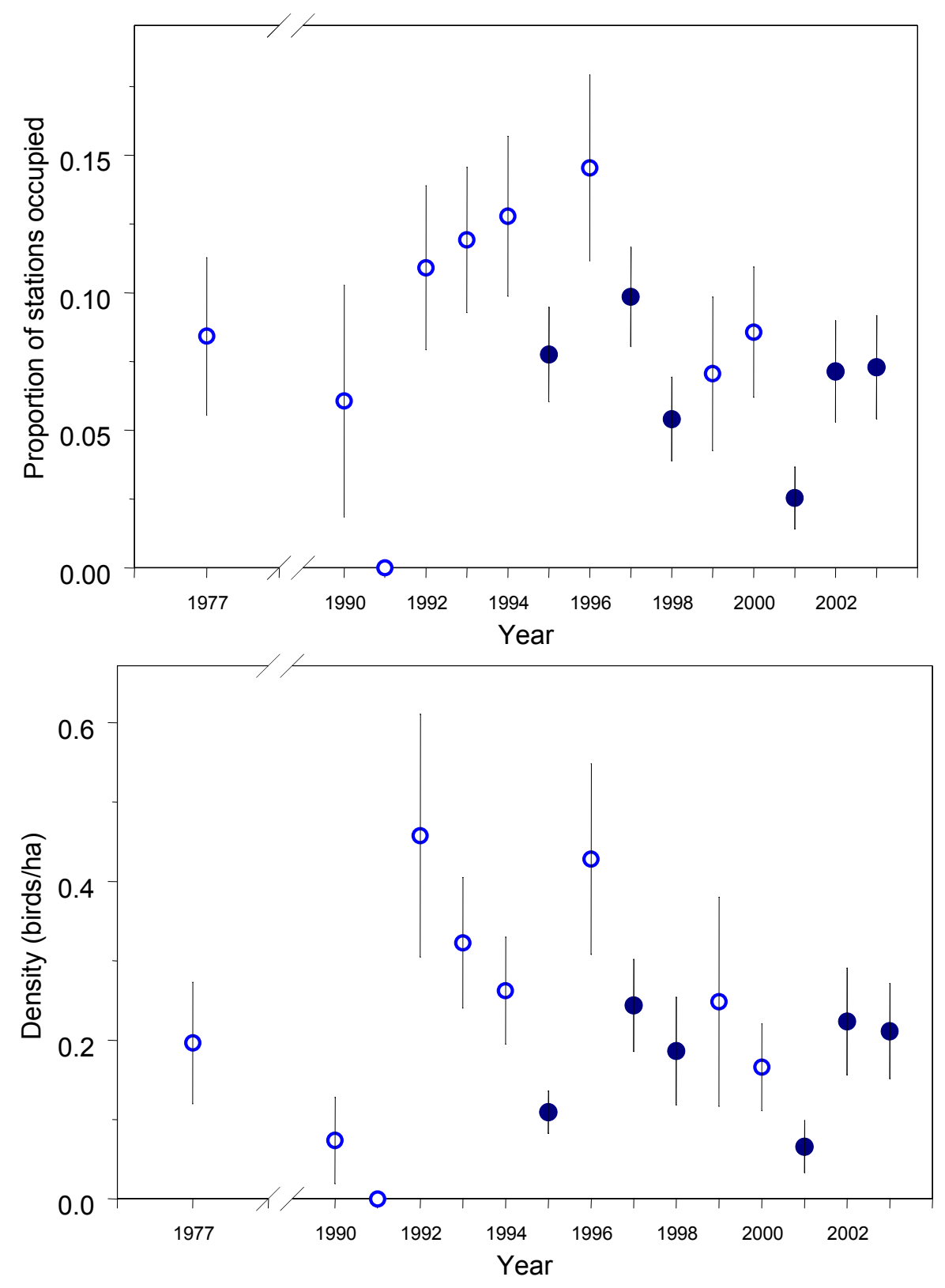

Figure 17. House Finch mean annual frequency of occurrence (proportion of stations occupied; scaled 0 to 1) and density (birds/hectare) between 1977 (HFBS) and 2003 in the Külani-Keauhou study area. Closed symbols indicate that surveys extended over the entire study area, whereas open circles indicate that coverage was incomplete. Contingency analysis determined the difference in frequency of occurrence between the 1995-1998 and 2001-2003 survey periods to be non-significant $(P=0.13)$. A z-test determined the difference in densities over the same two periods was also not significant $(P=0.32)$. 


\section{Hawai ${ }^{`}$ Elepaio at Mauna Loa Strip}
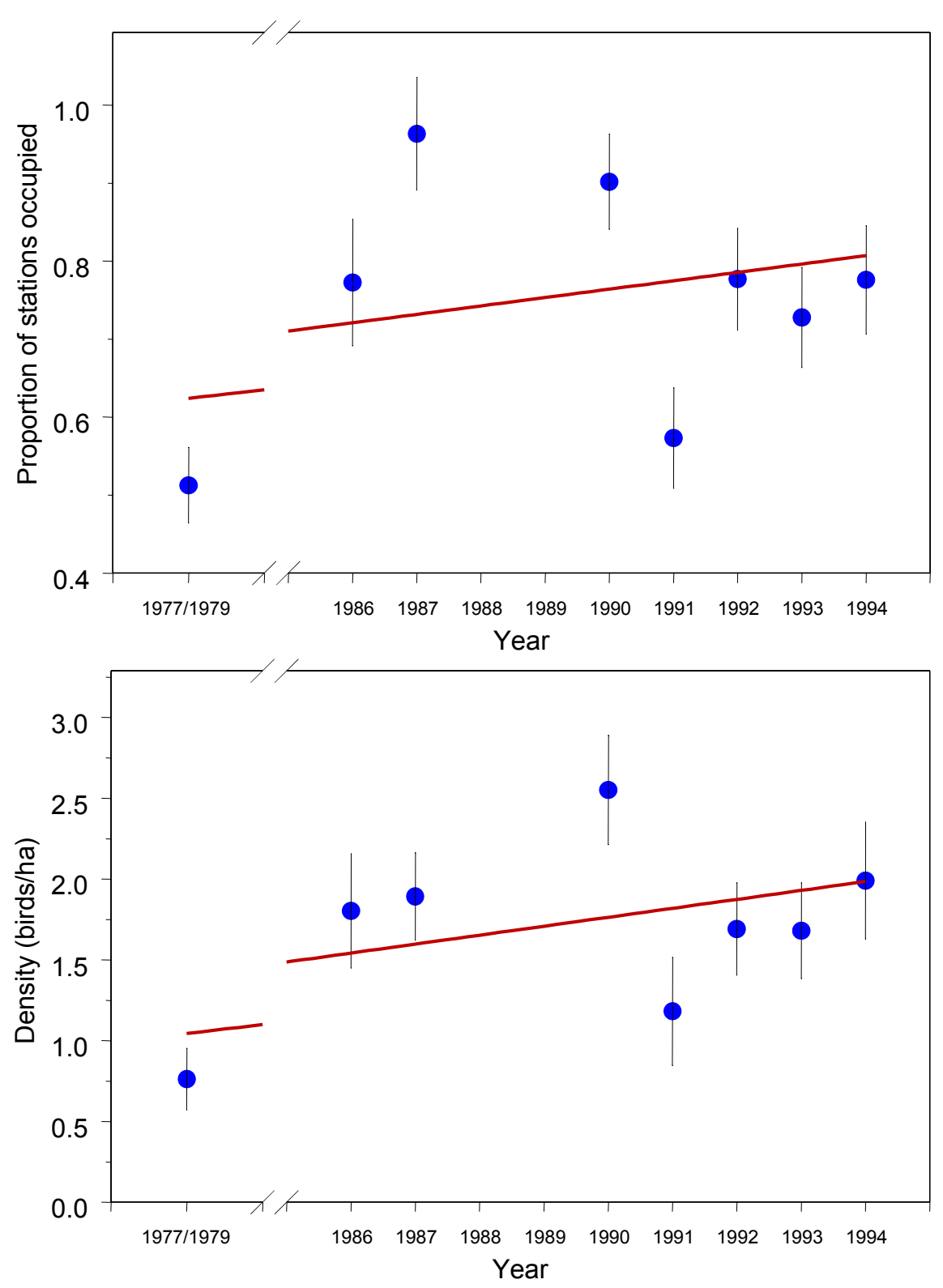

Figure 18. Hawai ' $i$ 'Elepaio mean annual frequency of occurrence (proportion of stations occupied; scaled 0 to 1) and density (birds/hectare) from 1977/1979 (HFBS) to 1994 in the Mauna Loa Strip study area. Trendlines show the general linear relationship between untransformed occurrence or density and survey year, and are included for illustrative purposes only. Logistic regression of occurrences and year was non-significant (slope $=0.052$; odds ratio $=1.053 ; 95 \%$ confidence limit $=1.015-1.093 ; P=0.144)$. The regression slope of logtransformed densities and year was non-significant (slope $=0.011 ; 95 \%$ confidence limit $=$ $\left.0.009-0.031 ; \mathrm{R}^{2}=0.23 ; P=0.230\right)$. 
'Ōma`o at Mauna Loa Strip

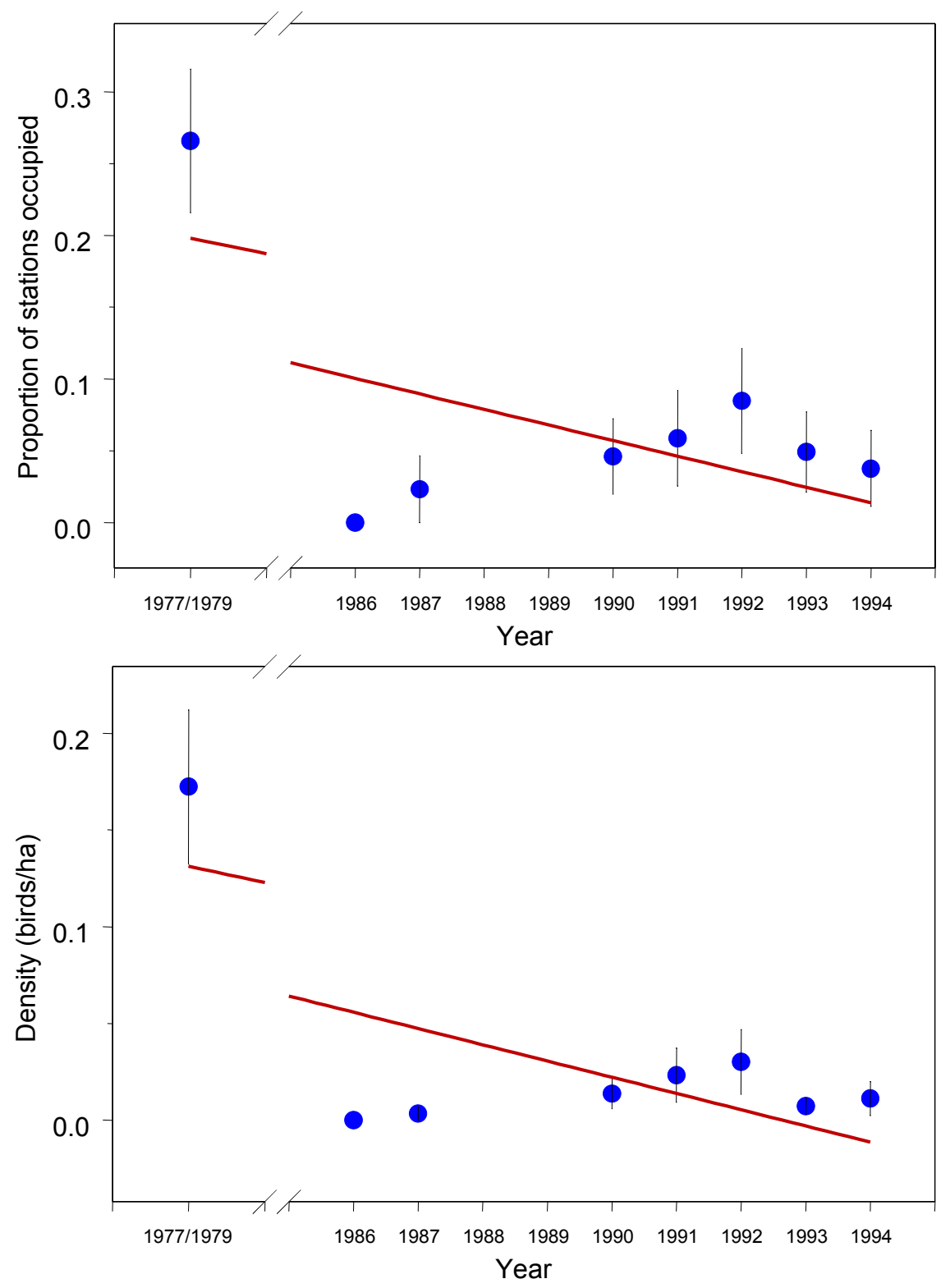

Figure 19. ' 'Oma'o mean annual frequency of occurrence (proportion of stations occupied; scaled 0 to 1) and density (birds/hectare) from 1977/1979 (HFBS) to 1994 in the Mauna Loa Strip study area. Trendlines show the general linear relationship between untransformed occurrence or density and survey year, and are included for illustrative purposes only. Logistic regression of occurrences and year was non-significant (slope $=-0.172$; odds ratio $=0.842 ; 95 \%$ confidence limit $=0.790-0.896 ; P=0.097)$. The regression slope of log-transformed densities and year was significantly negative (slope $=-0.004 ; 95 \%$ confidence limit $=-0.008--0.001 ; \mathrm{R}^{2}$ $=0.62 ; P=0.020$ ). 
Hawai 1 `Amakihi at Mauna Loa Strip
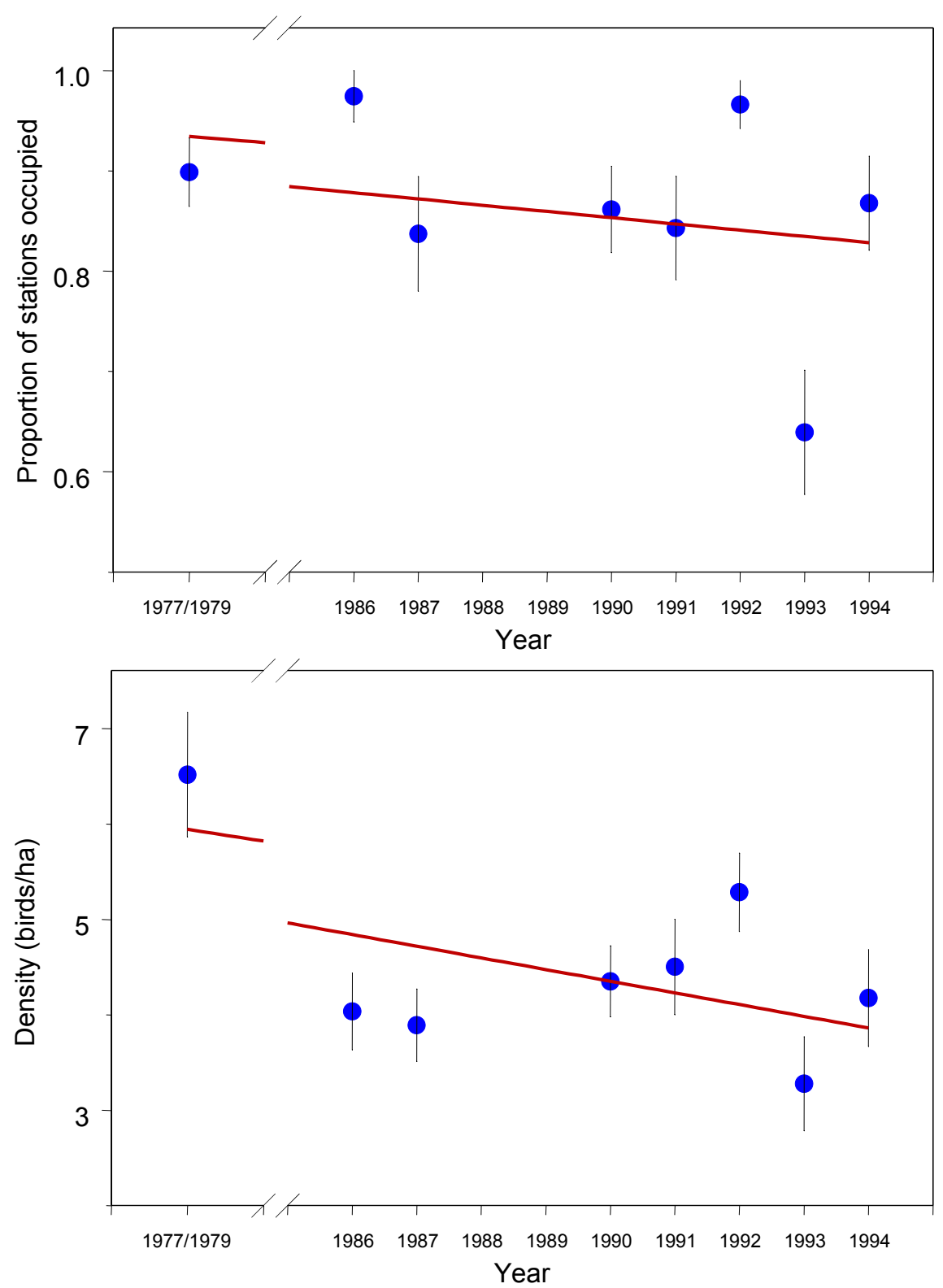

Figure 20. Hawai ' $`$ 'Amakihi mean annual frequency of occurrence (proportion of stations occupied; scaled 0 to 1) and density (birds/hectare) from 1977/1979 (HFBS) to 1994 in the Mauna Loa Strip study area. Trendlines show the general linear relationship between untransformed occurrence or density and survey year, and are included for illustrative purposes only. Logistic regression of occurrences and year was non-significant (slope $=-0.068$; odds ratio $=0.935 ; 95 \%$ confidence limit $=0.873-1.000 ; P=0.452$ ). The regression slope of logtransformed densities and year was non-significant (slope $=-0.011 ; 95 \%$ confidence limit $=$ $\left.0.029-0.007 ; \mathrm{R}^{2}=0.28 ; P=0.181\right)$. 
'T'iwi at Mauna Loa Strip
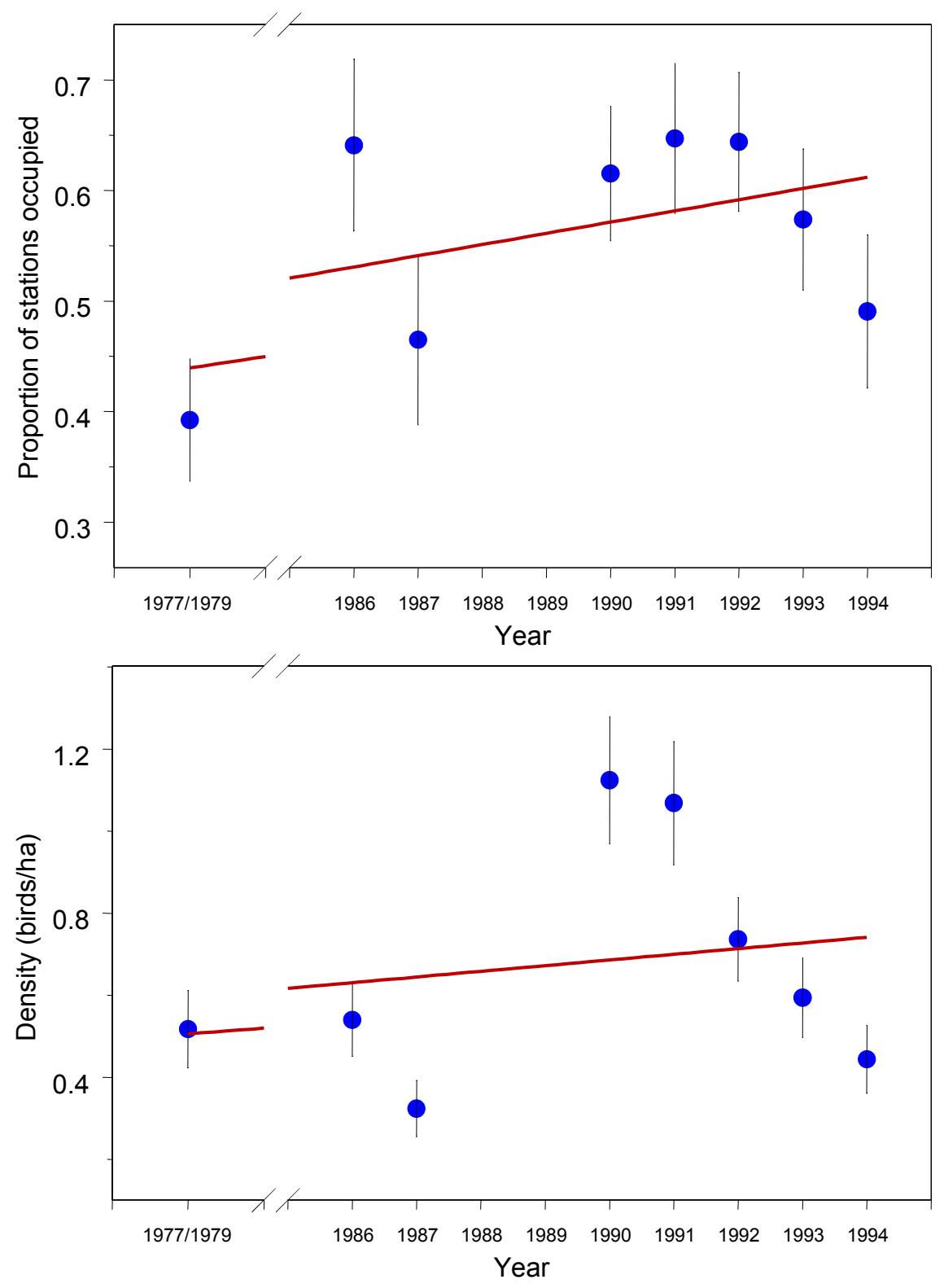

Figure 21. 'T'iwi mean annual frequency of occurrence (proportion of stations occupied; scaled 0 to 1 ) and density (birds/hectare) from 1977/1979 (HFBS) to 1994 in the Mauna Loa Strip study area. Trendlines show the general linear relationship between untransformed occurrence or density and survey year, and are included for illustrative purposes only. Logistic regression of occurrences and year was non-significant ( limit $=1.013-1.087 ; P=0.174)$. The regression slope of log-transformed densities and year was non-significant (slope $=0.005 ; 95 \%$ confidence limit $=-0.009-0.019 ; \mathrm{R}^{2}=0.12 ; P=$ $0.393)$. 
`Apapane at Mauna Loa Strip
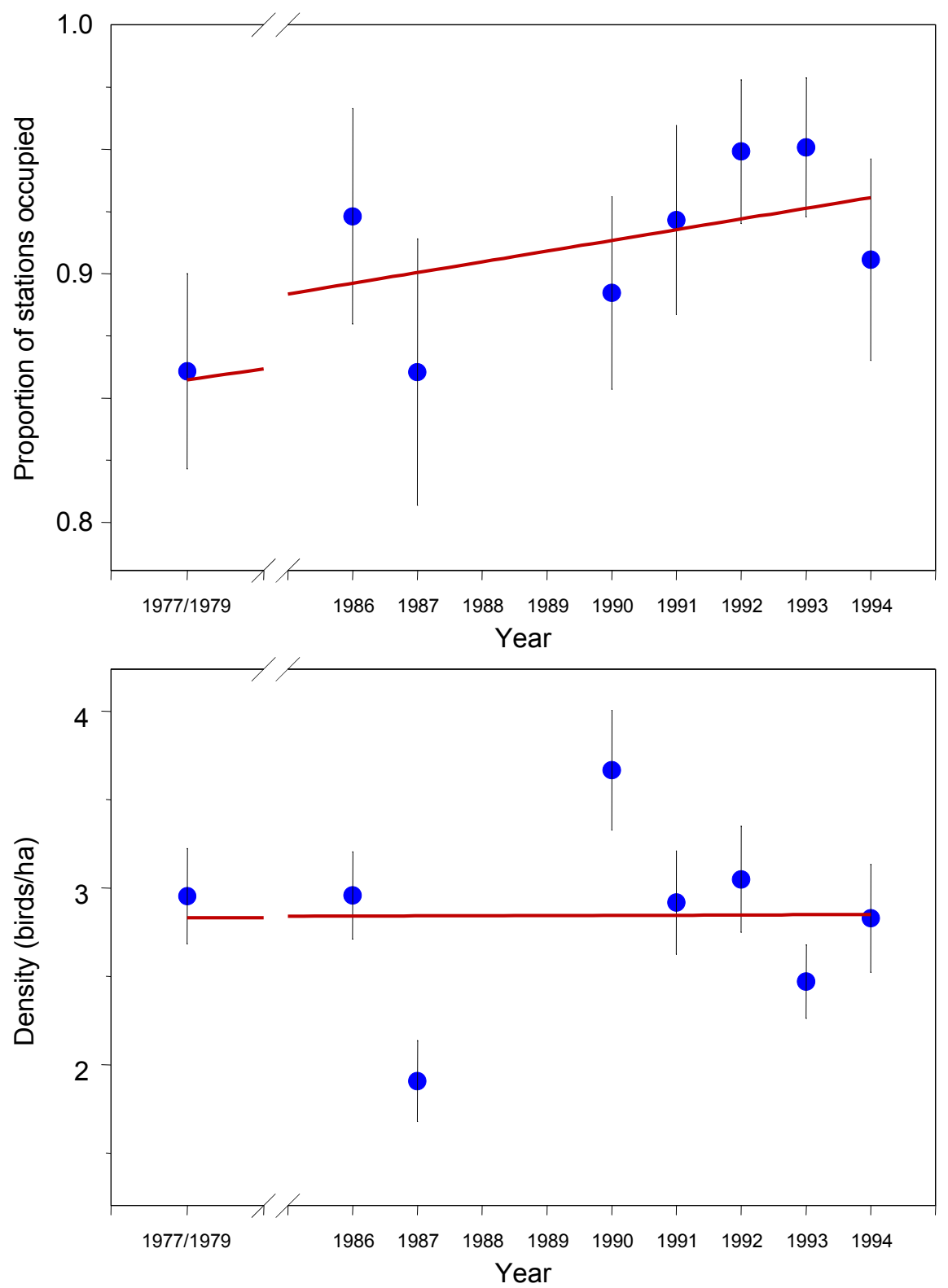

Figure 22. 'Apapane mean annual frequency of occurrence (proportion of stations occupied; scaled 0 to 1) and density (birds/hectare) from 1977/1979 (HFBS) to 1994 in the Mauna Loa Strip study area. Trendlines show the general linear relationship between untransformed occurrence or density and survey year, and are included for illustrative purposes only. Logistic regression of occurrences and year was non-significant (slope $=0.601$; odds ratio $=1.049 ; 95 \%$ confidence limit $=0.998-1.103 ; P=0.601)$. The regression slope of log-transformed densities and year was non-significant (slope $=0.002 ; 95 \%$ confidence limit $=-0.010-0.013 ; \mathrm{R}^{2}=0.02$; $P=0.714)$. 
Red-billed Leiothrix at Mauna Loa Strip
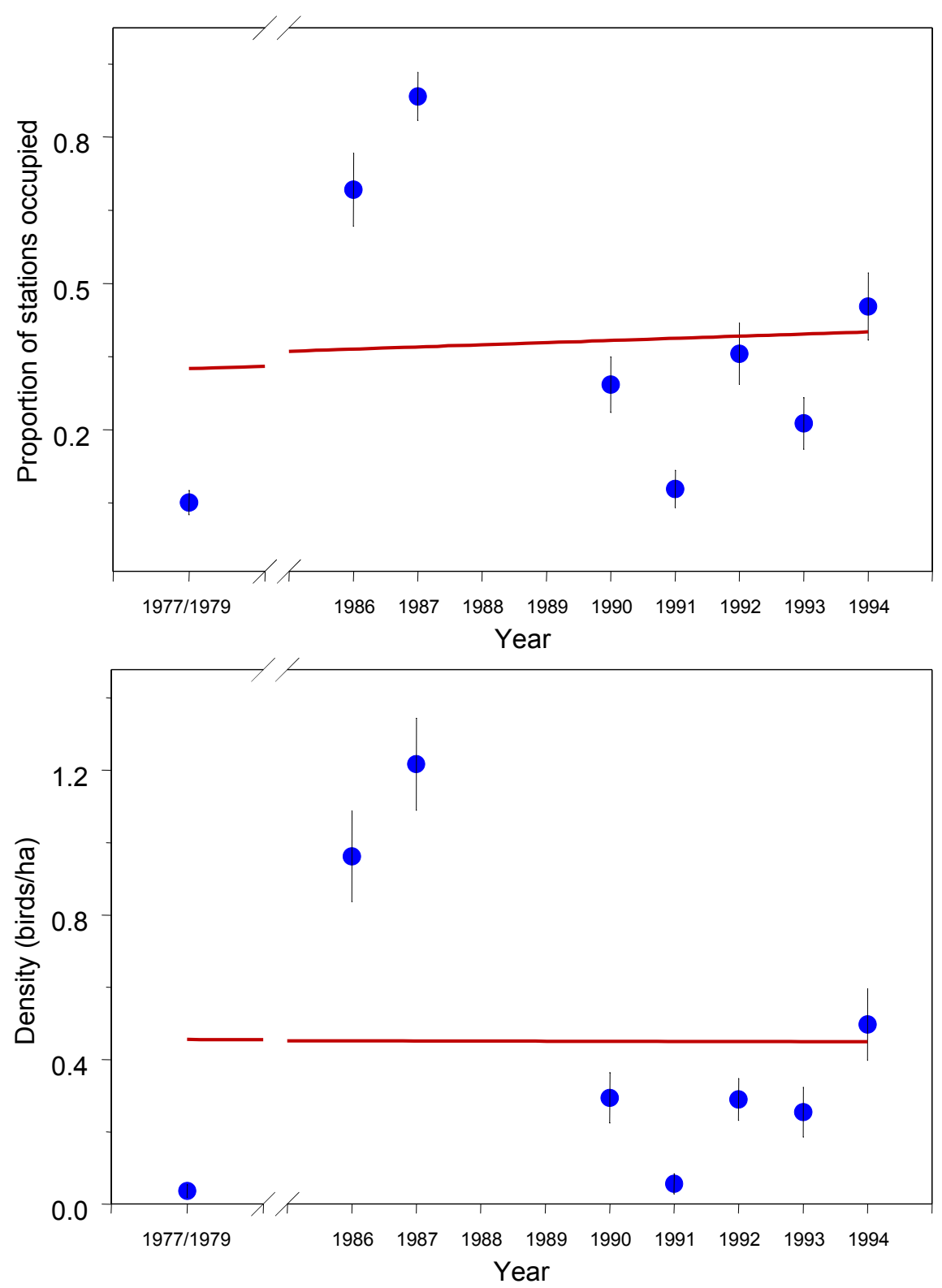

Figure 23. Red-billed Leiothrix mean annual frequency of occurrence (proportion of stations occupied; scaled 0 to 1) and density (birds/hectare) from 1977/1979 (HFBS) to 1994 in the Mauna Loa Strip study area. Trendlines show the general linear relationship between untransformed occurrence or density and survey year, and are included for illustrative purposes only. Logistic regression of occurrences and year was non-significant (slope $=0.039$; odds ratio $=1.040 ; 95 \%$ confidence limit $=0.999-1.082 ; P=0.289)$. The regression slope logtransformed densities and year was non-significant (slope $=0.0007 ; 95 \%$ confidence limit $=$ $\left.0.029--0.031 ; \mathrm{R}^{2}<0.01 ; P=0.959\right)$. 
Japanese White-eye at Mauna Loa Strip
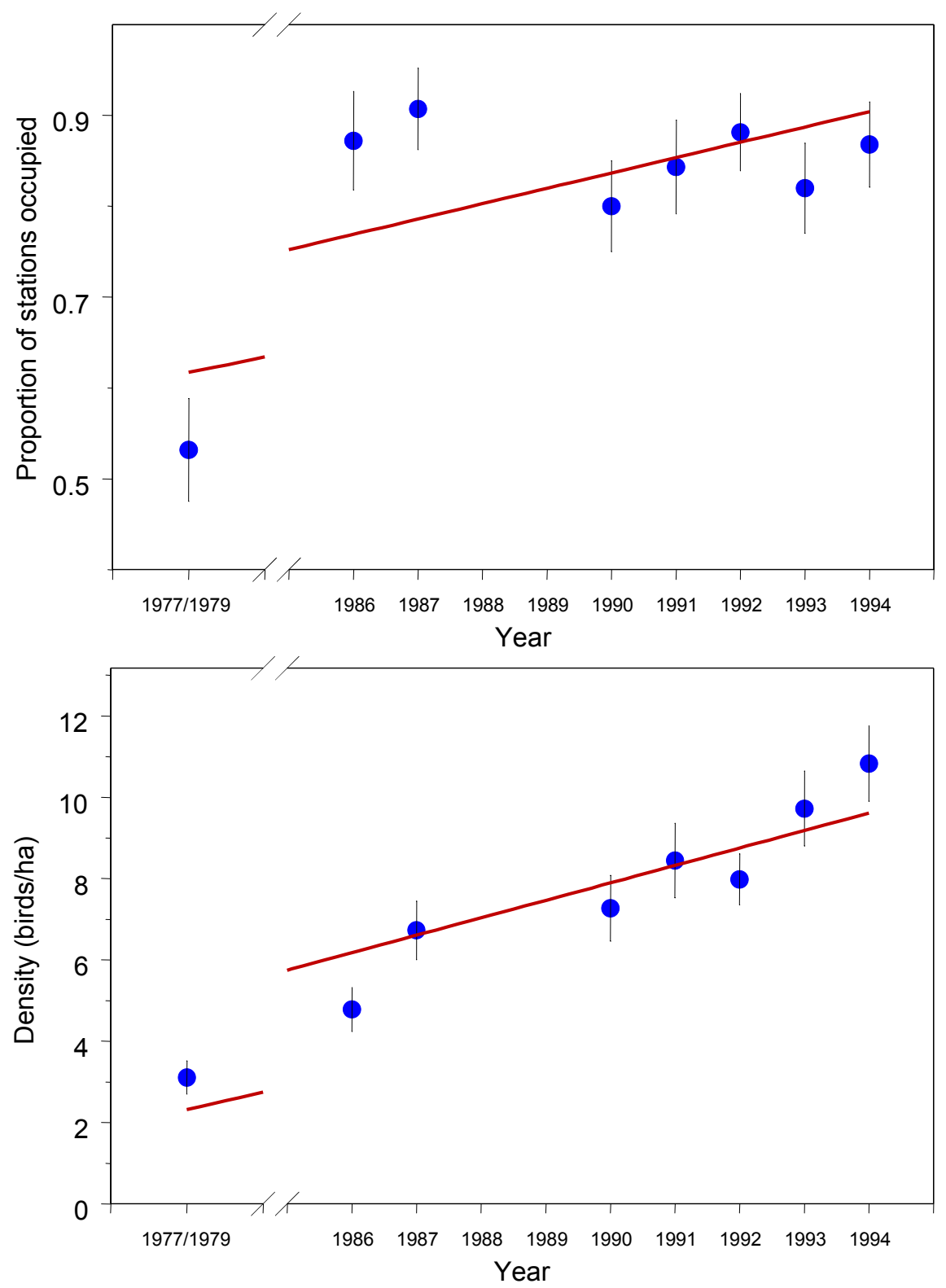

Figure 24. Japanese White-eye mean annual frequency of occurrence (proportion of stations occupied; scaled 0 to 1) and density (birds/hectare) from 1977/1979 (HFBS) to 1994 in the Mauna Loa Strip study area. Trendlines show the general linear relationship between untransformed occurrence or density and survey year, and are included for illustrative purposes only. Logistic regression of occurrences and year was significantly positive (slope $=0.119$; odds ratio $=1.127 ; 95 \%$ confidence limit $=1.085-1.170 ; P=0.018)$. The regression slope of logtransformed densities and year was significantly positive (slope $=0.034 ; 95 \%$ confidence limit $=$ $\left.0.025-0.042 ; \mathrm{R}^{2}=0.94 ; P<0.001\right)$. 
Northern Cardinal at Mauna Loa Strip
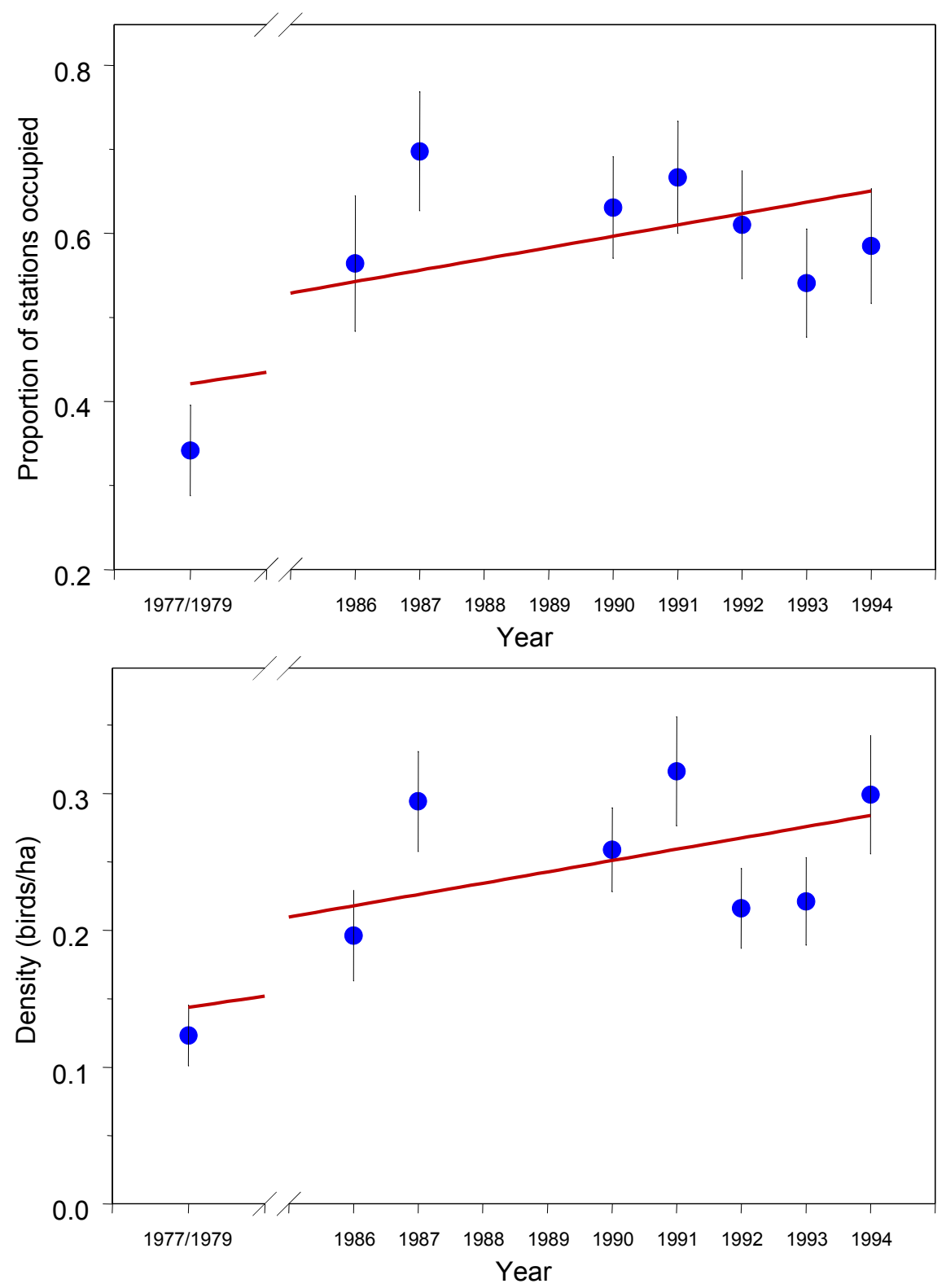

Figure 25. Northern Cardinal mean annual frequency of occurrence (proportion of stations occupied; scaled 0 to 1) and density (birds/hectare) from 1977/1979 (HFBS) to 1994 in the Mauna Loa Strip study area. Trendlines show the general linear relationship between untransformed occurrence or density and survey year, and are included for illustrative purposes only. Logistic regression of occurrences and year was non-significant (slope $=0.064$; odds ratio $=1.066 ; 95 \%$ confidence limit $=1.029-1.105 ; P=0.072)$. The regression slope of logtransformed densities and year was marginally significant and positive (slope $=0.005 ; 95 \%$ confidence limit $\left.=0.000-0.009 ; \mathrm{R}^{2}=0.49 ; P=0.054\right)$. 
House Finch at Mauna Loa Strip
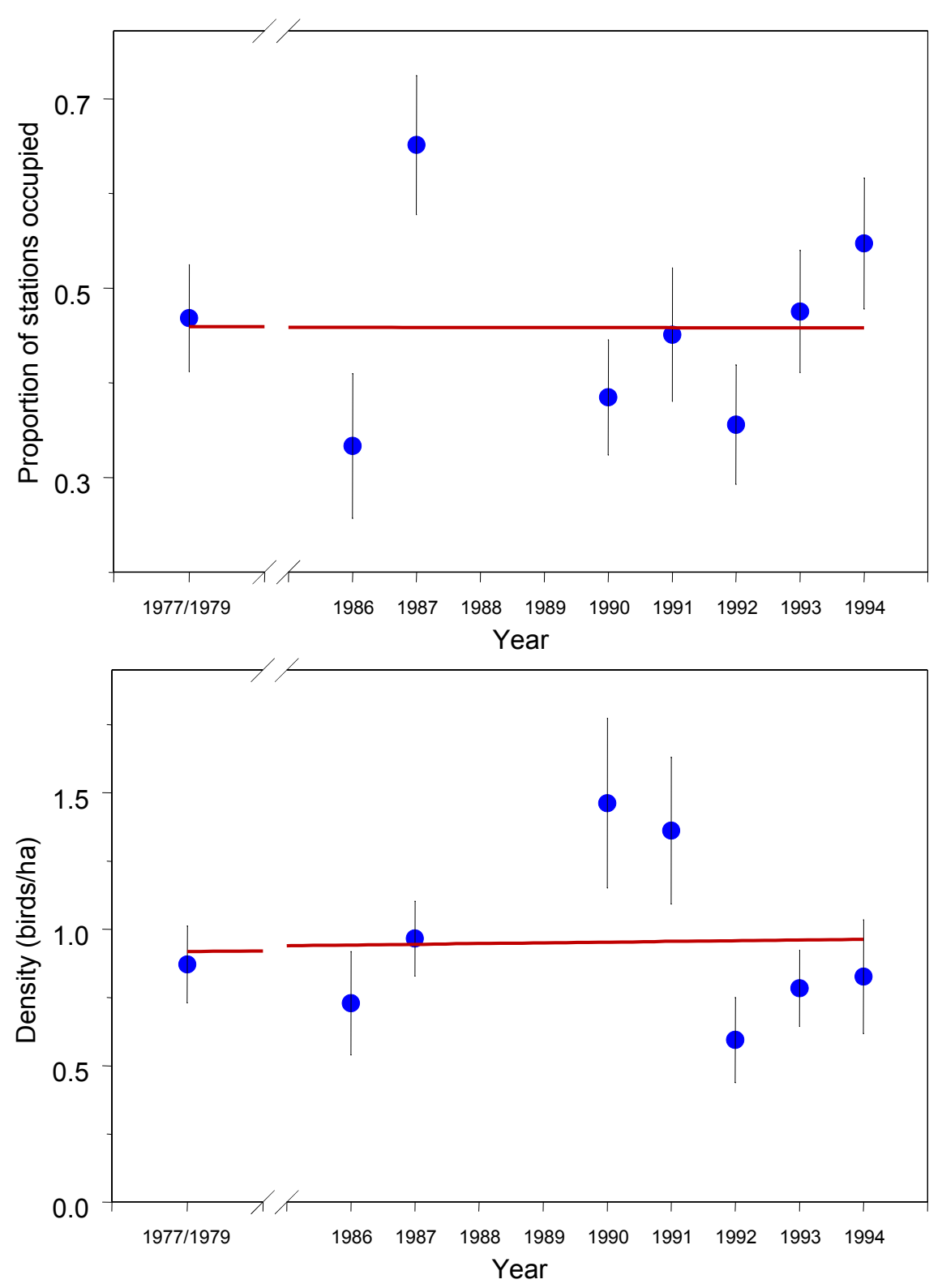

Figure 26. House Finch mean annual frequency of occurrence (proportion of stations occupied; scaled 0 to 1) and density (birds/hectare) from 1977/1979 (HFBS) to 1994 in the Mauna Loa Strip study area. Trendlines show the general linear relationship between untransformed occurrence or density and survey year, and are included for illustrative purposes only. Logistic regression of occurrences and year was non-significant (slope $=-0.002$; odds ratio $=0.998 ; 95 \%$ confidence limit $=0.964-1.033 ; P=0.949)$. The regression slope of log-transformed densities and year was non-significant $\left(\right.$ slope $=-0.001 ; 95 \%$ confidence limit $=-0.002-0.010 ; R^{2}=0.01$; $P=0.844)$. 


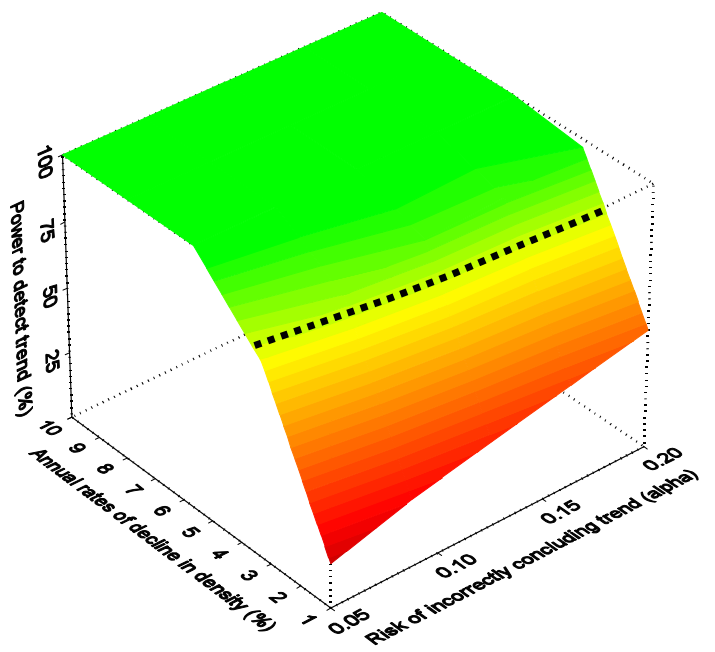

Hawai'i 'Elepaio

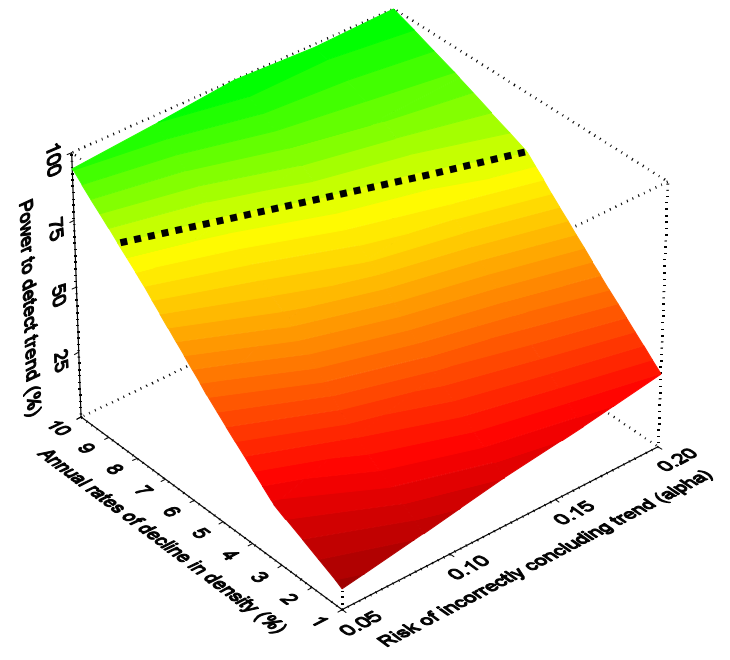

'Akiapōlā'au

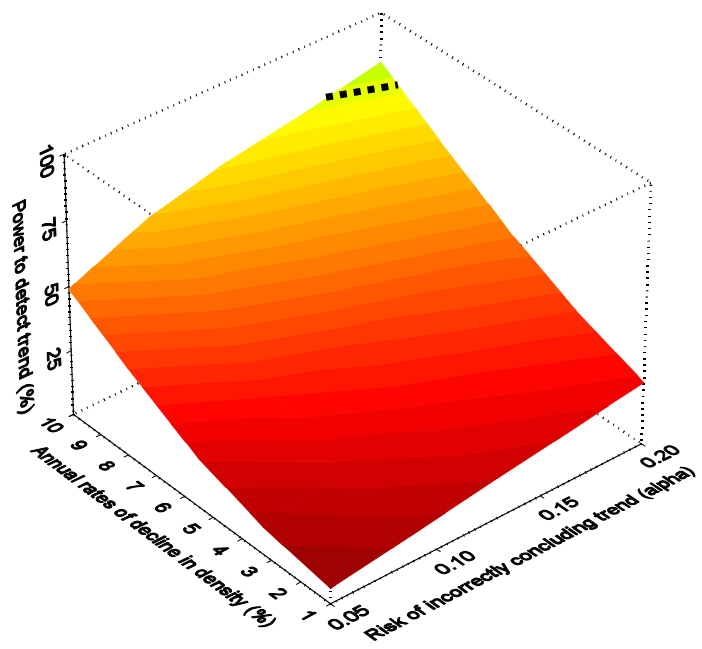

Hawai'i Creeper

Figure 27. The power to detect a trend in density diminishesas a function of the annual rate of decline and the risk of incorrectly concluding a trend exists (i.e., Type I error as indicated by the significance threshold [alpha] used to declare significance). Power to detect a trend in density as a function of the annual rate of decline and the risk of incorrectly concluding a trend exists (i.e., Type I error as indicated by the significance threshold [alpha] used to declare significance). Adequate power $(\geq 80 \%)$ is indicated by the (green) area above the dashed line. Surface plots are presented for Hawai `i 'Elepaio, 'Akiapōlā'au, and Hawai i Creeper (i.e., species with low, moderate, and high variability in density, respectively). 


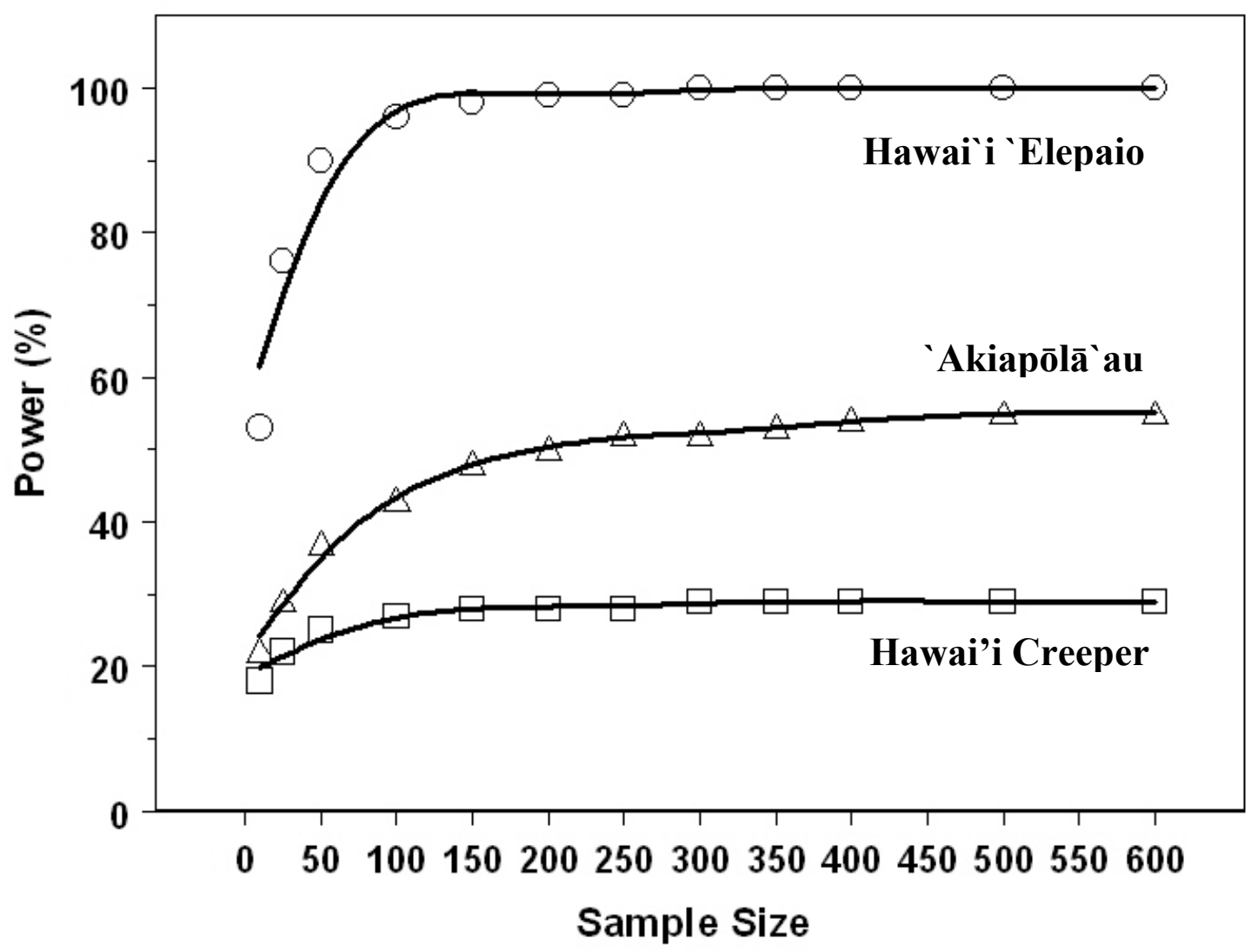

Figure 28. Power to detect a trend in density increases, then tapers off with larger sample sizes, and past a certain point there is little gain in power from greater sampling effort. Shown here are responses in power as a function of sample size, given a 5\% decline in annual mean density and a significance threshold of 0.10 . Adequate power is defined here at $\geq 80 \%$. Power curves are presented for Hawai ' `Elepaio, 'Akiapōlā’au, and Hawai`i Creeper (i.e., species with low, moderate, and high variability in density, respectively). 


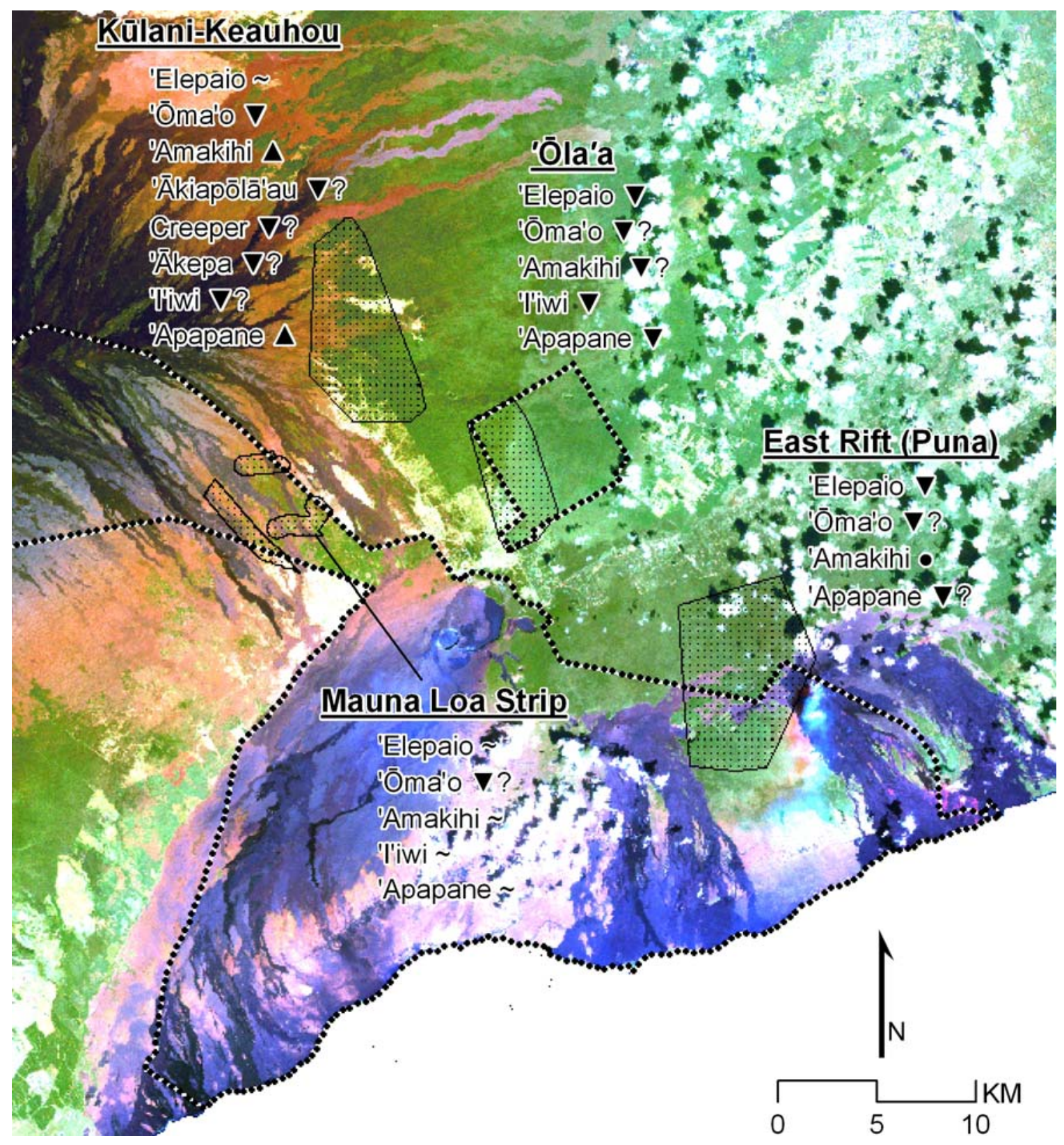

Figure 29. Summary of population trends for native forest birds. Trends are based on current changes in both estimated density and occurrence. The symbols $\boldsymbol{\Lambda}, \boldsymbol{\nabla}, \bullet$ and $\sim$ indicate increasing trends, decreasing trends, near absence, and an apparently stable population, respectively. A question mark refers to uncertainty in the trend assessment as caused by high variability in observed densities and/or occurrences. The Hawaii Volcanoes National Park boundary is delineated with a dashed line. 


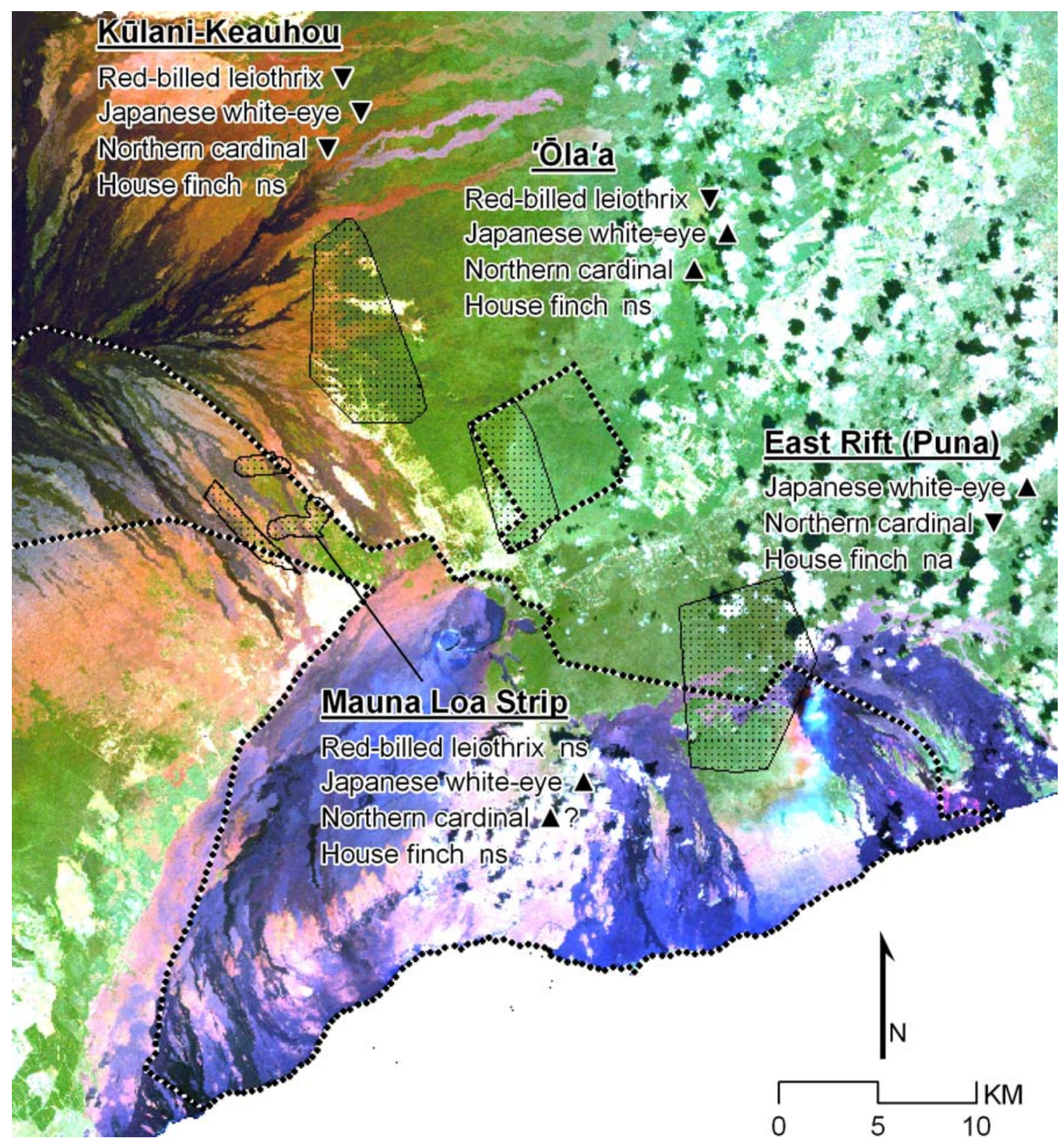

Figure 30. Summary of population trends for non-native forest birds in the Kūlani-Keauhou, 'Ōla'a, East Rift, and Mauna Loa Strip study areas. Trends are based on current changes in both estimated density and occurrence. The symbols $\boldsymbol{\Lambda}, \boldsymbol{\nabla}$, ns and na indicate increasing trends, decreasing trends, non-significant trends, and not analyzed (i.e., insufficient data), respectively. The Hawaii Volcanoes National Park boundary is delineated with a dashed line. 


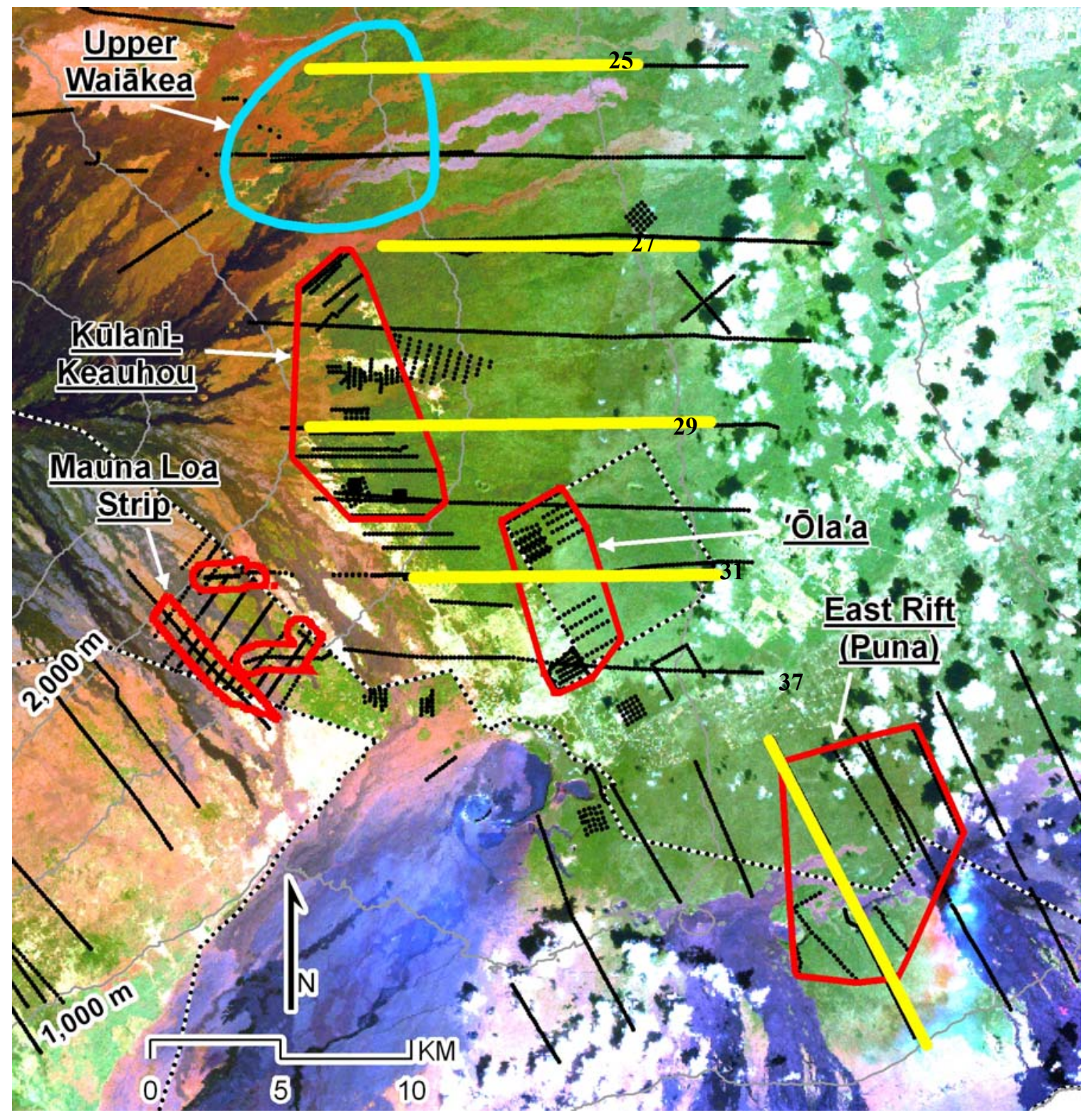

Figure 31. Recommended changes to survey design in the Central Windward region include the intensive annual sampling in the Upper Waiākea (blue polygon). This area may provide an important link between populations of endangered species in the Kūlani-Keauhou and Hāmākua regions. Extensive surveys that target broad habitat gradients and are conducted at longer time intervals also should be carried out to monitor changes in species' range. Transects (numbered yellow lines) that build on what was surveyed by the HFBS in the late 1970s are shown for illustrative purposes. 
Table 1. Annual surveys conducted within each study area in the Central Windward region. Survey transects are identified by number. Due to inconsistent coverage, trend analyses were restricted to data from select transects (bold) and pooled across years (indicated with superscript).

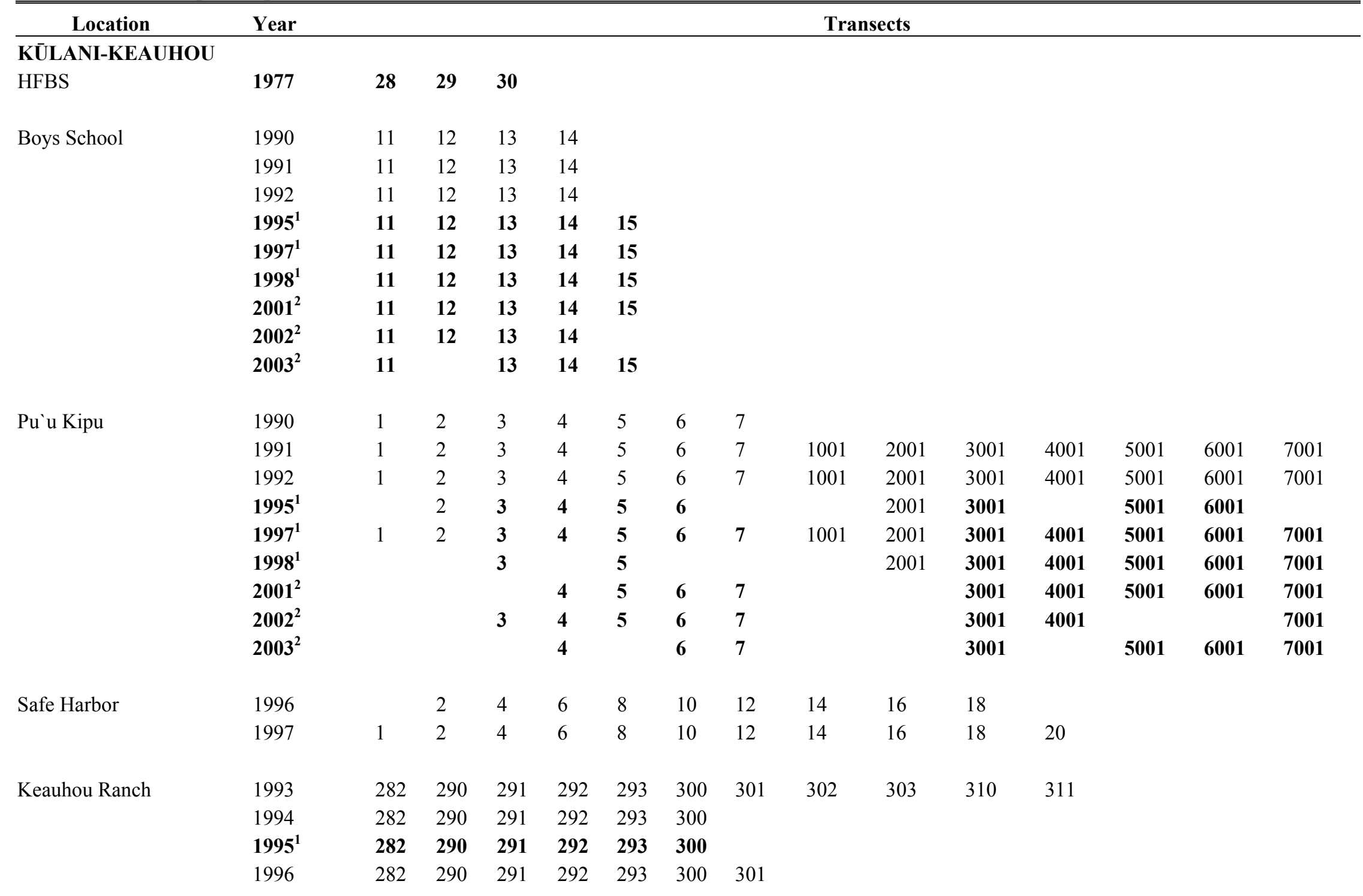




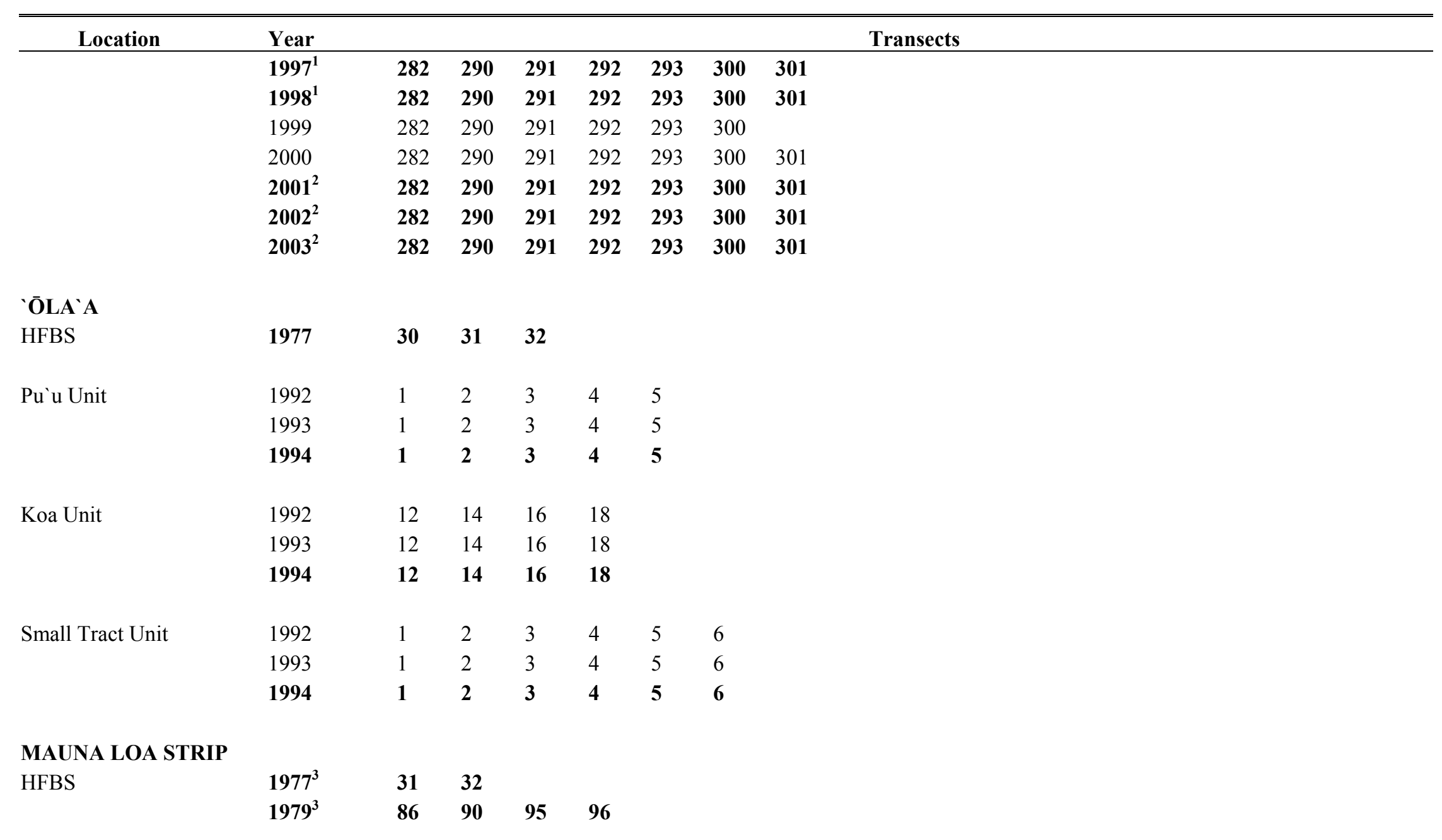




\begin{tabular}{|c|c|c|c|c|c|c|c|c|c|c|c|c|c|c|}
\hline \multirow{2}{*}{$\frac{\text { Location }}{\text { Nat'l Park Service }}$} & \multirow{2}{*}{$\frac{\text { Year }}{1986}$} & \multicolumn{13}{|c|}{ Transects } \\
\hline & & 7 & & 9 & 10 & 11 & 12 & 13 & 14 & 15 & 16 & 17 & 18 & 19 \\
\hline & 1987 & 7 & & 9 & 10 & 11 & 12 & 13 & 14 & 15 & 16 & 17 & 18 & 19 \\
\hline & 1990 & & 8 & & 10 & 11 & 12 & 13 & 14 & 15 & 16 & & 18 & \\
\hline & 1991 & & 8 & & 10 & & 12 & & 14 & & 16 & & 18 & \\
\hline & 1992 & & 8 & & 10 & & 12 & & 14 & 15 & 16 & & 18 & \\
\hline & 1993 & & 8 & 9 & 10 & & 12 & & 14 & 15 & 16 & & 18 & \\
\hline & 1994 & & & 9 & 10 & & 12 & & 14 & 15 & 16 & & 18 & \\
\hline \multicolumn{15}{|l|}{ EAST RIFT } \\
\hline HFBS & 1979 & 37 & 38 & & & & & & & & & & & \\
\hline Puna Geothermal & $1993^{4}$ & 370 & 371 & 380 & 381 & & & & & & & & & \\
\hline \multirow[t]{3}{*}{ Nat'1 Park Service } & 1992 & 1 & 2 & 3 & & & & & & & & & & \\
\hline & 1993 & 1 & 2 & 3 & 3001 & & & & & & & & & \\
\hline & $1994^{4}$ & 1 & 2 & 3 & 3001 & & & & & & & & & \\
\hline
\end{tabular}


Table 2. Effective detection radius (EDR; meters) and variance estimates (\%CV) by species in the Kūlani-Keauhou and `Ōla`a study areas. Presented for each species are the number of detections and number modeled, distance (meters) at which data were truncated $(\mathrm{Rt}=$ right truncation; $\mathrm{Lt}=$ left truncation), models $(\mathrm{H}-\mathrm{rate}=$ hazard rate key function; H-norm = half normal key function; S-poly 1adj = simple polynomial with 1 adjustment term), and covariate variables used to adjust detection function $(\mathrm{C}=\mathrm{Cloud}$ cover; $\mathrm{R}=$ Rain; $\mathrm{W}=$ Wind; $\mathrm{G}=$ Gust; $\mathrm{T}=$ Time; $\mathrm{M}=$ Month; $\mathrm{Y}=$ Year; $\mathrm{O}=$ Observer).

\begin{tabular}{|c|c|c|c|c|c|c|c|}
\hline$\underline{\text { Species }}$ & EDR & $\% \mathrm{CV}$ & No. Detections & No. Modeled & Truncation & Detection Function & Covariates \\
\hline Hawa'` `Elepaio & 31.73 & 0.51 & 7,103 & 5,567 & Rt 46.9 Lt 5.56 & H-rate Key & $R \& G$ \\
\hline 'Ōma`o & 61.15 & 0.29 & 23,728 & 21,369 & Rt 108.0 & H-rate S-poly 1-adj & $M \& T$ \\
\hline Hawai’ ' 'Amakihi & 37.03 & 0.50 & 9,819 & 8,838 & Rt 68.0 & H-rate S-poly 1-adj & $\mathrm{O}$ \\
\hline ‘Akiapōlā’au & 56.21 & 2.05 & 670 & 603 & Rt 96.0 & H-rate Key & $\mathrm{C}, \mathrm{R}, \mathrm{W} \& \mathrm{C}$ \\
\hline Hawai’i Creeper & 40.18 & 1.57 & 1,155 & 1,035 & Rt 69.9 & H-rate Key & $\mathrm{O}$ \\
\hline Hawai`i 'Ākepa & 35.30 & 1.32 & 1,159 & 1,044 & Rt 57.0 & H-rate Key & $\mathrm{R}, \mathrm{G}, \mathrm{T} \& \mathrm{O}$ \\
\hline 'Tiwi & 32.76 & 0.41 & 18,599 & 16,655 & Rt 74.9 & H-rate Key & $O \& Y$ \\
\hline 'Apapane & 34.06 & 0.19 & 59,488 & 53,555 & Rt 67 & H-norm Key & $\mathrm{O}$ \\
\hline Red-billed Leiothrix & 42.17 & 0.56 & 9,312 & 8,359 & Rt 81.0 & H-rate Key & $O \& Y$ \\
\hline Japanese White-eye & 27.54 & 0.37 & 16,148 & 14,592 & Rt 45.0 & H-rate S-poly 1-adj & $O \& G$ \\
\hline Northern Cardinal & 69.91 & 0.81 & 3,857 & 3,404 & Rt 144.0 & H-rate Key & $O \& Y$ \\
\hline House Finch & 44.27 & 1.30 & 1,683 & 1,507 & Rt 89.0 & H-norm Key & $O \& Y$ \\
\hline
\end{tabular}


Table 3. Effective detection radius (EDR; meters) and variance estimates (\%CV) by species in the Mauna Loa Strip study area. Presented for each species are the number of detections and number modeled, distance (meters) at which data were truncated $(\mathrm{Rt}=$ right truncation; $\mathrm{Lt}=$ left truncation), models $(\mathrm{H}$-rate $=$ hazard rate key function; $\mathrm{H}$-norm $=$ half normal key function; $\mathrm{S}$-poly 1 -adj $=$ simple polynomial with 1 adjustment term), and covariate variables used to adjust detection function $(\mathrm{C}=\mathrm{Cloud}$ cover; $\mathrm{R}=\mathrm{Rain}$; $\mathrm{W}=$ Wind; $\mathrm{G}=$ Gust; $\mathrm{T}=$ Time; $\mathrm{M}=$ Month; $\mathrm{Y}=$ Year; $\mathrm{O}=$ Observer).

\begin{tabular}{|c|c|c|c|c|c|c|c|}
\hline Species & EDR & $\% \mathrm{CV}$ & No. Detections & No. Modeled & Truncation & Detection Function & Covariates \\
\hline Hawai i `Elepaio & 39.79 & 1.67 & 1,119 & 974 & Rt 76.0 Lt 5.2 & H-rate Key & $\mathrm{O}$ \\
\hline 'Ōma`o & 103.67 & 4.69 & 179 & 162 & Rt 183.0 & H-norm Key & None \\
\hline Hawai`i 'Amakihi & 45.74 & 0.95 & 3,548 & 3,231 & Rt 91.0 & H-rate Key & O \& Y \\
\hline 'I'iwi & 71.70 & 1.37 & 1,274 & 1,163 & Rt 122.0 & H-rate Key & $\mathrm{O} \& \mathrm{Y}$ \\
\hline 'Apapane & 64.76 & 0.70 & 4,857 & 4,393 & Rt 107.0 & H-rate Key & $\mathrm{O} \& \mathrm{Y}$ \\
\hline Red-billed Leiothrix & 66.42 & 2.02 & 748 & 645 & Rt 108.1 & H-norm Key & O \& Y \\
\hline Japanese White-eye & 31.47 & 0.82 & 3,584 & 3,219 & Rt 60.1 & H-rate Key & $O \& Y$ \\
\hline Northern Cardinal & 106.99 & 1.15 & 1,355 & 1,050 & Rt 148.0 & H-rate Key & $\mathrm{O}$ \\
\hline House Finch & 52.88 & 1.24 & 1,494 & 4,272 & Rt 84.0 & H-rate Key & $\mathrm{O}, \mathrm{Y} \& \mathrm{G}$ \\
\hline
\end{tabular}


Table 4. Effective detection radius (EDR; meters) and variance estimates $(\% \mathrm{CV})$ by species in the East Rift study area. Presented for each species are the number of detections and number modeled, distance (meters) at which data were truncated $(\mathrm{Rt}=\mathrm{right}$ truncation; $\mathrm{Lt}=$ left truncation), models $(\mathrm{H}-\mathrm{rate}=$ hazard rate key function; H-norm $=$ half normal key function; S-poly 1 -adj $=$ simple polynomial with 1 adjustment term), and covariate variables used to adjust detection function $(\mathrm{C}=$ Cloud cover; $\mathrm{R}=\mathrm{Rain} ; \mathrm{W}=\mathrm{Wind}$; $\mathrm{G}=\mathrm{Gust}$; $\mathrm{T}=$ Time; $\mathrm{M}=$ Month; $\mathrm{Y}=$ Year; $\mathrm{O}=$ Observer).

\begin{tabular}{|c|c|c|c|c|c|c|c|}
\hline Species & EDR & $\% \mathrm{CV}$ & No. Detections & No. Modeled & Truncation & Detection Function & Covariates \\
\hline Hawai`i `Elepaio & 47.49 & 3.77 & 241 & 218 & Rt 76.0 & H-rate Key & $\mathrm{O} \& \mathrm{~T}$ \\
\hline 'Ōma`o & 80.93 & 1.28 & 1,645 & 1,487 & Rt 137.0 & H-rate S-poly 1 -adj & $\mathrm{O}$ \\
\hline Hawai 'i 'Amakihi & 64.67 & 2.15 & 553 & 500 & Rt 143.0 & H-rate Key & $\mathrm{O}$ \\
\hline Apapane & 51.52 & 0.69 & 4,470 & 4,032 & Rt 98.0 & H-rate S-poly 1-adj & M \\
\hline Japanese White-eye & 29.82 & 0.86 & 3,379 & 2,875 & Rt 49.0 & H-rate Key & $\mathrm{O}$ \\
\hline Northern Cardinal & 79.81 & 2.77 & 603 & 492 & Rt 146.0 & H-norm Key & $\mathrm{O}, \mathrm{Y} \& \mathrm{C}$ \\
\hline House Finch & 47.76 & 3.87 & 284 & 190 & Rt 89.7 & H-norm Key & $\mathrm{O} \& \mathrm{~W}$ \\
\hline
\end{tabular}


Table 5. Bird occurrence and trends in the Kūlani-Keauhou study area. Occurrence was calculated as the proportion of sampled stations for which a species was present. Standard error is designated as SE. Comparisons between the 1995-1998 (i.e., "1990s") and 2001-2003 (i.e., "2000s") survey periods were assessed with a significance threshold of $\leq 0.10$ for the endangered species `Akiapōlā'au, Hawai i Creeper and Hawai'i `Ākepa, and $\leq 0.05$ for all other species. 'Apapane data was not analyzed because it occurred at all sites during both survey periods. The general trend is summarized with upward $(\uparrow)$ and downward $(\downarrow)$ symbols, and ns refers to a statistically non-significant result. Species are ordered taxonomically within native and alien groups.

\begin{tabular}{|c|c|c|c|c|c|c|c|}
\hline Species & Period & Presence & Absence & Occurrence & SE & $\mathbf{P}$ & Change \\
\hline Hawai`i & $1990 \mathrm{~s}$ & 390 & 303 & 0.56 & 0.02 & & \\
\hline `Elepaio & $2000 \mathrm{~s}$ & 261 & 291 & 0.47 & 0.02 & $<0.01$ & $\downarrow$ \\
\hline \multirow[t]{2}{*}{ `Ōma`o } & $1990 \mathrm{~s}$ & 721 & 20 & 0.97 & 0.01 & & \\
\hline & $2000 \mathrm{~s}$ & 533 & 52 & 0.91 & 0.01 & $<0.01$ & $\downarrow$ \\
\hline Hawai`i & $1990 \mathrm{~s}$ & 546 & 195 & 0.74 & 0.02 & & \\
\hline `Amakihi & $2000 \mathrm{~s}$ & 445 & 140 & 0.76 & 0.02 & 0.34 & ns \\
\hline \multirow[t]{2}{*}{ ‘Akiapōlā’au } & $1990 \mathrm{~s}$ & 78 & 558 & 0.12 & 0.01 & & \\
\hline & $2000 \mathrm{~s}$ & 43 & 463 & 0.08 & 0.01 & 0.04 & $\downarrow$ \\
\hline Hawai`i & $1990 \mathrm{~s}$ & 88 & 605 & 0.13 & 0.01 & & \\
\hline Creeper & $2000 \mathrm{~s}$ & 41 & 511 & 0.07 & 0.01 & $<0.01$ & $\downarrow$ \\
\hline Hawai $i$ & $1990 \mathrm{~s}$ & 70 & 623 & 0.10 & 0.01 & & \\
\hline 'Ākepa & $2000 \mathrm{~s}$ & 42 & 510 & 0.08 & 0.01 & 0.14 & ns \\
\hline \multirow{2}{*}{ 'I'iwi } & $1990 \mathrm{~s}$ & 681 & 60 & 0.92 & 0.01 & & \\
\hline & $2000 \mathrm{~s}$ & 517 & 68 & 0.88 & 0.01 & 0.03 & $\downarrow$ \\
\hline \multirow[t]{2}{*}{ 'Apapane } & $1990 \mathrm{~s}$ & 741 & 0 & 1.00 & 0.00 & & \\
\hline & $2000 \mathrm{~s}$ & 585 & 0 & 1.00 & 0.00 & na & na \\
\hline Red-billed & $1990 \mathrm{~s}$ & 345 & 396 & 0.47 & 0.02 & & \\
\hline Leiothrix & $2000 \mathrm{~s}$ & 157 & 428 & 0.27 & 0.02 & $<0.01$ & $\downarrow$ \\
\hline Japanese & $1990 \mathrm{~s}$ & 629 & 112 & 0.85 & 0.01 & & \\
\hline White-eye & $2000 \mathrm{~s}$ & 380 & 205 & 0.65 & 0.02 & $<0.01$ & $\downarrow$ \\
\hline Northern & $1990 \mathrm{~s}$ & 237 & 504 & 0.32 & 0.02 & & \\
\hline Cardinal & $2000 \mathrm{~s}$ & 96 & 489 & 0.16 & 0.02 & $<0.01$ & $\downarrow$ \\
\hline House & $1990 \mathrm{~s}$ & 58 & 683 & 0.08 & 0.01 & & \\
\hline Finch & $2000 \mathrm{~s}$ & 33 & 552 & 0.06 & 0.01 & 0.13 & ns \\
\hline
\end{tabular}


Table 6. Power to detect a negative trend in occurrence for native bird species of the Kulani-Keauhou study area. Power (percentage) is the probability of detecting a trend when one actually occurs. Declines of $1 \%, 3 \%, 5 \%$ and $10 \%$ in the mean annual occurrence were calculated for a prospective 10-year monitoring period with the program TRENDS, given linear trends, 1-tailed significance levels (alpha) of 0.05, 0.10 and 0.20, and observed coefficient of variation (CV) and variance structure of mean occurrence over time. The type of variance structures applicable for each species include: (a) CV proportional to $\sqrt{\text { occurrence; }}$ and (b) CV proportional to $1 /$ Joccurrence. Bold text indicates that there is adequate power $(\geq 80 \%)$ to detect a negative trend.

\begin{tabular}{|c|c|c|c|c|c|c|c|c|c|c|c|c|c|c|}
\hline \multirow[b]{2}{*}{ Species } & \multirow[b]{2}{*}{ CV } & \multirow[b]{2}{*}{ type } & \multicolumn{4}{|c|}{ Alpha 0.05} & \multicolumn{4}{|c|}{ Alpha 0.10} & \multicolumn{4}{|c|}{ Alpha 0.20} \\
\hline & & & $1 \%$ & $3 \%$ & $5 \%$ & $10 \%$ & $1 \%$ & $3 \%$ & $5 \%$ & $10 \%$ & $1 \%$ & $3 \%$ & $5 \%$ & $10 \%$ \\
\hline Apapane & 0.008 & $\mathrm{a}$ & 100 & 100 & 100 & 100 & 100 & 100 & 100 & 100 & 100 & 100 & 100 & 100 \\
\hline '̄ma`o & 0.024 & $\mathrm{a}$ & 98 & 100 & 100 & 100 & 100 & 100 & 100 & 100 & 100 & 100 & 100 & 100 \\
\hline 'I'iwi & 0.048 & $\mathrm{a}$ & 58 & 100 & 100 & 100 & 74 & 100 & 100 & 100 & 87 & 100 & 100 & 100 \\
\hline Hawai`i `Amakihi & 0.076 & $\mathrm{a}$ & 32 & 100 & 100 & 100 & 47 & 100 & 100 & 100 & 66 & 100 & 100 & 100 \\
\hline `Elepaio & 0.096 & $\mathrm{~b}$ & 22 & 87 & 100 & 100 & 36 & 95 & 100 & 100 & 54 & 98 & 100 & 100 \\
\hline ‘Akiapōlā’au & 0.428 & $\mathrm{~b}$ & 7 & 15 & 29 & 83 & 14 & 26 & 44 & 92 & 26 & 43 & 63 & 97 \\
\hline Hawai`i `Ākepa & 0.490 & $\mathrm{~b}$ & 7 & 14 & 25 & 76 & 14 & 24 & 39 & 86 & 26 & 40 & 57 & 95 \\
\hline Hawai i Creeper & 0.511 & $\mathrm{~b}$ & 7 & 13 & 24 & 71 & 13 & 23 & 37 & 84 & 25 & 39 & 56 & 93 \\
\hline
\end{tabular}


Table 7. Bird density and trends in the Kūlani-Keauhou study area. Change in density (\#/ha) was assessed with a significance threshold of $\leq 0.10$ for the endangered species 'Akiapōlā'au, Hawai $i$ Creeper and Hawai' $i$ 'A kepa, and $\leq 0.05$ for all other species. The general trend is summarized with upward $(\uparrow)$ and downward $(\downarrow)$ symbols, and ns refers to a statistically nonsignificant result. Standard error is designated as SE. Species are ordered taxonomically within native and alien groups.

\begin{tabular}{|c|c|c|c|c|c|}
\hline Species & Period & Density & SE & $\mathbf{P}$ & Change \\
\hline Hawai`i & $1990 \mathrm{~s}$ & 2.29 & 0.11 & & \\
\hline 'Elepaio & $2000 \mathrm{~s}$ & 2.22 & 0.16 & 0.70 & ns \\
\hline \multirow[t]{2}{*}{ `Ōma`o } & $1990 \mathrm{~s}$ & 2.79 & 0.06 & & \\
\hline & $2000 \mathrm{~s}$ & 2.02 & 0.06 & $<0.01$ & $\downarrow$ \\
\hline Hawai`i & $1990 \mathrm{~s}$ & 3.22 & 0.14 & & \\
\hline 'Amakihi & $2000 \mathrm{~s}$ & 4.01 & 0.19 & $<0.01$ & $\uparrow$ \\
\hline \multirow[t]{2}{*}{ ‘Akiapōlā’au } & $1990 \mathrm{~s}$ & 0.10 & 0.01 & & \\
\hline & $2000 \mathrm{~s}$ & 0.09 & 0.02 & 0.70 & ns \\
\hline Hawai`i & $1990 \mathrm{~s}$ & 0.34 & 0.04 & & \\
\hline Creeper & $2000 \mathrm{~s}$ & 0.23 & 0.05 & 0.10 & $\downarrow$ \\
\hline Hawai`i & $1990 \mathrm{~s}$ & 0.30 & 0.05 & & \\
\hline `Ākepa & $2000 \mathrm{~s}$ & 0.23 & 0.04 & 0.26 & ns \\
\hline \multirow[t]{2}{*}{ 'Tiwi } & $1990 \mathrm{~s}$ & 9.84 & 0.32 & & \\
\hline & $2000 \mathrm{~s}$ & 8.49 & 0.28 & $<0.01$ & $\downarrow$ \\
\hline \multirow[t]{2}{*}{ Apapane } & $1990 \mathrm{~s}$ & 24.43 & 0.52 & & \\
\hline & $2000 \mathrm{~s}$ & 28.35 & 0.56 & $<0.01$ & $\uparrow$ \\
\hline Red-billed & $1990 \mathrm{~s}$ & 1.47 & 0.08 & & \\
\hline Leiothrix & $2000 \mathrm{~s}$ & 0.78 & 0.07 & $<0.01$ & $\downarrow$ \\
\hline Japanese & $1990 \mathrm{~s}$ & 8.77 & 0.23 & & \\
\hline White-eye & $2000 \mathrm{~s}$ & 5.56 & 0.27 & $<0.01$ & $\downarrow$ \\
\hline Northern & $1990 \mathrm{~s}$ & 0.23 & 0.02 & & \\
\hline Cardinal & $2000 \mathrm{~s}$ & 0.13 & 0.02 & $<0.01$ & $\downarrow$ \\
\hline House & $1990 \mathrm{~s}$ & 0.24 & 0.05 & & \\
\hline Finch & $2000 \mathrm{~s}$ & 0.17 & 0.04 & 0.32 & ns \\
\hline
\end{tabular}


Table 8. Power to detect a negative trend in density for native bird species of the Kūlani-Keauhou study area. Power is the probability of detecting a trend when one actually occurs, and can range from 0 to 100 percent. Declines of $1 \%, 3 \%, 5 \%$ and $10 \%$ in the mean annual density per station (DPS) were calculated for a prospective 10-year monitoring period with the program TRENDS, given linear trends, 1-tailed significance levels (alpha) of 0.05, 0.10 and 0.20, and observed coefficient of variation (CV) and variance structure of mean annual DPS over time. The types of variance structures applicable for each species include: (a) CV constant relative to mean; and (b) CV proportional to $1 / \sqrt{ }$ DPS. Bold text indicates that there is adequate power ( $\geq 80 \%)$ to detect a negative trend.

\begin{tabular}{|c|c|c|c|c|c|c|c|c|c|c|c|c|c|c|}
\hline \multirow[b]{2}{*}{ Species } & \multirow[b]{2}{*}{$\mathbf{C V}$} & \multirow[b]{2}{*}{ type } & \multicolumn{4}{|c|}{ Alpha 0.05} & \multicolumn{4}{|c|}{ Alpha 0.10} & \multicolumn{4}{|c|}{ Alpha 0.20} \\
\hline & & & $1 \%$ & $3 \%$ & $5 \%$ & $10 \%$ & $1 \%$ & $3 \%$ & $5 \%$ & $10 \%$ & $1 \%$ & $3 \%$ & $5 \%$ & $10 \%$ \\
\hline Apapane & 0.088 & $\mathrm{a}$ & 26 & 94 & 100 & 100 & 40 & 98 & 100 & 100 & 58 & 100 & 100 & 100 \\
\hline `Elepaio & 0.118 & $\mathrm{~b}$ & 18 & 78 & 100 & 100 & 30 & 89 & 100 & 100 & 48 & 96 & 100 & 100 \\
\hline 'Ōma`o & 0.130 & $\mathrm{~b}$ & 17 & 71 & 100 & 100 & 28 & 84 & 100 & 100 & 45 & 93 & 100 & 100 \\
\hline Hawai`i `Amakihi & 0.135 & $\mathrm{a}$ & 16 & 68 & 99 & 100 & 27 & 82 & 100 & 100 & 44 & 92 & 100 & 100 \\
\hline 'I'iwi & 0.148 & $\mathrm{a}$ & 15 & 61 & 97 & 100 & 25 & 77 & 100 & 100 & 42 & 89 & 100 & 100 \\
\hline ‘Akiapōlā’au & 0.325 & $\mathrm{~b}$ & 8 & 22 & 49 & 100 & 16 & 36 & 65 & 100 & 29 & 54 & 81 & 100 \\
\hline Hawai`i `Ākepa & 0.574 & $\mathrm{~b}$ & 7 & 13 & 23 & 75 & 13 & 22 & 37 & 87 & 25 & 38 & 56 & 95 \\
\hline Hawai i Creeper & 0.656 & $\mathrm{~b}$ & 7 & 11 & 20 & 65 & 13 & 20 & 33 & 80 & 24 & 35 & 51 & 91 \\
\hline
\end{tabular}


Table 9. Bird occurrence and trends in the 'Ōla' a study area. Occurrence was calculated as the proportion of sampled stations for which a species was present. Standard error is designated as SE. Comparisons between the 1977 (i.e., HFBS) and 1994 survey (bold) survey periods were assessed with a significance threshold of $\leq 0.05$ for all species. The general trend in occurrence and density is summarized with upward $(\uparrow)$ and downward $(\downarrow)$ symbols, and ns refers to a statistically non-significant result. Species are ordered taxonomically within native and alien groups.

\begin{tabular}{|c|c|c|c|c|c|c|c|}
\hline Species & Period & Presence & Absence & Occurrence & SE & $\mathbf{P}$ & Change \\
\hline Hawai`i & 1977 & 22 & 32 & 0.41 & 0.07 & & \\
\hline \multirow[t]{3}{*}{ Elepaio } & 1992 & 1 & 140 & 0.01 & 0.01 & & \\
\hline & 1993 & 4 & 138 & 0.03 & 0.01 & & \\
\hline & 1994 & 0 & 142 & 0.00 & 0.00 & $<0.01$ & $\downarrow$ \\
\hline \multirow[t]{4}{*}{ ‘̄̄ma`o } & 1977 & 36 & 18 & 0.67 & 0.06 & & \\
\hline & 1992 & 24 & 117 & 0.17 & 0.03 & & \\
\hline & 1993 & 68 & 74 & 0.48 & 0.04 & & \\
\hline & 1994 & 60 & 82 & 0.42 & 0.04 & $<0.01$ & $\downarrow$ \\
\hline Hawai`i & 1977 & 4 & 50 & 0.07 & 0.04 & & \\
\hline \multirow[t]{3}{*}{ Amakihi } & 1992 & 0 & 141 & 0.00 & 0.00 & & \\
\hline & 1993 & 0 & 142 & 0.00 & 0.00 & & \\
\hline & 1994 & 1 & 141 & 0.01 & 0.01 & 0.02 & $\downarrow$ \\
\hline \multirow{4}{*}{ 'Tiwi } & 1977 & 29 & 25 & 0.54 & 0.07 & & \\
\hline & 1992 & 6 & 135 & 0.04 & 0.02 & & \\
\hline & 1993 & 11 & 131 & 0.08 & 0.02 & & \\
\hline & 1994 & 7 & 135 & 0.05 & 0.02 & $<0.01$ & $\downarrow$ \\
\hline \multirow[t]{4}{*}{ Apapane } & 1977 & 52 & 2 & 0.96 & 0.03 & & \\
\hline & 1992 & 53 & 88 & 0.38 & 0.04 & & \\
\hline & 1993 & 104 & 38 & 0.73 & 0.04 & & \\
\hline & 1994 & 83 & 59 & 0.58 & 0.04 & $<0.01$ & $\downarrow$ \\
\hline Red-billed & 1977 & 30 & 24 & 0.56 & 0.07 & & \\
\hline \multirow[t]{3}{*}{ Leiothrix } & 1992 & 0 & 141 & 0.00 & 0.00 & & \\
\hline & 1993 & 9 & 133 & 0.06 & 0.02 & & \\
\hline & 1994 & 12 & 130 & 0.08 & 0.02 & $<0.01$ & $\downarrow$ \\
\hline Japanese & 1977 & 49 & 5 & 0.91 & 0.04 & & \\
\hline \multirow[t]{3}{*}{ White-eye } & 1992 & 78 & 63 & 0.55 & 0.04 & & \\
\hline & 1993 & 130 & 12 & 0.92 & 0.02 & & \\
\hline & 1994 & 135 & 7 & 0.95 & 0.02 & 0.32 & ns \\
\hline Northern & 1977 & 8 & 46 & 0.15 & 0.05 & & \\
\hline \multirow[t]{3}{*}{ Cardinal } & 1992 & 15 & 126 & 0.11 & 0.03 & & \\
\hline & 1993 & 37 & 105 & 0.26 & 0.04 & & \\
\hline & 1994 & 47 & 252 & 0.16 & 0.02 & 1.00 & ns \\
\hline House & 1977 & 1 & 53 & 0.02 & 0.02 & & \\
\hline \multirow[t]{3}{*}{ Finch } & 1992 & 3 & 138 & 0.02 & 0.01 & & \\
\hline & 1993 & 10 & 132 & 0.07 & 0.02 & & \\
\hline & 1994 & 7 & 135 & 0.05 & 0.02 & 0.45 & $\mathrm{~ns}$ \\
\hline
\end{tabular}


Table 10. Bird density and trends in the 'Ōla'a study area. Change in density (\#/ha) between the HFBS (i.e., 1977) and 1994 survey (bold) was assessed with a significance threshold of $\leq 0.05$ for all species. Standard error is designated as SE. The general trend is summarized with upward $(\uparrow)$ and downward $(\downarrow)$ symbols, and ns refers to a statistically non-significant result. Species are ordered taxonomically within native and alien groups.

\begin{tabular}{|c|c|c|c|c|c|}
\hline Species & Period & Density & SE & $\mathbf{P}$ & Change \\
\hline Hawai`i & 1977 & 1.64 & 0.31 & & \\
\hline \multirow[t]{3}{*}{ Elepaio } & 1992 & 0.02 & 0.02 & & \\
\hline & 1993 & 0.09 & 0.04 & & \\
\hline & 1994 & 0.00 & 0.00 & $<0.01$ & $\downarrow$ \\
\hline \multirow[t]{4}{*}{ Ōma`o } & 1977 & 1.17 & 0.15 & & \\
\hline & 1992 & 0.21 & 0.04 & & \\
\hline & 1993 & 1.20 & 0.14 & & \\
\hline & 1994 & 0.91 & 0.11 & 0.16 & ns \\
\hline Hawai`i & 1977 & 0.21 & 0.11 & & \\
\hline \multirow{3}{*}{ Amakihi } & 1992 & 0.00 & 0.00 & & \\
\hline & 1993 & 0.00 & 0.00 & & \\
\hline & 1994 & 0.02 & 0.02 & 0.08 & ns \\
\hline \multirow[t]{4}{*}{ 'Tiwi } & 1977 & 2.91 & 0.46 & & \\
\hline & 1992 & 0.17 & 0.08 & & \\
\hline & 1993 & 0.28 & 0.10 & & \\
\hline & 1994 & 0.23 & 0.09 & $<0.01$ & $\downarrow$ \\
\hline \multirow{4}{*}{ Apapane } & 1977 & 18.70 & 1.27 & & \\
\hline & 1992 & 2.00 & 0.30 & & \\
\hline & 1993 & 7.46 & 0.61 & & \\
\hline & 1994 & 6.92 & 0.83 & $<0.01$ & $\downarrow$ \\
\hline Red-billed & 1977 & 1.94 & 0.29 & & \\
\hline \multirow[t]{3}{*}{ Leiothrix } & 1992 & 0.00 & 0.00 & & \\
\hline & 1993 & 0.16 & 0.06 & & \\
\hline & 1994 & 0.24 & 0.07 & $<0.01$ & $\downarrow$ \\
\hline Japanese & 1977 & 13.48 & 1.31 & & \\
\hline \multirow[t]{3}{*}{ White-eye } & 1992 & 4.46 & 0.47 & & \\
\hline & 1993 & 15.47 & 0.81 & & \\
\hline & 1994 & 17.44 & 0.81 & 0.01 & $\uparrow$ \\
\hline Northern & 1977 & 0.13 & 0.05 & & \\
\hline \multirow[t]{3}{*}{ Cardinal } & 1992 & 0.08 & 0.02 & & \\
\hline & 1993 & 0.33 & 0.06 & & \\
\hline & 1994 & 0.42 & 0.06 & $<0.01$ & $\uparrow$ \\
\hline House & 1977 & 0.03 & 0.03 & & \\
\hline \multirow[t]{3}{*}{ Finch } & 1992 & 0.03 & 0.02 & & \\
\hline & 1993 & 0.16 & 0.05 & & \\
\hline & 1994 & 0.10 & 0.04 & 0.15 & ns \\
\hline
\end{tabular}


Table 11. Bird occurrence and density trends in the Mauna Loa Strip study area. Summary includes the annual sampling effort (\# Stn), number of stations occupied (\# Occ), number of individuals detected (\# Birds), proportion of stations with occurrence, mean density (birds/ha), standard error (SE) and significance $(P)$ of the regression of occurrence and density on year. General trend in occurrence and density is indicated with upward $(\uparrow)$ and downward $(\downarrow)$ symbols, and ns refers to a statistically non-significant result. Species are ordered taxonomically within native and alien groups.

\begin{tabular}{|c|c|c|c|c|c|c|c|c|}
\hline Species & Year & \# Stn & \# Occ & \# Birds & Occurrence & SE & Density & SE \\
\hline Hawai’i & $1977-79$ & 79 & 19 & 42 & 0.24 & 0.05 & 0.76 & 0.19 \\
\hline \multirow[t]{8}{*}{ 'Elepaio } & 1986 & 39 & 19 & 37 & 0.49 & 0.08 & 1.80 & 0.35 \\
\hline & 1987 & 43 & 29 & 64 & 0.67 & 0.07 & 1.89 & 0.27 \\
\hline & 1990 & 65 & 40 & 97 & 0.62 & 0.06 & 2.55 & 0.34 \\
\hline & 1991 & 51 & 15 & 30 & 0.29 & 0.06 & 1.18 & 0.33 \\
\hline & 1992 & 59 & 29 & 83 & 0.49 & 0.07 & 1.69 & 0.29 \\
\hline & 1993 & 61 & 27 & 96 & 0.44 & 0.06 & 1.68 & 0.30 \\
\hline & 1994 & 53 & 26 & 102 & 0.49 & 0.07 & 1.99 & 0.36 \\
\hline & & & & & & \multicolumn{3}{|c|}{$\begin{aligned} \text { Occurrence } P & =0.14, \text { change }=\mathrm{ns} \\
\text { Density } P & =0.23, \text { change }=\mathrm{ns}\end{aligned}$} \\
\hline \multirow[t]{9}{*}{ 'Ōma`o } & $1977-79$ & 79 & 21 & 52 & 0.27 & 0.05 & 0.17 & 0.04 \\
\hline & 1986 & 39 & 0 & 0 & 0.00 & 0.00 & 0.00 & 0.00 \\
\hline & 1987 & 43 & 1 & 1 & 0.02 & 0.02 & $<0.01$ & $<0.01$ \\
\hline & 1990 & 65 & 3 & 3 & 0.05 & 0.03 & 0.01 & 0.01 \\
\hline & 1991 & 51 & 3 & 4 & 0.06 & 0.03 & 0.02 & 0.01 \\
\hline & 1992 & 59 & 5 & 9 & 0.08 & 0.04 & 0.03 & 0.02 \\
\hline & 1993 & 61 & 3 & 3 & 0.05 & 0.03 & 0.01 & $<0.01$ \\
\hline & 1994 & 53 & 2 & 4 & 0.04 & 0.03 & 0.01 & 0.01 \\
\hline & & & & & & \multicolumn{3}{|c|}{$\begin{array}{r}\text { Occurrence } P=0.14 \text {, change }=\text { ns } \\
\text { Density } P=0.02 \text {, change }=\downarrow\end{array}$} \\
\hline Hawai` i & $1977-79$ & 79 & 71 & 470 & 0.90 & 0.03 & 6.52 & 0.65 \\
\hline \multirow[t]{8}{*}{ 'Amakihi } & 1986 & 39 & 38 & 105 & 0.97 & 0.03 & 4.04 & 0.40 \\
\hline & 1987 & 43 & 36 & 186 & 0.84 & 0.06 & 3.89 & 0.38 \\
\hline & 1990 & 65 & 56 & 210 & 0.86 & 0.04 & 4.35 & 0.37 \\
\hline & 1991 & 51 & 43 & 151 & 0.84 & 0.05 & 4.50 & 0.50 \\
\hline & 1992 & 59 & 57 & 260 & 0.97 & 0.02 & 5.29 & 0.41 \\
\hline & 1993 & 61 & 39 & 161 & 0.64 & 0.06 & 3.28 & 0.49 \\
\hline & 1994 & 53 & 46 & 186 & 0.87 & 0.05 & 4.18 & 0.51 \\
\hline & & & & & & \multicolumn{3}{|c|}{$\begin{aligned} \text { Occurrence } P & =0.48, \text { change }=\mathrm{ns} \\
\text { Density } P & =0.18, \text { change }=\mathrm{ns}\end{aligned}$} \\
\hline
\end{tabular}




\begin{tabular}{|c|c|c|c|c|c|c|c|c|}
\hline Species & Year & \# Stn & \# Occ & \# Birds & Occurrence & SE & Density & SE \\
\hline \multirow[t]{9}{*}{ 'Tiwi } & $1977-79$ & 79 & 31 & 81 & 0.39 & 0.06 & 0.09 & 0.52 \\
\hline & 1986 & 39 & 25 & 34 & 0.64 & 0.08 & 0.09 & 0.54 \\
\hline & 1987 & 43 & 20 & 39 & 0.47 & 0.08 & 0.07 & 0.32 \\
\hline & 1990 & 65 & 40 & 134 & 0.62 & 0.06 & 0.16 & 1.12 \\
\hline & 1991 & 51 & 33 & 88 & 0.65 & 0.07 & 0.15 & 1.07 \\
\hline & 1992 & 59 & 38 & 91 & 0.64 & 0.06 & 0.10 & 0.74 \\
\hline & 1993 & 61 & 35 & 72 & 0.57 & 0.06 & 0.10 & 0.59 \\
\hline & 1994 & 53 & 26 & 48 & 0.49 & 0.07 & 0.08 & 0.44 \\
\hline & & & & & & \multicolumn{3}{|c|}{$\begin{aligned} \text { Occurrence } P & =0.18, \text { change }=\mathrm{ns} \\
\text { Density } P & =0.39, \text { change }=\mathrm{ns}\end{aligned}$} \\
\hline \multirow[t]{9}{*}{ Apapane } & $1977-79$ & 79 & 68 & 401 & 0.86 & 0.04 & 0.27 & 2.95 \\
\hline & 1986 & 39 & 36 & 153 & 0.92 & 0.04 & 0.25 & 2.96 \\
\hline & 1987 & 43 & 37 & 187 & 0.86 & 0.05 & 0.23 & 1.91 \\
\hline & 1990 & 65 & 58 & 353 & 0.89 & 0.04 & 0.34 & 3.67 \\
\hline & 1991 & 51 & 47 & 196 & 0.92 & 0.04 & 0.29 & 2.92 \\
\hline & 1992 & 59 & 56 & 300 & 0.95 & 0.03 & 0.30 & 3.05 \\
\hline & 1993 & 61 & 58 & 255 & 0.95 & 0.03 & 0.21 & 2.47 \\
\hline & 1994 & 53 & 48 & 265 & 0.91 & 0.04 & 0.31 & 2.83 \\
\hline & & & & & & \multicolumn{3}{|c|}{$\begin{aligned} \text { Occurrence } P & =0.56, \text { change }=\mathrm{ns} \\
\text { Density } P & =0.71, \text { change }=\mathrm{ns}\end{aligned}$} \\
\hline Red-billed & $1977-79$ & 79 & 4 & 5 & 0.05 & 0.02 & 0.02 & 0.04 \\
\hline \multirow[t]{8}{*}{ Leiothrix } & 1986 & 39 & 27 & 54 & 0.69 & 0.07 & 0.13 & 0.96 \\
\hline & 1987 & 43 & 38 & 107 & 0.88 & 0.05 & 0.13 & 1.22 \\
\hline & 1990 & 65 & 19 & 32 & 0.29 & 0.06 & 0.07 & 0.29 \\
\hline & 1991 & 51 & 4 & 4 & 0.08 & 0.04 & 0.03 & 0.06 \\
\hline & 1992 & 59 & 21 & 38 & 0.36 & 0.06 & 0.06 & 0.29 \\
\hline & 1993 & 61 & 13 & 43 & 0.21 & 0.05 & 0.07 & 0.25 \\
\hline & 1994 & 53 & 24 & 72 & 0.45 & 0.07 & 0.10 & 0.50 \\
\hline & & & & & & \multicolumn{3}{|c|}{$\begin{aligned} \text { Occurrence } P & =0.24, \text { change }=\mathrm{ns} \\
\text { Density } P & =0.96, \text { change }=\mathrm{ns}\end{aligned}$} \\
\hline Japanese & $1977-79$ & 79 & 42 & 105 & 0.53 & 0.06 & 0.40 & 3.11 \\
\hline \multirow[t]{8}{*}{ White-eye } & 1986 & 39 & 34 & 59 & 0.87 & 0.05 & 0.54 & 4.78 \\
\hline & 1987 & 43 & 39 & 130 & 0.91 & 0.04 & 0.72 & 6.73 \\
\hline & 1990 & 65 & 52 & 179 & 0.80 & 0.05 & 0.81 & 7.27 \\
\hline & 1991 & 51 & 43 & 134 & 0.84 & 0.05 & 0.91 & 8.45 \\
\hline & 1992 & 59 & 52 & 216 & 0.88 & 0.04 & 0.63 & 7.98 \\
\hline & 1993 & 61 & 50 & 298 & 0.82 & 0.05 & 0.92 & 9.72 \\
\hline & 1994 & 53 & 46 & 288 & 0.87 & 0.05 & 0.93 & 10.83 \\
\hline & & & & & & \multicolumn{3}{|c|}{$\begin{array}{r}\text { Occurrence } P=0.03, \text { change }=\uparrow \\
\text { Density } P=<0.001, \text { change }=\uparrow\end{array}$} \\
\hline
\end{tabular}




\begin{tabular}{|c|c|c|c|c|c|c|c|c|}
\hline Species & Year & \# Stn & \# Occ & \# Birds & Occurrence & SE & Density & SE \\
\hline Northern & $1977-79$ & 79 & 27 & 42 & 0.34 & 0.05 & 0.02 & 0.02 \\
\hline \multirow[t]{8}{*}{ Cardinal } & 1986 & 39 & 22 & 29 & 0.56 & 0.08 & 0.03 & 0.03 \\
\hline & 1987 & 43 & 30 & 74 & 0.70 & 0.07 & 0.04 & 0.04 \\
\hline & 1990 & 65 & 41 & 70 & 0.63 & 0.06 & 0.03 & 0.03 \\
\hline & 1991 & 51 & 34 & 58 & 0.67 & 0.07 & 0.04 & 0.04 \\
\hline & 1992 & 59 & 36 & 69 & 0.61 & 0.06 & 0.03 & 0.03 \\
\hline & 1993 & 61 & 33 & 79 & 0.54 & 0.06 & 0.03 & 0.03 \\
\hline & 1994 & 53 & 31 & 98 & 0.58 & 0.07 & 0.04 & 0.04 \\
\hline & & & & & & \multicolumn{3}{|c|}{$\begin{array}{c}\text { Occurrence } P=0.07, \text { change }=\mathrm{ns} \\
\text { Density } P=0.054, \text { change }=\mathrm{ns}\end{array}$} \\
\hline House & $1977-79$ & 79 & 37 & 81 & 0.47 & 0.06 & 0.14 & 0.14 \\
\hline \multirow[t]{8}{*}{ Finch } & 1986 & 39 & 13 & 25 & 0.33 & 0.08 & 0.19 & 0.19 \\
\hline & 1987 & 43 & 28 & 58 & 0.65 & 0.07 & 0.14 & 0.14 \\
\hline & 1990 & 65 & 25 & 89 & 0.38 & 0.06 & 0.31 & 0.31 \\
\hline & 1991 & 51 & 23 & 61 & 0.45 & 0.07 & 0.27 & 0.27 \\
\hline & 1992 & 59 & 21 & 51 & 0.36 & 0.06 & 0.16 & 0.16 \\
\hline & 1993 & 61 & 29 & 71 & 0.48 & 0.06 & 0.14 & 0.14 \\
\hline & 1994 & 53 & 29 & 57 & 0.55 & 0.07 & 0.21 & 0.21 \\
\hline & & & & & & \multicolumn{3}{|c|}{$\begin{aligned} \text { Occurrence } P & =0.95, \text { change }=\mathrm{ns} \\
\text { Density } P & =0.84, \text { change }=\mathrm{ns}\end{aligned}$} \\
\hline
\end{tabular}


Table 12. Bird occurrence and trends in the East Rift study area. Occurrence was calculated as the proportion of stations at which a species was present. Standard error is designated as SE. Comparison of the results of the 1979 HFBS and the combined December 1993-January 1994 survey (bold) was assessed with a significance threshold of $\leq 0.05$ for all species. General trend in occurrence and density is summarized with upward $(\uparrow)$ and downward $(\downarrow)$ symbols, and ns refers to a statistically non-significant result. Species are ordered taxonomically within native and alien groups.

\begin{tabular}{|c|c|c|c|c|c|c|c|}
\hline Species & Period & Presence & Absence & Occurrence & SE & $\mathbf{P}$ & Change \\
\hline Hawai`i & 1979 & 31 & 68 & 0.31 & 0.05 & & \\
\hline \multirow[t]{3}{*}{ Elepaio } & 1992 & 0 & 38 & 0.00 & 0.00 & & \\
\hline & 1993 (Jan) & 0 & 56 & 0.00 & 0.00 & & \\
\hline & $1993-94$ & 15 & 143 & 0.09 & 0.02 & $<0.01$ & $\downarrow$ \\
\hline \multirow[t]{4}{*}{ `Ōma`o } & 1979 & 92 & 7 & 0.93 & 0.03 & & \\
\hline & 1992 & 13 & 25 & 0.34 & 0.08 & & \\
\hline & 1993 (Jan) & 45 & 11 & 0.80 & 0.05 & & \\
\hline & $1993-94$ & 143 & 15 & 0.91 & 0.02 & 0.65 & ns \\
\hline Hawai`i & 1979 & 2 & 97 & 0.02 & 0.01 & & \\
\hline \multirow[t]{3}{*}{ Amakihi } & 1992 & 0 & 38 & 0.00 & 0.00 & & \\
\hline & 1993 (Jan) & 1 & 55 & 0.02 & 0.02 & & \\
\hline & $1993-94$ & 5 & 153 & 0.03 & 0.01 & 0.71 & ns \\
\hline \multirow[t]{4}{*}{ 'Apapane } & 1979 & 99 & 0 & 1.00 & 0.00 & & \\
\hline & 1992 & 37 & 1 & 0.97 & 0.03 & & \\
\hline & 1993 (Jan) & 56 & 0 & 1.00 & 0.00 & & \\
\hline & 1993-94 & 153 & 5 & 0.97 & 0.01 & 0.16 & ns \\
\hline Japanese & 1979 & 94 & 5 & 0.95 & 0.02 & & \\
\hline \multirow[t]{3}{*}{ White-eye } & 1992 & 29 & 9 & 0.76 & 0.07 & & \\
\hline & 1993 (Jan) & 56 & 0 & 1.00 & 0.00 & & \\
\hline & $1993-94$ & 156 & 2 & 0.99 & 0.01 & 0.11 & ns \\
\hline Northern & 1979 & 23 & 76 & 0.23 & 0.04 & & \\
\hline \multirow[t]{3}{*}{ Cardinal } & 1992 & 1 & 37 & 0.03 & 0.03 & & \\
\hline & 1993 (Jan) & 5 & 51 & 0.09 & 0.04 & & \\
\hline & $1993-94$ & 12 & 146 & 0.08 & 0.02 & $<0.01$ & $\downarrow$ \\
\hline House & 1979 & 0 & 99 & 0.00 & 0.00 & & \\
\hline \multirow[t]{3}{*}{ Finch } & 1992 & 2 & 36 & 0.05 & 0.04 & & \\
\hline & 1993 (Jan) & 0 & 56 & 0.00 & 0.00 & & \\
\hline & 1993-94 & 3 & 155 & 0.02 & 0.01 & 0.29 & ns \\
\hline
\end{tabular}


Table 13. Bird density and trends in the East Rift study area. Change in density (\#/ha) between the HFBS (i.e., 1979) and the combined December 1993-January 1994 survey (bold) was assessed with a significance threshold of $\leq 0.05$ for all species. Standard error is designated as SE. Species are ordered taxonomically within native and alien groups.

\begin{tabular}{|c|c|c|c|c|c|}
\hline Species & Period & Density & SE & $\mathbf{P}$ & Change \\
\hline Hawai`i & 1979 & 0.60 & 0.11 & & \\
\hline \multirow[t]{3}{*}{ Elepaio } & 1992 & 0.00 & 0.00 & & \\
\hline & 1993 (Jan) & 0.00 & 0.00 & & \\
\hline & $1993-94$ & 0.21 & 0.06 & $<0.01$ & $\downarrow$ \\
\hline \multirow{4}{*}{ `Ōma`o } & 1979 & 1.40 & 0.08 & & \\
\hline & 1992 & 0.24 & 0.06 & & \\
\hline & 1993 (Jan) & 0.76 & 0.08 & & \\
\hline & $1993-94$ & 1.01 & 0.05 & $<0.01$ & $\downarrow$ \\
\hline Hawai`i & 1979 & 0.02 & 0.01 & & \\
\hline \multirow[t]{3}{*}{ 'Amakihi } & 1992 & 0.00 & 0.00 & & \\
\hline & 1993 (Jan) & 0.01 & 0.01 & & \\
\hline & 1993-94 & 0.04 & 0.02 & 0.27 & ns \\
\hline \multirow[t]{4}{*}{ Apapane } & 1979 & 10.16 & 0.44 & & \\
\hline & 1992 & 4.23 & 0.47 & & \\
\hline & 1993 (Jan) & 7.13 & 0.33 & & \\
\hline & 1993-94 & 6.44 & 0.31 & $<0.01$ & $\downarrow$ \\
\hline Japanese & 1979 & 8.03 & 0.45 & & \\
\hline \multirow[t]{3}{*}{ White-eye } & 1992 & 7.25 & 0.95 & & \\
\hline & 1993 (Jan) & 17.33 & 0.95 & & \\
\hline & $1993-94$ & 11.90 & 0.49 & $<0.01$ & $\uparrow$ \\
\hline Northern & 1979 & 0.14 & 0.03 & & \\
\hline \multirow[t]{3}{*}{ Cardinal } & 1992 & 0.01 & 0.01 & & \\
\hline & 1993 (Jan) & 0.05 & 0.02 & & \\
\hline & $1993-94$ & 0.04 & 0.01 & $<0.01$ & $\downarrow$ \\
\hline House & 1979 & 0.00 & 0.00 & & \\
\hline \multirow[t]{3}{*}{ Finch } & 1992 & 0.07 & 0.05 & & \\
\hline & 1993 (Jan) & 0.00 & 0.00 & & \\
\hline & $1993-94$ & 0.03 & 0.02 & na & na \\
\hline
\end{tabular}


Table 14. Power to detect a negative trend in density as a function of sample size for select native bird species of the Kūlani-Keauhou study area. Power is the probability of detecting a trend when one actually occurs, and can range from 0 to 100 percent. The analysis was performed for three species for which variability in density was high, moderate and low: Hawai'i Creeper, 'Akiapōlā'au, and Hawai $i$ 'Elepaio (indicated with the abbreviations HCRE, AKIP and ELEP). Three combinations of effect size (i.e., rate of decline) and alpha levels were used to capture the range of power under various scenarios (listed here from low to high power): (1) small declines with use of a fairly conservative alpha (i.e., decline rate $=3 \%$ and alpha $=0.05$ ); (2) moderate declines with use of a moderately liberal alpha (i.e., decline rate $=5 \%$ and alpha $=0.10$ ); and (3) severe declines with use of a very liberal alpha (i.e., decline

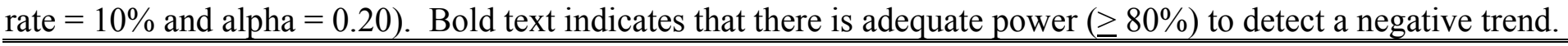

\begin{tabular}{|c|c|c|c|c|c|c|c|c|c|c|c|c|}
\hline \multirow{2}{*}{$\begin{array}{c}\text { Sample } \\
\text { Size }\end{array}$} & \multicolumn{3}{|c|}{ Coefficient of Variation } & \multicolumn{3}{|c|}{$\begin{array}{c}\text { alpha }=0.05 \\
\text { decline }=3 \%\end{array}$} & \multicolumn{3}{|c|}{$\begin{array}{c}\text { alpha }=0.10 \\
\text { decline }=5 \%\end{array}$} & \multicolumn{3}{|c|}{$\begin{array}{c}\text { alpha }=0.20 \\
\text { decline }=10 \%\end{array}$} \\
\hline & HCRE & AKIP & ELEP & HCRE & AKIP & ELEP & HCRE & AKIP & ELEP & HCRE & AKIP & ELEP \\
\hline 10 & 1.281 & 0.986 & 0.361 & 8 & 9 & 18 & 18 & 22 & 53 & 54 & 65 & 100 \\
\hline 25 & 0.934 & 0.667 & 0.247 & 9 & 11 & 29 & 22 & 29 & 76 & 67 & 83 & 100 \\
\hline 50 & 0.804 & 0.522 & 0.192 & 10 & 13 & 40 & 25 & 37 & 90 & 74 & 93 & 100 \\
\hline 100 & 0.734 & 0.438 & 0.160 & 10 & 15 & 51 & 27 & 43 & 96 & 78 & 97 & 100 \\
\hline 150 & 0.708 & 0.400 & 0.144 & 10 & 17 & 58 & 28 & 48 & 98 & 80 & 98 & 100 \\
\hline 200 & 0.695 & 0.384 & 0.141 & 10 & 17 & 60 & 28 & 50 & 99 & 81 & 99 & 100 \\
\hline 250 & 0.687 & 0.370 & 0.137 & 11 & 18 & 62 & 28 & 52 & 99 & 82 & 100 & 100 \\
\hline 300 & 0.682 & 0.365 & 0.132 & 11 & 18 & 65 & 29 & 52 & 100 & 82 & 100 & 100 \\
\hline 350 & 0.681 & 0.360 & 0.131 & 11 & 18 & 65 & 29 & 53 & 100 & 82 & 100 & 100 \\
\hline 400 & 0.675 & 0.352 & 0.129 & 11 & 19 & 67 & 29 & 54 & 100 & 82 & 100 & 100 \\
\hline 500 & 0.671 & 0.349 & 0.127 & 11 & 19 & 68 & 29 & 55 & 100 & 83 & 100 & 100 \\
\hline 600 & 0.671 & 0.345 & 0.125 & 11 & 19 & 69 & 29 & 55 & 100 & 83 & 100 & 100 \\
\hline
\end{tabular}


Appendix 1. Results of the annual forest bird survey in the Külani-Keauhou study area. Summary includes the annual sampling effort (\# Stn), number of stations occupied (\#Occ), number of individuals detected (\# Birds), proportion of stations occupied (i.e., occurrence $[$ Occur] $)$, mean density (\#/ha), and standard error (SE). Species are ordered taxonomically within native and alien groups.

\begin{tabular}{lccrrrrrl}
\hline \hline Species & Year & \# Stn & \# Occ & \# Birds & Occur & SE & Density & SE \\
\hline Hawai'i & 1977 & 80 & 42 & 67 & 0.53 & 0.06 & 2.61 & 0.34 \\
'Elepaio & 1990 & 33 & 1 & 1 & 0.03 & 0.03 & 0.05 & 0.05 \\
& 1991 & 105 & 16 & 23 & 0.15 & 0.04 & 0.60 & 0.15 \\
& 1992 & 107 & 50 & 66 & 0.47 & 0.05 & 1.95 & 0.23 \\
& 1993 & 144 & 70 & 108 & 0.49 & 0.04 & 2.37 & 0.25 \\
& 1994 & 126 & 78 & 190 & 0.62 & 0.04 & 2.47 & 0.24 \\
& 1995 & 229 & 131 & 288 & 0.57 & 0.03 & 2.32 & 0.17 \\
& 1996 & 103 & 55 & 96 & 0.53 & 0.05 & 2.82 & 0.32 \\
& 1997 & 257 & 158 & 339 & 0.61 & 0.03 & 2.50 & 0.16 \\
& 1998 & 207 & 101 & 163 & 0.49 & 0.03 & 2.21 & 0.19 \\
& 1999 & 78 & 47 & 78 & 0.60 & 0.06 & 3.16 & 0.40 \\
& 2000 & 133 & 73 & 195 & 0.55 & 0.04 & 2.67 & 0.25 \\
& 2001 & 182 & 75 & 128 & 0.41 & 0.04 & 2.22 & 0.25 \\
& 2002 & 187 & 93 & 145 & 0.50 & 0.04 & 2.29 & 0.22 \\
& 2003 & 183 & 93 & 147 & 0.51 & 0.04 & 2.54 & 0.22 \\
\hline 1977 & 95 & 95 & 318 & 1.00 & 0.00 & 2.82 & 0.10 \\
& 1990 & 33 & 24 & 46 & 0.73 & 0.08 & 0.83 & 0.13 \\
& 1991 & 108 & 67 & 121 & 0.62 & 0.05 & 0.81 & 0.08 \\
& 1992 & 110 & 100 & 278 & 0.91 & 0.03 & 2.15 & 0.12 \\
& 1993 & 151 & 125 & 463 & 0.83 & 0.03 & 2.60 & 0.15 \\
& 1994 & 133 & 130 & 684 & 0.98 & 0.01 & 2.27 & 0.09 \\
& 1995 & 245 & 240 & 1,318 & 0.98 & 0.01 & 3.10 & 0.09 \\
& 1996 & 110 & 107 & 387 & 0.97 & 0.02 & 2.74 & 0.13 \\
& 1997 & 274 & 268 & 1,309 & 0.98 & 0.01 & 2.56 & 0.07 \\
& 1998 & 222 & 213 & 718 & 0.96 & 0.01 & 2.55 & 0.09 \\
& 1999 & 85 & 80 & 251 & 0.94 & 0.03 & 2.51 & 0.15 \\
& 2000 & 140 & 140 & 592 & 1.00 & 0.00 & 2.85 & 0.11 \\
& 2002 & 197 & 179 & 420 & 0.91 & 0.02 & 1.80 & 0.07 \\
& 196 & 180 & 468 & 0.92 & 0.02 & 2.22 & 0.09 \\
& 192 & 174 & 547 & 0.91 & 0.02 & 2.43 & 0.10 \\
\hline & & & & & & & &
\end{tabular}




\begin{tabular}{|c|c|c|c|c|c|c|c|c|}
\hline Species & Year & \# Stn & \# Occ & \# Birds & Occur & SE & Density & SE \\
\hline Hawai’i & 1977 & 95 & 78 & 148 & 0.82 & 0.04 & 3.58 & 0.28 \\
\hline \multirow[t]{14}{*}{ 'Amakihi } & 1990 & 33 & 10 & 12 & 0.30 & 0.08 & 0.70 & 0.21 \\
\hline & 1991 & 108 & 28 & 47 & 0.26 & 0.04 & 0.82 & 0.15 \\
\hline & 1992 & 110 & 78 & 171 & 0.71 & 0.04 & 3.61 & 0.34 \\
\hline & 1993 & 151 & 68 & 135 & 0.45 & 0.04 & 2.08 & 0.24 \\
\hline & 1994 & 133 & 89 & 280 & 0.67 & 0.04 & 2.50 & 0.22 \\
\hline & 1995 & 245 & 198 & 615 & 0.81 & 0.03 & 3.95 & 0.21 \\
\hline & 1996 & 110 & 70 & 162 & 0.64 & 0.05 & 3.08 & 0.28 \\
\hline & 1997 & 274 & 194 & 568 & 0.71 & 0.03 & 2.98 & 0.18 \\
\hline & 1998 & 222 & 154 & 300 & 0.69 & 0.03 & 2.86 & 0.18 \\
\hline & 1999 & 85 & 63 & 125 & 0.74 & 0.05 & 3.41 & 0.36 \\
\hline & 2000 & 140 & 115 & 288 & 0.82 & 0.03 & 3.19 & 0.19 \\
\hline & 2001 & 197 & 155 & 354 & 0.79 & 0.03 & 4.13 & 0.26 \\
\hline & 2002 & 196 & 152 & 394 & 0.78 & 0.03 & 4.39 & 0.27 \\
\hline & 2003 & 192 & 138 & 333 & 0.72 & 0.03 & 4.03 & 0.26 \\
\hline \multirow[t]{15}{*}{ ‘Akiapōlā’au } & 1977 & 52 & 3 & 5 & 0.06 & 0.03 & 0.10 & 0.06 \\
\hline & 1990 & 33 & 1 & 1 & 0.03 & 0.03 & 0.02 & 0.02 \\
\hline & 1991 & 103 & 3 & 3 & 0.03 & 0.02 & 0.03 & 0.02 \\
\hline & 1992 & 105 & 4 & 4 & 0.04 & 0.02 & 0.04 & 0.02 \\
\hline & 1993 & 135 & 4 & 8 & 0.03 & 0.01 & 0.06 & 0.03 \\
\hline & 1994 & 117 & 17 & 27 & 0.15 & 0.03 & 0.10 & 0.03 \\
\hline & 1995 & 209 & 21 & 25 & 0.10 & 0.02 & 0.08 & 0.02 \\
\hline & 1996 & 99 & 6 & 6 & 0.06 & 0.02 & 0.05 & 0.02 \\
\hline & 1997 & 238 & 39 & 46 & 0.16 & 0.02 & 0.11 & 0.02 \\
\hline & 1998 & 189 & 18 & 25 & 0.10 & 0.02 & 0.12 & 0.03 \\
\hline & 1999 & 73 & 10 & 10 & 0.14 & 0.04 & 0.14 & 0.04 \\
\hline & 2000 & 124 & 28 & 40 & 0.23 & 0.04 & 0.18 & 0.04 \\
\hline & 2001 & 163 & 16 & 20 & 0.10 & 0.02 & 0.12 & 0.03 \\
\hline & 2002 & 177 & 10 & 14 & 0.06 & 0.02 & 0.07 & 0.02 \\
\hline & 2003 & 166 & 17 & 19 & 0.10 & 0.02 & 0.12 & 0.03 \\
\hline Hawai`i & 1977 & 80 & 5 & 6 & 0.06 & 0.03 & 0.14 & 0.07 \\
\hline \multirow[t]{14}{*}{ Creeper } & 1990 & 33 & 1 & 2 & 0.03 & 0.03 & 0.06 & 0.06 \\
\hline & 1991 & 105 & 5 & 9 & 0.05 & 0.02 & 0.10 & 0.05 \\
\hline & 1992 & 107 & 21 & 31 & 0.20 & 0.04 & 0.57 & 0.13 \\
\hline & 1993 & 144 & 5 & 7 & 0.03 & 0.02 & 0.10 & 0.05 \\
\hline & 1994 & 126 & 10 & 17 & 0.08 & 0.02 & 0.17 & 0.06 \\
\hline & 1995 & 229 & 28 & 52 & 0.12 & 0.02 & 0.41 & 0.09 \\
\hline & 1996 & 103 & 1 & 2 & 0.01 & 0.01 & 0.01 & 0.01 \\
\hline & 1997 & 257 & 25 & 37 & 0.10 & 0.02 & 0.19 & 0.04 \\
\hline & 1998 & 207 & 35 & 55 & 0.17 & 0.03 & 0.50 & 0.09 \\
\hline & 1999 & 78 & 7 & 12 & 0.09 & 0.03 & 0.30 & 0.11 \\
\hline & 2000 & 133 & 9 & 14 & 0.07 & 0.02 & 0.11 & 0.04 \\
\hline & 2001 & 182 & 19 & 28 & 0.10 & 0.02 & 0.29 & 0.07 \\
\hline & 2002 & 187 & 16 & 32 & 0.09 & 0.02 & 0.26 & 0.07 \\
\hline & 2003 & 183 & 6 & 6 & 0.03 & 0.01 & 0.06 & 0.03 \\
\hline
\end{tabular}




\begin{tabular}{|c|c|c|c|c|c|c|c|c|}
\hline Species & Year & \# Stn & \# Occ & \# Birds & Occur & SE & Density & SE \\
\hline Hawai'i & 1977 & 80 & 10 & 12 & 0.13 & 0.04 & 0.38 & 0.13 \\
\hline \multirow[t]{14}{*}{ 'Ākepa } & 1990 & 33 & 0 & 0 & 0.00 & 0.00 & 0.00 & 0.00 \\
\hline & 1991 & 105 & 5 & 15 & 0.05 & 0.02 & 0.21 & 0.10 \\
\hline & 1992 & 107 & 17 & 22 & 0.16 & 0.04 & 0.53 & 0.13 \\
\hline & 1993 & 144 & 9 & 12 & 0.06 & 0.02 & 0.21 & 0.08 \\
\hline & 1994 & 126 & 9 & 12 & 0.07 & 0.02 & 0.11 & 0.04 \\
\hline & 1995 & 229 & 26 & 47 & 0.11 & 0.02 & 0.41 & 0.09 \\
\hline & 1996 & 103 & 0 & 0 & 0.00 & 0.00 & 0.00 & 0.00 \\
\hline & 1997 & 257 & 31 & 39 & 0.12 & 0.02 & 0.27 & 0.05 \\
\hline & 1998 & 207 & 13 & 27 & 0.06 & 0.02 & 0.23 & 0.07 \\
\hline & 1999 & 78 & 10 & 14 & 0.13 & 0.04 & 0.46 & 0.16 \\
\hline & 2000 & 133 & 7 & 9 & 0.05 & 0.02 & 0.15 & 0.07 \\
\hline & 2001 & 182 & 11 & 11 & 0.06 & 0.02 & 0.15 & 0.05 \\
\hline & 2002 & 187 & 17 & 21 & 0.09 & 0.02 & 0.28 & 0.07 \\
\hline & 2003 & 183 & 14 & 23 & 0.08 & 0.02 & 0.32 & 0.10 \\
\hline \multirow[t]{15}{*}{ 'T'iwi } & 1977 & 95 & 86 & 278 & 0.91 & 0.03 & 8.59 & 0.52 \\
\hline & 1990 & 33 & 26 & 69 & 0.79 & 0.07 & 4.63 & 0.67 \\
\hline & 1991 & 108 & 74 & 210 & 0.69 & 0.04 & 4.56 & 0.39 \\
\hline & 1992 & 110 & 103 & 565 & 0.94 & 0.02 & 15.24 & 0.82 \\
\hline & 1993 & 151 & 87 & 189 & 0.58 & 0.04 & 3.70 & 0.39 \\
\hline & 1994 & 133 & 123 & 622 & 0.92 & 0.02 & 6.96 & 0.41 \\
\hline & 1995 & 245 & 231 & 1,291 & 0.94 & 0.01 & 11.12 & 0.49 \\
\hline & 1996 & 110 & 96 & 434 & 0.87 & 0.03 & 9.89 & 0.71 \\
\hline & 1997 & 274 & 266 & 1,356 & 0.97 & 0.01 & 9.55 & 0.34 \\
\hline & 1998 & 222 & 184 & 687 & 0.83 & 0.03 & 8.51 & 0.42 \\
\hline & 1999 & 85 & 74 & 258 & 0.87 & 0.04 & 9.00 & 0.65 \\
\hline & 2000 & 140 & 119 & 413 & 0.85 & 0.03 & 6.75 & 0.45 \\
\hline & 2001 & 197 & 183 & 607 & 0.93 & 0.02 & 9.05 & 0.39 \\
\hline & 2002 & 196 & 174 & 661 & 0.89 & 0.02 & 9.30 & 0.44 \\
\hline & 2003 & 192 & 160 & 504 & 0.83 & 0.03 & 7.79 & 0.42 \\
\hline \multirow[t]{15}{*}{ Apapane } & 1977 & 95 & 95 & 670 & 1.00 & 0.00 & 19.24 & 0.81 \\
\hline & 1990 & 33 & 28 & 122 & 0.85 & 0.06 & 7.32 & 1.03 \\
\hline & 1991 & 108 & 87 & 330 & 0.81 & 0.04 & 6.63 & 0.51 \\
\hline & 1992 & 110 & 108 & 1,097 & 0.98 & 0.01 & 27.36 & 1.26 \\
\hline & 1993 & 151 & 138 & 695 & 0.91 & 0.02 & 12.57 & 0.61 \\
\hline & 1994 & 133 & 132 & 1,652 & 0.99 & 0.01 & 17.73 & 0.66 \\
\hline & 1995 & 245 & 245 & 2,604 & 1.00 & 0.00 & 20.90 & 0.63 \\
\hline & 1996 & 110 & 107 & 888 & 0.97 & 0.02 & 19.69 & 0.83 \\
\hline & 1997 & 274 & 274 & 4,022 & 1.00 & 0.00 & 26.76 & 0.66 \\
\hline & 1998 & 222 & 222 & 2,138 & 1.00 & 0.00 & 24.59 & 0.82 \\
\hline & 1999 & 85 & 85 & 853 & 1.00 & 0.00 & 27.54 & 1.16 \\
\hline & 2000 & 140 & 140 & 1,767 & 1.00 & 0.00 & 27.27 & 1.07 \\
\hline & 2001 & 197 & 197 & 1,824 & 1.00 & 0.00 & 25.08 & 0.73 \\
\hline & 2002 & 196 & 196 & 2,399 & 1.00 & 0.00 & 31.49 & 0.92 \\
\hline & 2003 & 192 & 192 & 1,991 & 1.00 & 0.00 & 28.45 & 0.77 \\
\hline
\end{tabular}




\begin{tabular}{|c|c|c|c|c|c|c|c|c|}
\hline Species & Year & \# Stn & \# Occ & \# Birds & Occur & SE & Density & SE \\
\hline Red-billed & 1977 & 95 & 62 & 162 & 0.65 & 0.05 & 3.00 & 0.30 \\
\hline \multirow[t]{14}{*}{ Leiothrix } & 1990 & 33 & 4 & 5 & 0.12 & 0.06 & 0.19 & 0.09 \\
\hline & 1991 & 108 & 6 & 9 & 0.06 & 0.02 & 0.11 & 0.05 \\
\hline & 1992 & 110 & 31 & 44 & 0.28 & 0.04 & 0.72 & 0.13 \\
\hline & 1993 & 151 & 126 & 323 & 0.83 & 0.03 & 3.79 & 0.22 \\
\hline & 1994 & 133 & 97 & 312 & 0.73 & 0.04 & 2.17 & 0.18 \\
\hline & 1995 & 245 & 145 & 462 & 0.59 & 0.03 & 1.96 & 0.14 \\
\hline & 1996 & 110 & 33 & 63 & 0.30 & 0.04 & 1.03 & 0.18 \\
\hline & 1997 & 274 & 136 & 444 & 0.50 & 0.03 & 1.44 & 0.11 \\
\hline & 1998 & 222 & 64 & 130 & 0.29 & 0.03 & 0.85 & 0.11 \\
\hline & 1999 & 85 & 12 & 23 & 0.14 & 0.04 & 0.48 & 0.15 \\
\hline & 2000 & 140 & 65 & 261 & 0.46 & 0.04 & 1.72 & 0.21 \\
\hline & 2001 & 197 & 70 & 118 & 0.36 & 0.03 & 1.07 & 0.13 \\
\hline & 2002 & 196 & 38 & 66 & 0.19 & 0.03 & 0.54 & 0.09 \\
\hline & 2003 & 192 & 49 & 83 & 0.26 & 0.03 & 0.77 & 0.11 \\
\hline Japanese & 1977 & 95 & 72 & 150 & 0.76 & 0.04 & 6.58 & 0.54 \\
\hline \multirow[t]{14}{*}{ White-eye } & 1990 & 33 & 7 & 8 & 0.21 & 0.07 & 0.70 & 0.25 \\
\hline & 1991 & 108 & 17 & 38 & 0.16 & 0.04 & 1.01 & 0.26 \\
\hline & 1992 & 110 & 74 & 155 & 0.67 & 0.04 & 5.91 & 0.57 \\
\hline & 1993 & 151 & 138 & 518 & 0.91 & 0.02 & 14.26 & 0.70 \\
\hline & 1994 & 133 & 129 & 648 & 0.97 & 0.01 & 10.77 & 0.43 \\
\hline & 1995 & 245 & 192 & 749 & 0.78 & 0.03 & 8.07 & 0.41 \\
\hline & 1996 & 110 & 106 & 317 & 0.96 & 0.02 & 11.46 & 0.55 \\
\hline & 1997 & 274 & 259 & 1035 & 0.95 & 0.01 & 10.12 & 0.32 \\
\hline & 1998 & 222 & 178 & 407 & 0.80 & 0.03 & 7.24 & 0.35 \\
\hline & 1999 & 85 & 70 & 159 & 0.82 & 0.04 & 7.85 & 0.63 \\
\hline & 2000 & 140 & 109 & 347 & 0.78 & 0.04 & 6.67 & 0.48 \\
\hline & 2001 & 197 & 128 & 292 & 0.65 & 0.03 & 6.20 & 0.48 \\
\hline & 2002 & 196 & 120 & 250 & 0.61 & 0.03 & 5.16 & 0.41 \\
\hline & 2003 & 192 & 132 & 262 & 0.69 & 0.03 & 5.73 & 0.38 \\
\hline Northern & 1977 & 95 & 18 & 25 & 0.19 & 0.04 & 0.15 & 0.04 \\
\hline \multirow[t]{14}{*}{ Cardinal } & 1990 & 33 & 0 & 0 & 0.00 & 0.00 & 0.00 & 0.00 \\
\hline & 1991 & 108 & 2 & 4 & 0.02 & 0.01 & 0.02 & 0.01 \\
\hline & 1992 & 110 & 6 & 6 & 0.05 & 0.02 & 0.04 & 0.01 \\
\hline & 1993 & 151 & 64 & 105 & 0.42 & 0.04 & 0.44 & 0.05 \\
\hline & 1994 & 133 & 53 & 110 & 0.40 & 0.04 & 0.28 & 0.04 \\
\hline & 1995 & 245 & 78 & 135 & 0.32 & 0.03 & 0.20 & 0.02 \\
\hline & 1996 & 110 & 38 & 57 & 0.35 & 0.05 & 0.33 & 0.05 \\
\hline & 1997 & 274 & 91 & 160 & 0.33 & 0.03 & 0.22 & 0.02 \\
\hline & 1998 & 222 & 68 & 97 & 0.31 & 0.03 & 0.27 & 0.03 \\
\hline & 1999 & 85 & 16 & 19 & 0.19 & 0.04 & 0.15 & 0.04 \\
\hline & 2000 & 140 & 41 & 69 & 0.29 & 0.04 & 0.22 & 0.04 \\
\hline & 2001 & 197 & 38 & 52 & 0.19 & 0.03 & 0.17 & 0.03 \\
\hline & 2002 & 196 & 24 & 33 & 0.12 & 0.02 & 0.10 & 0.02 \\
\hline & 2003 & 192 & 34 & 48 & 0.18 & 0.03 & 0.16 & 0.03 \\
\hline
\end{tabular}




\begin{tabular}{lcccccccc}
\hline \hline Species & Year & \# Stn & \# Occ & \# Birds & Occur & SE & Density & SE \\
\hline House & 1977 & 95 & 8 & 12 & 0.08 & 0.03 & 0.20 & 0.08 \\
Finch & 1990 & 33 & 2 & 2 & 0.06 & 0.04 & 0.07 & 0.05 \\
& 1991 & 108 & 0 & 0 & 0.00 & 0.00 & 0.00 & 0.00 \\
& 1992 & 110 & 12 & 31 & 0.11 & 0.03 & 0.46 & 0.15 \\
& 1993 & 151 & 18 & 30 & 0.12 & 0.03 & 0.32 & 0.08 \\
& 1994 & 133 & 17 & 40 & 0.13 & 0.03 & 0.26 & 0.07 \\
& 1995 & 245 & 19 & 29 & 0.08 & 0.02 & 0.11 & 0.03 \\
& 1996 & 110 & 16 & 29 & 0.15 & 0.03 & 0.43 & 0.12 \\
& 1997 & 274 & 27 & 68 & 0.10 & 0.02 & 0.24 & 0.06 \\
& 1998 & 222 & 12 & 28 & 0.05 & 0.02 & 0.19 & 0.07 \\
& 1999 & 85 & 6 & 13 & 0.07 & 0.03 & 0.25 & 0.13 \\
& 2000 & 140 & 12 & 18 & 0.09 & 0.02 & 0.17 & 0.05 \\
& 2001 & 197 & 5 & 8 & 0.03 & 0.01 & 0.07 & 0.03 \\
& 2002 & 196 & 14 & 28 & 0.07 & 0.02 & 0.22 & 0.07 \\
\hline \hline
\end{tabular}

